\title{
Talking to the Brain at the Blood-Brain Barrier through Inflammation-Induced Prostaglandin $\mathrm{E}_{2}$
}

\author{
Ana Maria Vasilache
}

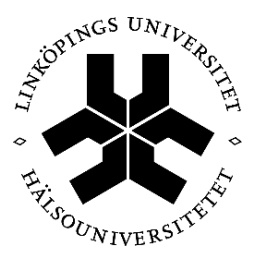

Division of Cell Biology and

Division of Clinical Immunology and Transfusion Medicine, Department of Clinical and Experimental Medicine, Faculty of Health Sciences, Linköping University, Sweden 
(C) Ana Maria Vasilache

Published articles have been reprinted with permission from the respective copyright holders. The cover sketch is an original drawing.

ISBN: 978-91-7519-155-3

ISSN: 0345-0082

Printed by LIU-tryck, Linköping, Sweden, 2015 
After all, we know nothing more or less than what we can reveal.

Adaptation from House of Cards, character Francis Underwood 


\section{List of Papers}

I. $\quad$ Engström, L., Ruud, J., Eskilsson, A., Larsson, A., Mackerlova, L., Kugelberg, U., Qian, H., Vasilache, A. M., Larsson, P., Engblom, D., Sigvardsson, M., Jönsson, J. I., Blomqvist, A. (2012) Lipopolysaccharide-induced fever depends on prostaglandin E2 production specifically in brain endothelial cells. Endocrinology 153 (10), 4849-61

II. Vasilache, A. M., Qian, H., Blomqvist A. (2015) Immune challenge by intraperitoneal administration of lipopolysaccharide directs gene expression in distinct blood-brain barrier cells toward enhanced prostaglandin E2 signaling. Brain Behav Immun, DOI: 10.1016/j.bbi.2015.02.003.

III. Vasilache, A. M., Andersson, J., Nilsberth, C. (2007) Expression of PGE2 EP3 receptor subtypes in the mouse preoptic region. Neurosci Lett 423 (3), 179-83

IV. Vasilache, A. M., Kugelberg, U., Blomqvist, A., Nilsberth, C. (2013) Minor changes in gene expression in the mouse preoptic hypothalamic region by inflammation-induced prostaglandin E2. J Neuroendocrinol 25 (7), 635-43 


\section{Table of contents}

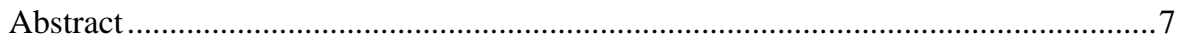

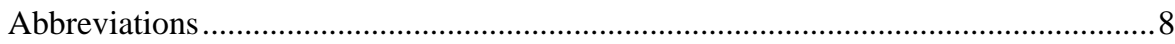

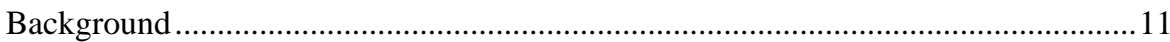

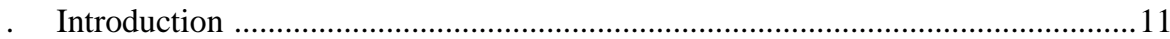

. Homeostasis in health and sickness

- Acute systemic inflammation

. Immune-to-brain signaling

Cytokines, PRRs, PAMPs, alarmins and DAMPs .......................................... 16

. Danger recognition

. Endotoxin

- TLRs and interleukin-1 receptors

. Pro-inflammatory cytokines

. Interleukin-1

. Interleukin-6

. Tumor necrosis factors

- General remarks on the transcription factors of inflammation

. Prostaglandins

- The prostaglandin cascade

. PGE2 biosynthesis and degradation, transporters, and receptors

. Pathways for cytokine-to-brain signaling

- Afferent neuronal pathways

. Humoral pathways

- Prostaglandin $E_{2}$ as a critical mediator in immune-to-brain signaling 39

. $\mathrm{PGE}_{2}$-sensitive CNS regions mediating manifestations of the sickness syndrome:

. Fever

. Release of stress hormones

. Hyperalgesia

- Anorexia

- Sleepiness

- Fever in acute systemic inflammation

- General considerations

- Central neuronal pathways for fever regulation

Aims

- Methodology

- Animal models

- Laser capture microdissection and enzymatic cell dissociation

- Flow cytometry

- Protein methods: Immunohistochemistry, immunoassays

- mRNA methods: In situ hybridization, gene expression microarray, RT-qPCR

- Results and discussion

Concluding remarks and future perspectives.

- Acknowledgments

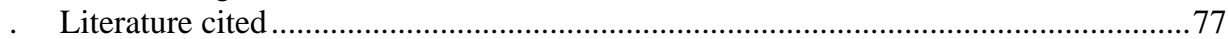

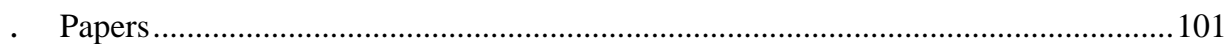




\section{Abstract}

The immune-to-brain signaling is a critical survival factor when the body is confronted by pathogens, and in particular by microorganisms. During infections, the ability of the immune system to engage the central nervous system (CNS) in the management of the inflammatory response is just as important as its ability to mount a specific immune response against the pathogen, since the CNS can provide a systemic negative feed-back to the immune activation by release of stress hormones and also can prioritize the usage of the energy resources by the vital organs. Prostaglandin E2 ( $\mathrm{PGE}_{2}$ ) and pro-inflammatory cytokines were among the first mediators to be identified to participate in the immune-to-brain signaling, a process that is clinically recognized by the development of manifestations of common illness such as fever, anorexia, decreased social interactions, lethargy, sleepiness, and hyperalgesia.

In this thesis the contribution of $\mathrm{PGE}_{2}$ to the immune-to-brain signaling was further characterized at the blood-brain-barrier (BBB) and in the anterior preoptic area (POA) of the hypothalamus (i.e. the thermoregulatory region or, in sickness, the fever generating region).

$\mathrm{BBB}$ is the major interface region between peripheral circulating cytokines and the neuronal parenchyma and a critical source of PGE2. Using chimeric mice lacking the inducible enzyme for PGE2 synthesis, microsomal PGE synthase-1 (mPGES-1), in either hematopoietic or nonhematopoietic cells, we demonstrate in paper I that brain endothelial cells are the critical source of $\mathrm{PGE}_{2}$ in $\mathrm{BBB}$ during peripheral inflammation. For the demonstration of the mPGES-1 expression in the BBB cells we developed in paper I a method for enzymatic dissociation of these cells, followed by fluorescence activated cell sorting (FACS). Using the same method, we show in paper II that the BBB response to immune stimuli is towards an increased production of PGE2 in endothelial cells and an increased sensitivity of these cells for proinflammatory cytokines. These changes are supported by decreased PGE2 degradation and decreased synthesis of other prostanoids in perivascular macrophages, which hence respond in concordance with the endothelial cells in enhancing PGE2 signaling.

Once released in the neuronal tissue, $\mathrm{PGE}_{2}$ has been shown to be critical for the fever response by acting on the type 3 PGE2 receptors (EP3) within POA. By laser capture microdissection (LCM) we extracted the EP3 receptor expressing region in POA, defined by in situ hybridization histochemistry, from mouse brain sections. We demonstrate in paper III that the predominant subtypes of the EP3 receptor in POA are EP3 $\alpha$ and EP3 $\gamma$. In paper IV we further analyze the effect of $\mathrm{PGE}_{2}$ on the LCM dissected EP-rich POA using gene expression microarrays. We demonstrate that $\mathrm{PGE}_{2}$ has a limited effect on the gene expression changes within POA, suggesting that the neuronal activity is modulated by PGE2 in a transcriptionindependent manner and that the profound gene expression changes that are seen in the CNS during inflammation are accordingly PGE2-independent. 


\section{Abbreviations}

15-PGDH

Abcc 4

ADAM

Anpep

AP1

BBB

CD

CNS

COX-(1-2)

CPGES

CR1

CSF

CVO

CXCL10

DAMPs

EP1-4

FACS

FC

FMO

FSC

gp130

HPA

H-PGDS

HSP

Iba1

icv

IFN

$\operatorname{IkB} \alpha$

IKK

IL

IL-1R

IL-1RAcP

IL-6R

ip

iPGE $_{2}$

IRFs

iv

KO

LCM

L-PGDS

LPS 15-hydroxy-prostaglandin dehydrogenase

ATP-binding cassette transporter 4 or Mrp4

A disintegrin and metalloproteinase $(10,17)$

Alanyl membrane aminopeptidase

Activating protein-1

Blood-brain barrier

Cluster of differentiation

Central nervous system

Cyclooxygenase (1-2)

Cytosolic PGE synthase

Carbonyl reductase-1

Cerebrospinal fluid

Circumventricular organ

C-X-C motif chemokine 10

Danger-associated molecular patterns

Prostaglandin E receptor 1-4

Fluorescence activated cell sorting

Fold change

Fluorescence minus one

Forward-scatter light

Glycoprotein 130

Hypothalamic-pituitary adrenal

PGD2 synthases, hematopoietic

Heat shock protein

Ionized calcium binding adapter molecule 1

Intra-cerebroventricular

Interferon

Inhibitor of kappa B, subtype alpha

IкB kinase complex

Interleukin

Interleukin-1 receptor

IL-1R accessory protein

IL-6 receptor

Intraperitoneal

Inflammation-induced $\mathrm{PGE}_{2}$

Interferon transcription factors

Intravenous

Knock-out transgenic mouse

Laser capture microdissection

$\mathrm{PGD}_{2}$ synthases lipocalin-type

Lipopolysaccharide 


\begin{tabular}{|c|c|}
\hline MAPKs & Mitogen activated-protein kinases \\
\hline MMR & Macrophage mannose receptor or CD206 \\
\hline mPGES-1 & Microsomal PGE synthase-1 \\
\hline mPGES-2 & Microsomal PGE synthase-2 \\
\hline Mrp4 & Multi drug resistance-associated protein 4 or Abcc 4 \\
\hline MyD88 & Myeloid differentiation factor 88 \\
\hline NF-kB & Nuclear factor kappa-light-chain-enhancer of activated B cells \\
\hline NTS & Nucleus of the solitary tract \\
\hline OVLT & Organum vasculosum of lamina terminalis \\
\hline PAMPs & Pathogen-associated molecular patterns \\
\hline Pdgfrb & Platelet-derived growth factor receptor $\beta$ (CD140b) \\
\hline PECAM1 & Platelet endothelial cell adhesion molecule-1 or CD31 \\
\hline $\mathrm{PGE}_{2}\left(\mathrm{D}_{2}-\mathrm{I}_{2}\right)$ & Prostaglandin E2 (D2, E2, F2, G2, H2, I2) \\
\hline $\mathrm{PLA}_{2}$ & Phospholipase A2 \\
\hline POA & Anterior preoptic area of the hypothalamus \\
\hline PRRs & Pathogen recognition receptors \\
\hline PVN & Paraventricular nucleus of the hypothalamus \\
\hline RT-qPCR & Reverse Transcription-quantitative Polymerase Chain Reaction \\
\hline Slc & Solute carrier transporter family (organic cation) \\
\hline Slco & Solute carrier organic anion transporter family \\
\hline SOCS3 & Suppressor of cytokine signaling 3 \\
\hline SSC & Side-scatter light \\
\hline STAT & Signal transducer and activator of transcription \\
\hline TAK1 & Tumor growth factor $\beta$-Activated Kinase- 1 \\
\hline TICAM-1 & TIR domain-containing adaptor-inducing IFN-beta (or TRIF) \\
\hline TIR & Toll/IL-1Receptor \\
\hline TLDA & TaqMan Low Density Array \\
\hline TLR & Toll-like receptor \\
\hline TNF & Tumor necrosis factor \\
\hline TRIF & TIR domain-containing adaptor-inducing IFN-beta (or TICAM-1) \\
\hline vWF & Von Willebrand factor \\
\hline WT & Wilde type mouse \\
\hline
\end{tabular}




\title{
Background
}

\author{
Introduction
}

Feeling sick is the lesser of the two evils when we are confronted with disease. While alarming us of an impending need for medical attention, the sickness behavior has helped researchers to reveal an intimate, critical relationship between the central nervous system and the immune system. Fever and release of stress hormones were the first sickness manifestations demonstrated to be brain-mediated responses triggered by the activation of the immune system when confronting pathogens, and not by pathogens alone. This direct relationship between the immune system and the central nervous system has given the mechanisms of immune-to-brain signaling a permanent place in the pathophysiology of inflammation, thus opening up for new therapeutic strategies in several inflammatory and inflammation-related diseases (CouzinFrankel, 2010; Haroon et al., 2012).

\section{Homeostasis in health and in sickness}

The central nervous system (CNS) and the immune system are indispensable in complex organisms where several organs and systems have to interact. Through intricate feedback mechanisms, morphological, functional and metabolic demands are supported for each organ and system to create a stable unity, i.e. homeostasis (Figure 1).

To achieve homeostasis, there is a need to uninterruptedly monitor the integrity of tissues by removing senescent cells, apoptotic debris and pre-malign cells (immunological surveillance), as well as to coordinate the organs functionality (by the autonomic nervous system), and to adjust their metabolic demands and resources and regulate the body core temperature (through the neuroendocrine system, behavioral changes and thermoregulation).

Moreover, whenever the organism is challenged by invasive pathogens not only does the necessity of having the two systems as such become clear, but also the necessity of an immuneCNS collaboration. Systemic acute phase responses like fever, metabolic changes with release of stress hormones, as well as behavioral changes like anorexia, fatigue, increased slow wave sleep, warm-seeking behavior, and decreased social interaction (i.e. sickness behavior) (Hart, 1988) (Figure 2) are common cerebral-mediated manifestations in diseases associated with systemic inflammation. 


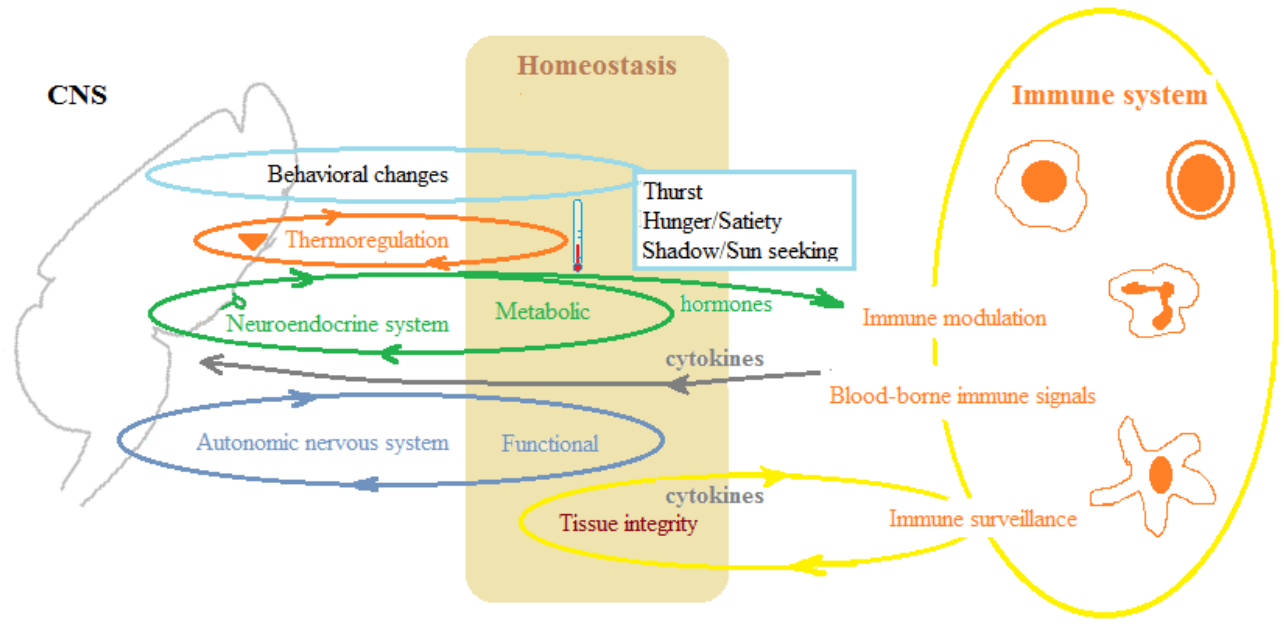

Figure 1. Homeostasis requires tissue integrity, functional coordination, and metabolic and thermal regulation, which can be reinforced by behavioral changes. These processes are controlled by the CNS (left side) or the immune system (right side) through feedback mechanisms (colored circles with directional arrowheads; orange triangle shows the approximate position of the thermoregulatory region and green line marks of the pituitary gland in a sagittal brain section through the mouse brain).

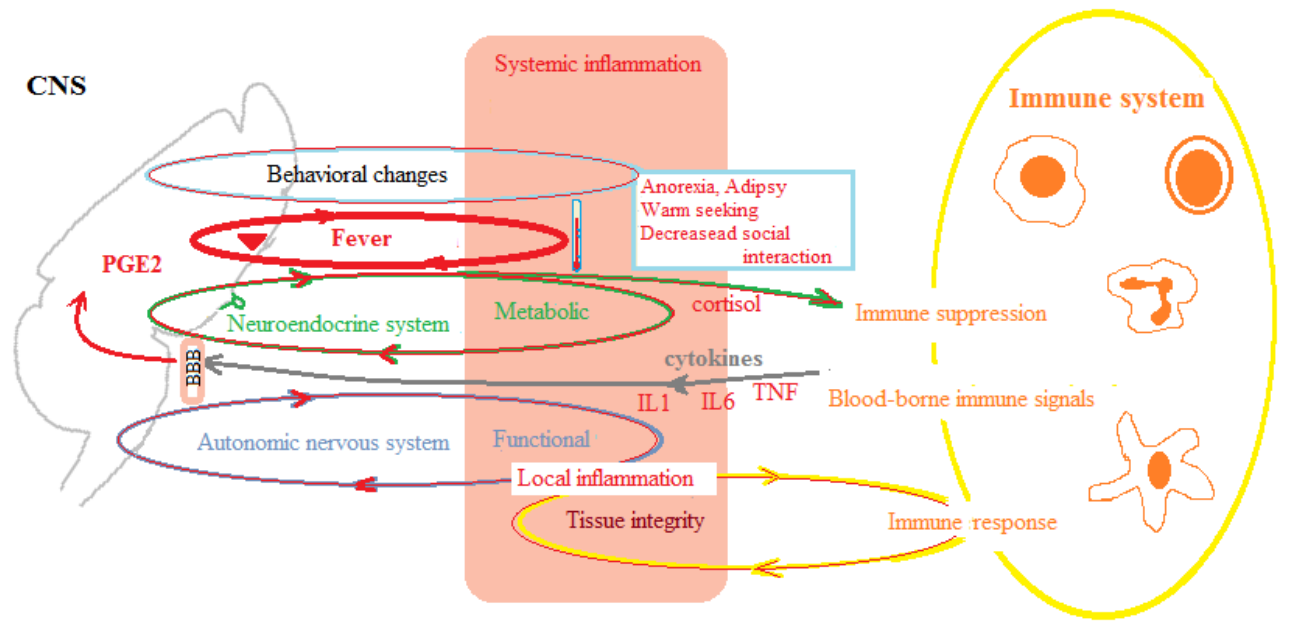

Figure 2. Acute phase responses in systemic inflammation and the $\mathrm{PGE}_{2}$ contribution in the CNS. Typical changes representing the sickness syndrome are presented in red text. Inflammation-induced prostaglandin E2 ( $\left.\mathrm{PGE}_{2}\right)$, released in the brain from the blood-brain barrier (BBB), is participating and contributing in varying degrees to the CNS responses. While it is critical for the fever response (whole red feedback circle), $\mathrm{PGE}_{2}$ is only partly regulating (partially red feedback circles) the stress hormone release (cortisol) and sickness behavioral changes like anorexia. 


\section{Acute systemic inflammation}

Inflammation is a central event in the pathogenesis of many diseases. It can express itself in various ways, playing a role in infections as well as in allergies, tissue damage, chronic rheumatic diseases and cancers. One of the most complex examples of molecular networking is seen in infections associated with acute systemic inflammation. While supporting the immune system in its fight to eliminate the intruder, the acute inflammation with its fast developing, simultaneous processes engaging several systems and organs can run the risk of progressing towards the worst scenario of septic shock and eventually death (Deutschman and Tracey, 2014).

Inflammation per se is a protective process against microbial intruders or endogenous danger molecules, aimed at minimizing both the invasion of pathogens and resulting tissue damage, and at restoring the internal homeostasis. It encompasses well-orchestrated induction and resolution processes that during a limited time frame, as long as the pathogen is recognized, allow defense mechanisms to identify and specifically eradicate intruders while it also initiates the healing process and tissue remodeling. The main conductor of inflammation is the immune system with its effector cells, leucocytes, macrophages, dendritic cells and mast cells, and its miscellaneous molecules, most importantly cytokines [interleukins (ILs), interferons (IFNs), tumor necrosis factors (TNFs), growth factors and chemokines], immunoglobulins and complement.

The intensity of the inflammatory process varies depending on the immune response and extent of the tissue damage. Scavenging is an inflammation-free function of immunity that takes place continuously in all tissues and helps maintaining a normal histology by eliminating senescent cells and apoptotic debris through phagocytosis (a physiological process of the innate immunity, i.e. immune surveillance) (Kerr et al., 1972). As soon as danger molecules are identified, the immune cells in the tissues release pro-inflammatory cytokines to initiate immune responses as well as local inflammation, clinically recognized by the cardinal signs of calor, rubor, tumor, dolor and functio laesa (Celsus A.C. 25 BC - ca AD 50, Galenus C AD 129 - ca 210, Virchow R Cellular Pathology 1858) (Ryan and Majno, 1977). If this process cannot be restrained or if the pathogens spread out, the immune system intensifies its effects by increasing leucocyte trafficking and cytokine release leading to systemic inflammation and clinical onset of systemic acute phase responses (Figure 2).

With an escalating severity of the infection there is a need for the immune system to amplify, renew and specialize the molecular and cellular immune components, leading to synthesis and release of acute phase proteins from the liver, enhanced myelo- and lymphopoiesis in the bone morrow, and selection and proliferation of pathogen-specific B and T-lymphocytes (adaptive immune response). Hence, the metabolic demands will increase, placing a strain on the 
available energy resources. Together with other potentially aggravating factors like hydroelectrolytic and cardiovascular imbalances, organ functionality can deteriorate leading to organ/system failure and life-threatening conditions such as septic shock. Critical survival factors in acute systemic inflammation are the ability of the organism to prioritize the functions of the vital organs by maintaining the supply of blood and energy to these organs through the contribution of the CNS and the ability to sustain but also at the same time to restrain the immune response and minimize the risk of extreme immune activation/ immune overshooting (Besedovsky and Sorkin, 1977; Sternberg, 2006).

\section{Immune-to-brain signaling}

The collaboration between the immune system and CNS was long underestimated due to the dogmatic view of the brain as an immune privileged organ. The seclusiveness of the CNS was demonstrated more than a century ago by Paul Ehrlich (Ehrlich, 1885) and Edwin Goldman (Goldmann, 1913) using trypan blue stains (Hawkins and Davis, 2005; Siso et al., 2010). In various animals they noticed that when the dye was injected into the circulation, the brain and spinal cord remained "white as snow" in contrast to all other tissues that turned blue. While Ehrlich believed that this phenomenon depended on the brain's low affinity for the dyes, Goldman demonstrated that the brain microvasculature functions as a barrier, since intracerebroventricularly (icv) administered dyes could stain the neuronal tissue but did not pass through it, to the outside the CNS (Bentivoglio and Kristensson, 2014; Goldmann, 1913). The barriers enclosing the CNS were later shown to display lower permeability and transcytosis than capillaries in other tissues, as well as limited trafficking of immune cells, properties that pointed out the brain as a tissue escaping the normal immune surveillance and which, as a consequence, became to be considered an "immune privileged organ".

The immune-to-brain collaboration was revealed along with the discovery and characterization of pro-inflammatory cytokines as inducers of fever, a well-known cerebral (hypothalamic)mediated response to infections. The first recognition of this collaboration resulted from the identification of pyrogens (molecules inducing fever), like pyrexin, in sterile extracts of damaged tissue (Menkin, 1944), later on to be named endogenous pyrogens (body's own produced pyrogens) of sterile tissue extracts and exudates, and of neutrophils (Bennett and Beeson, 1953). Subsequently, Atkins and Wood independently could show that upon stimulation, not only neutrofils but several types of immune cells released different molecules that induced fever (Atkins and Bodel, 1971; Moore et al., 1970; Wood, 1962). These endogenous pyrogens proved to be rather large proteins of 15-40 kDa (Bernheim et al., 1979; Dinarello et al., 1974). Despite being unable to pass the blood-brain barrier (BBB), the cytokines evoked cerebral-mediated responses like fever and sickness behavior even if 
administrated peripherally and in the absence of a viral or bacterial infection that might affect the integrity of the CNS-barriers. Thus, early studies of cytokines (reviewed in Dinarello, 1996; Kluger, 1991 and briefly annotated in the cytokine section) revealed not only their functions but also demonstrated that sickness symptoms are not primarily due to infection-induced organ loss-of-function, but instead are early brain-coordinated adaptive responses evoked by peripheral immune signals (Dantzer et al., 1998; Hart, 1988), anticipating and preparing the organism for the septic-shock hazard. Hence, the question was raised on how this immune-tobrain signaling (or cytokine-to-brain signaling) takes place.

In addition to cytokines, another major mediator of inflammation was acknowledged due to its connection to an ancient remedy. Used as extracts of willow tree bark by Assyrians, Egyptians, and Greek and Roman physicians like Hippocrates, Celsus and Galen, the active substance salicylate was purified in the early 1800 s and refined to the modern non-steroidal antiinflammatory drugs (NSAIDs) to become the most common antipyretic, anti-analgesic and anti-inflammatory drugs used worldwide (Levesque and Lafont, 2000). Despite centuries of use, the action mechanism of acetylsalicylic acid (Aspirin) was not described until 1971 by Sir John Vane ${ }^{1}$ who showed that acetylsalicylic acid was an inhibitor of prostaglandin synthesis (Vane, 1971). At this time, the prostaglandins ${ }^{2}$ had already been structurally characterized by Sune Bergström and Bengt Samuelsson (Bergström, 1967; Bergström and Samuelsson, 1965; Samuelsson, 2012) making it possible to identify PGE as an inflammatory prostaglandin. Reports were soon published showing that immune-challenged animals displayed increased levels of PGE in the cerebrospinal fluid. In addition, $\mathrm{PGE}_{2}$ injected into the cerebral ventricles (icv) was pyrogenic at low doses (Feldberg and Gupta, 1973; Feldberg and Saxena, 1971a; Feldberg and Saxena, 1971b; Milton and Wendlandt, 1971; Philipp-Dormston and Siegert, 1974). And additionally, if injected intradermally or intravascularly, PGE 2 decreased the pain threshold to induce hyperalgesia (Ferreira, 1972; Ferreira et al., 1973).

As a result of these early observations, pro-inflammatory cytokines and prostaglandins, particularly PGE2, were acknowledged as key mediators in immune-to-brain signaling. Therefore, before describing the paradigms of immune-to-brain signaling that are central for the fever response and sickness behavior in general, each of the cytokines and prostaglandins relevant for the research for this thesis are introduced individually, addressing their roles in inflammation and sickness behavior.

\footnotetext{
${ }^{1}$ Sir John Vane, Sune K. Bergström and Bengt I. Samuelsson were awarded the Nobel Prize in Medicine in 1982.

${ }^{2}$ The name prostaglandin was given by Ulf von Euler after the prostatic gland, since prostaglandin was first identified in seminal fluid by Kurzrok, Lieb and Goldblatt during the 1930's.
} 


\section{Cytokines, PRRs, PAMPs, alarmins and DAMPs}

The foundation for cytokine research was set almost 60 years ago by studies of endogenous pyrogens (Atkins and Wood, 1955; Bennett and Beeson, 1953) and the contemporary identification of interferon (IFN) (Isaacs and Lindenmann, 1957; Lindenmann, 2007). Since then, researchers have identified more than 300 cytokines (ILs, IFNs, TNFs, growth factors and chemokines) (Turner et al., 2014). These extracellular molecules are primarily produced to support the functions of the immune cells, and trafficking and communication between them, but also with and between somatic cells (from Greek, cyto-, cell and -kinos, movement), in health as well as during pathological processes.

\section{Danger recognition}

Immune and inflammatory responses are initiated by danger molecules (Matzinger, 2002). Exogenous, microbial-specific antigens expressing conserved pathogen-associated molecular patterns (PAMPs) and endogenous danger molecules i.e. alarmins (antigens that normally are not exposed to the immune surveillance unless there is a pathological accumulation or a tissue injury), are referred to together as danger-associated molecular patterns: DAMPs. They bind to pathogen recognition receptors (PRRs) expressed on cells at the front line of defense, namely macrophages, monocytes, dendritic cells, neutrophils and epithelial cells. PRRs are grouped into Toll-like receptors (TLRs), RIG-I-like receptors (RLRs), and NOD-like receptors (NLRs) (Kumar et al., 2011). Depending on the subsets of PRRs and cellular specialization/machinery of the receiver cell (e.g. macrophages, dendritic cells) the message will be translated into various degrees of innate (mostly inflammatory) and/or adaptive immune responses (antigen presentation and lymphocyte proliferation). While macrophages play a significant role in initiating the inflammatory response by an inflammasome ${ }^{3}$-dependent maturation and release of IL-1 $\beta$ and IL-18 (Schroder and Tschopp, 2010), the dendritic cells are critical for initiating adaptive immune responses and further selection of pathogen-specific B and T-cells (Medzhitov and Janeway, 2002). PRRs respond to DAMPs most commonly by activating pro-inflammatory transcription factors like nuclear transcription factor beta (NF-kB) and activating protein-1 (AP1), and interferon transcription factors (IRFs) for type I interferon production (Figure 3).

\footnotetext{
${ }^{3}$ Large intracellular protein assembly occurring after NLRs recognition of DAMPs. NLRs cleave pro-caspase-1 to its active form caspase- 1 which subsequently cleaves pro-IL- $1 \beta$ and pro-IL-8
} 


\section{Endotoxin}

Lipopolysaccharide (LPS) is an endotoxin, a heat-stable component of the cell-wall in gramnegative bacteria. It is the most widely used PAMP in animal models of inflammation as it can induce a septic-like syndrome in the absence of bacterial infection (Dantzer et al., 1998; Kluger, 1991) (and Beutler and Rietschel, 2003, with historical notes on endotoxin). Its effects have been shown to be transduced through Toll-like receptor 4 (TLR4) (Poltorak et al., 1998a) ${ }^{4}$ and its co-receptor myeloid differentiation factor-2 (MD2). On the cell membrane LPS binds to CD14 and is subsequently loaded on MD2 and presented for TLR4. This process induces oligomerization of TLR4 and signal transduction (Figure 3) (Kumar et al., 2011; Shimazu et al., 1999).

\section{TLRs and Interleukin-1 receptors}

The interleukin-1 receptor (IL-1R)/Toll-like receptor superfamily is characterized by the common, well conserved intracellular signaling TIR domain (Toll/IL-1Receptor; earlier coming from resistance). Activated TIR domains bind to two main adaptor proteins, myeloid differentiation factor 88 (MyD88, adaptor for all IL-1Rs and TLRs except TLR3) and TIR domain-containing adaptor-inducing IFN-beta (TRIF also known as TICAM-1, specific for TLRs) (Figure 3) (Casanova et al., 2011).

TLR4 is mostly expressed on myeloid cells (monocytes, macrophages, and glial cells) but also on non-hematopoietic cells like fibroblasts, endothelial cells and epithelial cells (Akira et al., 2006; Zhang et al., 1999). Although studied mostly for its LPS recognition, TLR4 has several other ligands of various origins. In addition to bacterial LPS, TLR4 can bind DAMPs of parasite (glycoinositolphospholipids), fungus (mannan), viral (envelope proteins RSV) and host origin (heat-shock proteins, fibrinogen) (Akira et al., 2006). Upon TLR4 activation, adapter proteins are recruited to TIR-domains and initiate complex downstream signaling pathways to activate several transcription factors like IRF3, NF-kB and AP1. Of these, NF-kB is activated by two pathways: an early, MyD88-dependent canonical pathway and a late, MyD88-independent, TRIF-dependent alternative pathway (Figure 3) (Akira et al., 2006; Palsson-McDermott and O'Neill, 2004).

Interleukin-1 receptors (IL-1Rs) binding IL-1 $\alpha$ and IL-1 $\beta$ are type I and type II IL-1R (IL1R1, IL-1R2), and IL-1R accessory protein (IL-1RAcP). Typical for IL-1Rs is the extracellular chain with 3 immunoglobulin-like domains in addition to the intracellular TIR domain shared with TLRs (Figure 3). IL-1R2 is different from the other IL-Rs by lacking the TIR-domain.

\footnotetext{
${ }^{4}$ Bruce A Beutler and Jules A Hoffmann, finders of TLR4, were awarded the Nobel Prize in 2011 together with Ralph A Steinman, for his discovery of the dendritic cell.
} 
Without TIR-domain IL-1R2 lacks the possibility of downstream signal transduction and thus acts as a decoy receptor trapping IL-1. IL-1R2 exists both as a membrane receptor and a soluble receptor in the extracellular space.

IL-1R1 and IL-1RAcP form the active IL-1 receptor by heterodimerization and intracellular TIR-dimerization. They are found prominently on endothelial cell, smooth muscle cells, epithelial cell, hepatocytes, fibroblasts, keratinocytes, epidermal dendritic cells, monocytes and T-lymphocytes (Dinarello, 1996). IL-1Rs signal through a MyD88 canonical pathway to activate NF-kB and/or AP1 (Figure 3) (Casanova et al., 2011; O'Neill, 2008).

\section{Pro-inflammatory cytokines}

IL-1 $\beta$, IL-6 and TNF $\alpha$ as the main pro-inflammatory cytokines have been extensively studied in different animal inflammatory models (acute, chronic, local or systemic) and more recently as mediators of autoinflammation.

Autoinflammation as a pathological process of the phagocytic cells was described a century ago by Elie Metchnikoff (1845-1916) but was then neglected until the late 1990s. The new term autoinflammation was defined by McDermott along with the discovery of the cause of the hereditary periodic fevers, a set of distinct clinical entities that could not be attributed to "infectious, allergic, endocrinologic, epileptic or migrainous influences" [as reviewed by (Reimann, 1949)]. Hereditary periodic fevers proved to be monogenic syndromes, with mutations limited to the genes of the innate immunity such as TNF-receptor 1 gene (McDermott et al., 1999) or IL-1/inflammasome-related genes (Mariathasan et al., 2004). These discoveries led to viewing autoinflammation (McDermott et al., 1999) as a new immunopathogenesis distinct from autoimmunity (driven by adaptive immune effectors: autoantibodies and auto-reactive B and T-lymphocytes). It came to confirm that cytokine imbalances leading to "sterile" systemic inflammation can evoke cerebral responses like fever. The distinction between autoinflammation and autoimmunity has led to revision of the pathogenesis of a long list of chronic diseases, not only monogenic but also polygenic, like Crohn's disease, diabetes mellitus and most of rheumatic diseases (McGonagle and McDermott, 2006) and even depressive disorders and neurodegenerative diseases like Alzheimer's disease, Parkinson's disease, and amyotrophic lateral sclerosis. As a result, antiproinflammatory cytokine therapy trials (anti-TNF $\alpha$, anti-IL-6 and anti-IL-1 $\beta$ ) have been started for several of these entities (Bradley, 2008; Chou, 2013; Dinarello et al., 2012; Rothwell and Luheshi, 2000). 


\section{Interleukin-1}

IL-1 $\beta$ and IL-1 $\alpha$ (together referred to as IL-1) were the first cytokines to be sequenced and cloned in the IL-1 family (Auron et al., 1984; March et al., 1985), a family of 11 known members that are ligands for receptors within the IL-1R-family (Garlanda et al., 2013). Although sharing only $24 \%$ protein sequence identity and acting in different pathological conditions, IL- $1 \alpha$ and IL-1 $\beta$ induce similar responses as they bind to the same receptors. IL- $1 \alpha$ is expressed in epithelial cells, endothelial cells and astroglia. It is considered an alarmin as it can bind to IL-1R1 only during tissue stress when IL-1 $\alpha$ is exposed on the cell membrane or released in the extracellular space from necrotic cells. IL- $1 \alpha$ is active both as precursor and in a cleaved form. In contrast, IL- $1 \beta$ is mainly produced by monocytes and phagocytes in response to DAMPs, immune complexes, and pro-inflammatory cytokines (IL-1, TNF $\alpha$, IL-6). Its activity is controlled at several levels, enhancing the possibility to restrain the powerful inflammatory effect of IL- $1 \beta$. Firstly, in unstimulated cells, IL- $1 \beta$ is similar to IL- $1 \alpha$ expressed as a pro-peptide, but at very low levels and as an inactive form. For an IL-1 $\beta$ activation to occur two processes are needed, first an up-regulation of the pro-IL-1 $\beta$ transcript, through TLRs or cytokine receptor signaling, and the second a cleavage activation of pro-IL-1 $\beta$ peptide by caspase-1 (IL-1-converting enzyme) that is also cleaved from its pro-form by NLRs activated inflammasomes (Schroder and Tschopp, 2010). Hence, the production and release of IL-1 $\beta$ is depending on a double PRR-signaling. Secondly, extracellular IL-1 $\beta$ acts mostly in an autoand paracrine way as IL-1R1 and IL-1R2 are richly expressed on most cells and even as soluble receptors (IL-1sRII). The blood levels of IL-1 $\beta$ are accordingly lower than what could be expected, even in septic patients. Thirdly, specific negative regulators like IL-1 receptor antagonist (IL-1Ra) are released in response to inflammation. IL-1Ra binds and blocks IL-1Rs, although with a lower affinity than IL-1. It is estimated that up to 1000-times more IL-1Ra than IL-1 is needed to block IL-1 signaling, because of the lower affinity of IL-1Ra compared to that of IL-1. It is well-known that low doses of IL-1 $\beta$ are enough to induce specific responses. On a cellular level, it was shown that as few as $2 \%$ of all IL-1R1 need to be activated to induce an effect (Arend, 2002; Dinarello et al., 2012; Garlanda et al., 2013; Sims and Smith, 2010; Turner et al., 2014).

\section{IL-1ß in immune-to-brain signaling}

Discovered as a macrophage-released factor that can potentiate T-lymphocytes, IL-1 was first named lymphocyte-activating factor (LAF) and studied for its role in the adaptive immune system (Gery et al., 1972; Mizel et al., 1978). Soon after it was acknowledged that IL-1 is a "pleiotropic, nonspecific hormone-like cytokine" that can induce various cells to differentiate and proliferate (Oppenheim et al., 1986). For its capacity to potentiate T-cells and induce neutrophilia (or neutrophil leukocytosis) at low doses, intravenous (iv) injection of IL-1 $\beta$ was even tested on human volunteers and cancer patients but with unsatisfactory results since it was 
found to be a strong inducer of unspecific sickness-related symptoms like fever, anorexia, fatigue, and gastrointestinal and sleep disturbances (Dinarello, 1996). Also during the 1980s it was shown in animal models that IL-1 $\beta$, when injected intravenously, gives rise to complex cerebral responses as it induces not only fever and sickness behavior, but also regulates the HPA-axis (hypothalamic-pituitary adrenal axis), increasing the blood levels of ACTH and glucocorticoids (Besedovsky et al., 1986) via central release of corticotropin- releasing factor (Berkenbosch et al., 1987; Sapolsky et al., 1987). Still, during systemic inflammation these properties proved not to be specific for IL-1 $\beta$ as first hypothesized (Atkins, 1984). Several other pyrogens were soon identified like TNF $\alpha$ and interferons (Atkins, 1988; Dinarello et al., 1988), and it was also shown in animal models that blocking IL-1 signaling would not abrogate fever, sickness behavior or HPA-axis activation. These studies led to various results due to their methodological complexity. Hence, in LPS-treated animals, impeding the IL-1 signaling either by exogenous IL-Ra, by blocking antibodies for IL-1 or IL-1R1, or by deleting genes critical for the IL-1 signaling (genes for IL-1 $\beta$ and IL-1R1, caspase-1) led to divergent results (Alheim and Bartfai, 1998; Dinarello, 1996; Fantuzzi and Dinarello, 1996). The fever response was either attenuated (Kozak et al., 1998), normal (Leon et al., 1996) or exacerbated (Alheim et al., 1997). As for the HPA-axis activation by IL-1 $\beta$, corticosteroid levels were reported to be either unchanged (Kozak et al., 1998) or increased (Alheim et al., 1997). These studies and many other related studies came to reveal what is widely accepted today, namely that the cytokine networking in systemic inflammation is complex as pro-inflammatory cytokines are pleiotropic and redundant. They have many different target cells, and the individual cytokines interact in complex ways by inducing each other or by subserving similar functions which makes it possible for them to compensate for each other (Zetterstrom et al., 1998). An elegant study on cytokine redundancy was carried out on mice lacking the gene for IL-1R1. It showed that in the absence of IL-1 signaling, the LPS-induced sickness behavior is controlled by TNF $\alpha$, compensating for IL-1 $\beta$, and that it can be abrogated by TNF-binding protein (Bluthe et al., 2000).

\section{Interleukin-6}

Interleukin 6 is the main member of the IL-6 family, a family characterized by the common plasma membrane glycoprotein 130 (gp130, also known as CD130) needed as signal transducer subunit in their receptor complexes (Figure 3). IL-6 blood levels were found to be increased in septic patients and animal models of inflammation, and it is hence well-known for its immune and pro-inflammatory properties. It is a strong inducer of acute phase proteins in the liver, it activates the HPA-axis, and it modulates lymphocyte differentiation and proliferation. It also activates endothelial cell to express adhesion molecules and chemokines and it increases vascular permeability. Recent advances [reviewed in (Scheller et al., 2011)] assign IL-6 newer 
functions in e.g. metabolic regulation and neuronal plasticity (which fall outside the aim of this thesis). It has also been shown that IL-6 has both pro- and anti-inflammatory properties, mostly as a result of its intricate receptor-complex building.

IL-6 receptor alpha (IL-6R, alternative names gp80, CD126) and gp130 exist as preformed receptors on the plasma membrane and as soluble receptors in the extracellular space. While gp130 is ubiquitously expressed on cells, IL-6R is constitutively expressed on macrophages, neutrophils, glial cells, hepatocytes and some types of T-lymphocytes, and after immune challenges also in the brain blood vessels (Vallieres and Rivest, 1997). After IL-6 ligand binding, IL-6R associates with two gp130 subunits resulting in dimerization of the intracellular signaling domains and downstream signal transduction (Figure 3). This is the IL-6 classicsignaling in cells that express membrane IL-6R (mbIL-6R). Cells lacking mbIL-6R can still respond to IL-6 by attaching soluble IL-6R (sIL-6R). IL-6/sIL-6R complexes can bind to membrane gp130, and induce an IL-6 trans-signaling. The soluble IL-6R is hypothesized to be generated by a proteolytic and/or transcriptional mechanism. Shedding or proteolytic cleavage of existing membrane IL-6R was demonstrated to be done by membrane metalloproteases ADAM17 and ADAM10, whereas the transcription mechanism is dependent on generation of an alternatively spliced IL-6R mRNA lacking the transmembrane and cytosolic domains (Scheller et al., 2011). Trans-signaling has been shown to be a central mechanism for monocyte recruitment during the non-phlogistic removal of apoptotic neutrophils (scavenging). Senescent neutrophils programmed to die (apoptotic neutrophils) shed their membrane IL-6Rs which instead activate endothelial cells through trans-signaling, thus inducing release of monocyte-specific chemokines (Chalaris et al., 2007). This process was proved to be relevant also in the resolution phase of acute inflammation, thus identifying IL-6 as an antiinflammatory cytokine. The initial neutrophil tissue infiltration during the induction phase of inflammation is followed by apoptotic neutrophil IL-6R-shedding and IL-6 trans-signaling on endothelial cells. This process leads to a switch in the endothelial cells from release of neutrophil specific chemokines to release of monocyte and T-lymphocyte specific chemokines and subsequent monocyte infiltration in the surrounding tissue (Chen et al., 2006; Hurst et al., 2001). Proteolytic shedding is seen also for the membrane gp130, but unlike sIL-6R, soluble gp130 is inactive and blocks sIL-6/IL-6R trans-signaling by complex sequestration.

\section{IL-6 and immune-to-brain signaling}

IL-6 has an indirect, critical role for fever generation. IL-6 fails to elicit fever by itself, unless given together with a low-dose of IL-1 $\beta$ (Cartmell et al., 2000). Nonetheless, in mice lacking IL-6 (IL-6 knock-out/KO mice or mice pretreated with IL-6 antiserum) the fever response and other components of sickness behavior are blunted both to LPS (Chai et al., 1996; Nilsberth et al., 2009a), though not to a high dose of LPS (Kozak et al., 1998), and to turpentine (Kozak et al., 1998; Kozak et al., 1997). Thus circulating IL-6 is necessary but not sufficient for fever 
and other sickness-behavior responses. LPS-treated IL-6 KO mice were shown to release more $\mathrm{TNF} \alpha$, and have lower circulating levels of PGE2 (Kozak et al., 1998). Contrasting findings were shown by our group. Thus, $\mathrm{PGE}_{2}$ levels in the cerebrospinal fluid and hypothalamic transcripts for cytokines and PGE2-synthesizing enzymes were similar between LPS treated WT and IL-6 KO mice (Nilsberth et al., 2009a), suggesting that IL-6 is not directly involved in the production of $\mathrm{PGE}_{2}$ but that it might modulate the $\mathrm{PGE}_{2}$ release on its targets, i.e. neuronal cells. However, in a subsequent study on IL-6R $\alpha$ transgenic mice, deletion of the IL6 receptor on brain endothelial cells resulted in decreased COX-2 levels and blunted fevers, implying that COX-2 is downstream of and partly regulated by IL-6 (Eskilsson A 2014).

\section{Tumor necrosis factor}

TNF $\alpha$ was first considered to be a component of endotoxins and was studied as early as 1891 by Coley (Coley, 1893) for its property of being able to induce tumor regression (Nauts et al., 1946). As bacterial toxins could not directly induce necrosis in tumor cultures, an indirect endotoxin action mechanism was suggested by Algire (Algire et al., 1952). This was proved to be true in 1975, when a macrophage-derived serum factor was shown to retain the tumor necrosis effect of endotoxin (thus called tumor necrosis factor) (Carswell et al., 1975). Ten years later, at the time of its isolation and characterization (Aggarwal et al., 1985), it became clear that TNF is a pleiotropic cytokine, proving to be the same molecule as cachectin (Beutler et al., 1985) that induced anorexia and cachexia, and in high doses septic shock (Tracey et al., 1986). This effect was not due to an LPS contamination, as was first hypothesized, since it was shown also in endotoxin-resistant mice (Cerami et al., 1985), which were later demonstrated to be lacking a functional TLR4 (Poltorak et al., 1998a; Poltorak et al., 1998b).

Today the TNF superfamily includes 30 receptors and 19 associated ligands [reviewed in (Aggarwal, 2003; Tracey et al., 2008; Turner et al., 2014)]. TNF $\alpha$ plays important roles in cell differentiation, inflammation, immunity, metabolism and apoptosis. It is produced by activated immune cells, monocytes, macrophages, T-cells, mast cells, and NK cells, but has also been shown to be expressed in keratinocytes, fibroblasts, and neurons. It has a membrane precursor $(\mathrm{mTNF} \alpha)$ that once present on the plasma membrane is assembled non-covalently in trimers. The soluble TNF $\alpha$ (sTNF $\alpha$ ) is the cleaved ectodomain of $\mathrm{mTNF} \alpha$ released by metalloproteases like ADAM17 (Figure 3).

Both sTNF $\alpha$ and mTNF $\alpha$ bind to the same receptors TNFR1 (TNFRSF1a, CD120a) and TNFR2 (TNFRSF1b, CD120b). TNFR1 and TNFR2 are homo-trimers formed on the plasma membrane independently of ligand-receptor binding. While TNFR1 is ubiquitously expressed on all cells, TNFR2 is considered an inducible receptor present mostly on leukocytes and 
endothelial cells (Bradley, 2008). TNFR1 differs from TNFR2 by presenting an intracellular death-domain (TNF receptor associated death domain, TRADD) that can induce either apoptosis or promote cell survival and inflammation through its two adaptor molecules FADD (Fas-Associated Death Domain) and TRAF (TNF Receptor Associated Factor), respectively (Figure 3). The pathway-selection strategy is as yet poorly understood. Of the two receptors TNFR1 has proved to be a stronger NF-kB activator and to have higher affinity for TNF $\alpha$ than TNFR2, thus being considered the most important pro-inflammatory TNF $\alpha$ receptor. TNFR2 is less well characterized but was shown to promote tissue repair and angiogenesis (Bradley, 2008). Like gp130, TNFRs are shed by metalloproteases (e.g. ADAM17) stopping the intracellular $\mathrm{TNF} \alpha$ signaling and eventually promoting the resolution phase of inflammation.

\section{TNFa and immune-to-brain signaling}

$\mathrm{TNF} \alpha$ administered to cancer patients induced sickness symptoms (Creagan et al., 1988; Steinmetz et al., 1988), similarly to IL-1 $\beta$. In contrast to IL-1 $\beta, \mathrm{TNF} \alpha$ is not a direct pyrogen. When administered to humans or animals it induced fever (Dinarello et al., 1986; Morimoto et al., 1989b) probably through production of IL-6 (Sundgren-Andersson et al., 1998). However, physiologically it is considered an endogenous antipyretic (a cryogen) opposing the pyrogenic effect of IL-1 $\beta$, as animals with TNF-blockade, by TNF-blocking antibodies (Long et al., 1990; Mathison et al., 1988) or lacking the TNFR-genes (Leon et al., 1997), responded with exacerbated fever to LPS treatment.

\section{General remarks on the main transcription factors of inflammation}

The signaling pathways downstream from the cytokine receptors are too complex to be addressed in detail, but some important characteristics deserve to be highlighted (Figure 3).

The cellular responses depend not only on the presence of a certain individual receptor, but on the cellular receptor profile and on the specific intracellular machinery. Cytokine signals are integrated and several transcription factors can be induced to translocate simultaneously to the nucleus. Inducible genes have complex promoter regions where several transcription factors (e.g. AP-1, NF-kB, STAT3, IRF3) and nuclear receptors (e.g. glucocorticoid receptors) interact to switch on/off the gene transcription (De Bosscher et al., 2003; McKay and Cidlowski, 1999). Both TLR4, IL-1R1, and TNFR converge on the NF-kB and AP-1 transcription factors but through different intermediate steps (Aggarwal, 2003; O'Neill et al., 2013).

For $\mathbf{N F - k B}$ (Figure 3) two main pathways have been described: a canonical pathway for TLR4 and IL-1R1 (TIR-receptors) and a non-canonical pathway for TNFRs. In the canonical pathway IKK (IкB kinase complex) is phosphorylated by TAK1 (TGF $\beta$-Activated Kinase-1) with its 
associated binding proteins TAB1 and TAB2. As mentioned above, TLR4 can bind two different receptor adaptors MyD88 and TRIF that activate NF-kB in an early and a late manner, respectively (Casanova et al., 2011; Hayden and Ghosh, 2008). In the non-canonical pathway IKK is phosphorylated directly by RIP1 (Receptor-Interacting Protein-1), a protein often associated to TRAF proteins. The activation of the IKK complex leads to phosphorylation and degradation of $\mathrm{IkB} \alpha$ with subsequent release of the NF-kB heterodimers p65/p50 to translocate to the nucleus. NF-kB activation induces the expression of well over 150 genes, for example inflammation-related genes like IL-1, IL-6, TNF-alpha, cell adhesion molecules (E-selectin, ICAM-1, VCAM-1, fibronectin), and prostaglandin synthases (phospholipase A2, cyclooxygenase-2) (comprehensive list in Table 1 of Kumar et al., 2004). Interestingly, recent reports have found a TAK1 independent NF-kB activation diverging at TRAF6 (Yamazaki et al., 2009) as well as a predominant NF-kB independent TAK1-dependent COX-2 upregulation, through p38 MAPK and c-Jun activation, in brain endothelial cells (Ridder et al., 2011). These later findings raise questions about the complexity and degree of specialization of the brain endothelial cells.

IL-6 communicates through a JAK/STAT (JAnus Kinase/ Signal Transducer and Activator of Transcription) signaling pathway but can also activate MAPKs (mitogen activated-protein kinases) and eventually AP-1 (Heinrich et al., 2003) through its receptor adaptor JAK. IL-6JAK/STAT signaling transmission takes place through nuclear translocation of STAT3 (most commonly) (Figure 3) or STAT1, as phosphorylated homo-dimers.

There are complex, not fully elucidated crosstalk communications between the signaling pathways. While several pathway regulators await characterization, $\mathrm{IkB} \alpha$, a typical NF-kB binding inhibitor (Kumar et al., 2004) and SOCS3 (suppressor of cytokine signaling 3) blocking the JAK kinases from phosphorylating STAT proteins (Heinrich et al., 2003), are generally accepted as markers for pathway activation of NF-kB and STAT3, respectively. 


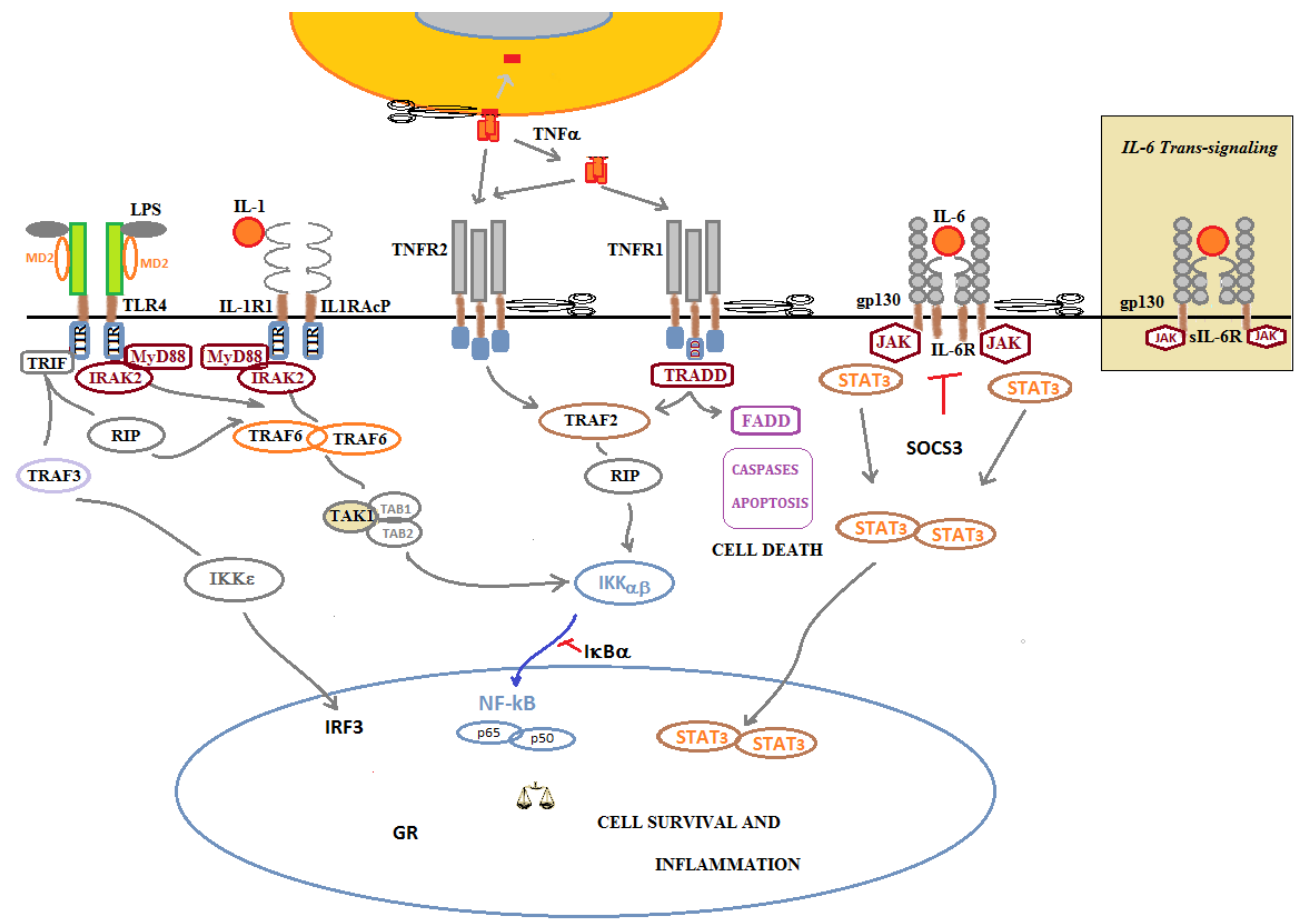

Figure 3. IRF3, NF-kB, and STAT3 signaling. Upon activation, both IRF3, NF-kB and STAT3 move to the nucleus to contribute to the gene transcription regulation together with nuclear hormone receptors like glucocorticoid receptors (GR) bound to glucocorticoid hormones. IRF3 is activated by LPS at TLR4 through TRIF-TRAF3 IKKE phosphorylation. NF-kB is activated by IKK $\alpha \beta$ either by LPS (at TLR4) or IL-1 (at IL1R1/IL-1RAcP) through a canonical TAK1-pathway, or by TNF (at TNFR1 and TNFR2) through a non-canonical RIP mediated pathway. Both RIP and TAK1 kinases are activated by specific TRAF proteins recruited and phosphorylated by receptor adaptor kinases, i.e. IRAK2 (interleukin-1 receptor associated kinase-like 2) for MyD88, TRADD for TNFR1 or directly by TNFR2. TNFR1 can induce either inflammation/cell survival by NF$\mathrm{kB}$ activation or apoptosis by the FADD-caspases pathway. IL-6 induces phosphorylation and dimerization of STAT3 by the IL-6R adaptor protein JAK. The IL-6 receptor can be formed either by IL-6R and gp130, for classic signaling, or by soluble IL-6R (sIL-6R) and gp130 for trans-signaling (yellow box). TNF $\alpha$ and several receptors (TNFR1, TNFR2, gp130 and IL-6R) can be cleaved from membranes by proteases (represented by scissors) like ADAMTS17. IkB $\alpha$ and SOCS3 are inhibitors for NF-kB and STAT3, respectively. 
Prostaglandins

\section{The prostaglandin cascade}

Prostaglandins are cyclic, oxygenated eicosanoids (Greek eicos-, 20) originating from twentycarbon, polyunsaturated fatty acids like arachidonic acid from membrane phospholipids. The prostaglandins (as all eicosanoids) are highly bioactive lipids, produced in minute volumes throughout the body. In general, they act locally fulfilling both physiological and pathological functions, playing a role in inflammation, immunity, cardiovascular and renal homeostasis, bone metabolism, reproduction, and sickness behavior. Several stimuli can modulate the prostaglandin production at three different enzymatic levels (Figure 4).

The first level of regulation is the cytosolic release of arachidonic acid from the sn2 position of the membrane phospholipids. This step is enzymatically catalyzed by phospholipase $\mathrm{A}_{2}\left(\mathrm{PLA}_{2}\right)$

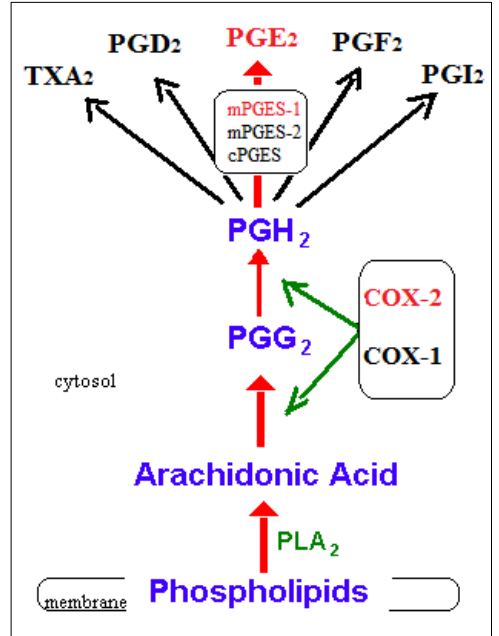

Figure 4. The Prostaglandin Cascade. In red inflammation-induced enzymes, COX-2 and mPGES-1 a heterogeneous enzyme superfamily that may also be associated with other enzymatic activities unrelated to the eicosanoids metabolism (Six and Dennis, 2000). The PLA2S can roughly be classified into cytosolic and secreted forms, with tissue specificities that await characterization. The cytosolic $\mathrm{PLA}_{2} \mathrm{~S}$ are intracellular membrane associated enzymes and have been shown to have a high arachidonate-substrate preference and therefore to be the dominant but not exclusive PLA2 regulating the eicosanoid metabolism (Farooqui et al., 1997). In a rat model of acute inflammation, both secretory PLA2-IIA and cytosolic PLA2- $\alpha$ were upregulated by LPS in the brain as well as in the peripheral organs, connecting them to the fever response and immune-to-brain signaling (Ivanov et al., 2002).

The second level of regulation is a prostaglandin specific step. Arachidonate, a substrate for all eicosanoids, once mobilized from the membrane is committed towards prostaglandin production by cyclooxygenases (also known as prostaglandin endoperoxide $\mathrm{H}$ synthases, PTGS). The first enzyme to be identified was cyclooxygenase 1 (COX-1 or PTGS-1) (Hamberg et al., 1974), followed in 1991 by the identification and cloning of cyclooxygenase 2 (COX-2 or PTGS-2) (Kujubu et al., 1991; Xie et al., 1991). Although catalyzing the same steps, converting arachidonic acid to PGG2 and finally to $\mathrm{PGH}_{2}$, the COX enzymes are distinct in several aspects. They are encoded by genes on different chromosomes (in mouse on chromosome 2 and 1, respectively; gene ID for Ptgs1: 
19224 and for Ptgs2: 19225), and share only 60-65\% amino acid sequence identity (Smith et al., 2011). They also show different patterns of expression. COX-1 is expressed constitutively in all tissues but by fewer cell types (e.g. macrophages, fibroblasts), estimated to be limited to approximately $10 \%$ of all mammalian cells, while COX-2 is transiently expressed, probably in all cells during replication/differentiation (Smith et al., 2011) and also during inflammation/cellular stress (Dubois et al., 1998). Of the two enzymes, inducible COX-2 was demonstrated to be necessary for the sickness syndrome ( $\mathrm{Li}$ et al., 1999; Lugarini et al., 2002). Brain COX-2 was found to be constitutively expressed in neurons (Breder et al., 1995; Yamagata et al., 1993) and reported to be induced by immune stimuli in vascular cells (Cao et al., 1995), and PVCs (Breder and Saper, 1996) but also in neurons by e.g. peripheral local inflammation, mechanical pain, seizures or brain tissue injury (An et al., 2014; Samad et al., 2001; Serrano et al., 2011; Vardeh et al., 2009; Yamagata et al., 1993). While neuronal COX2 is seen in neuronal insults or neuronal progenitor cells, proposed to be participating in cellular survival, development and proliferation, vascular COX-2 is central for the immune-to-brain signaling.

The third level of regulation is specific for each terminal prostaglandin. From the common precursor $\mathrm{PGH}_{2}$, prostaglandin products are formed through specific synthases such as hematopoietic and lipocalin-type PGD2 synthases (H-PGDS, L-PGDS), PGE2 synthases (to be presented separately), PGF2 synthase (PGFS), prostacyclin synthase (PGIS) and thromboxane A synthase 1 (TXAS).

Prostaglandins exert their functions through specific membrane G-protein coupled receptors (GPCRs) with seven transmembrane domains, i.e. heptahelical or serpentine receptors: DP1, EP1-4, FP, IP and TP, and in some cases even nuclear peroxisome proliferator activated receptors (PPARs). In addition, a second $\mathrm{PGD}_{2}$ receptor was identified which is not a GPCR but a chemoattractant receptor expressed on some leucocytes (Abe et al., 1999; Hirai et al., 2001).

\section{$\mathrm{PGE}_{2}$ biosynthesis}

Three PGE2 specific enzymes have been identified and characterized, two microsomal (membrane-bound) and one cytosolic enzyme. Microsomal prostaglandin E synthase-1 (mPGES-1) is an inducible enzyme (Ek et al., 2001; Jakobsson et al., 1999), with low constitutive levels in most tissues (Jakobsson et al., 1999) and is often co-expressed and functionally coupled with COX-2 (Murakami et al., 2000; Samuelsson et al., 2007; Thoren and Jakobsson, 2000). Being inducible enzymes, the COX-2 and mPGES-1 genes have complex promoter regions with binding motifs for several transcription factors like NF-kB (Crofford et 
al., 1997; Diaz-Munoz et al., 2010) and early growth response-1 (Egr-1) (Diaz-Munoz et al., 2010). Cytosolic prostaglandin E synthase, the second enzyme to be discovered, is constitutively expressed and functionally coupled with cPLA2 and COX-1 (Tanioka et al., 2000). The third enzyme is microsomal prostaglandin E synthase-2 (mPGES-2), also a constitutively expressed enzyme that was found to couple unselectively to both COX-1 and COX-2 (Murakami et al., 2003).

\section{$\mathrm{PGE}_{2}$ degradation}

Prostaglandins are short-lived lipid mediators, with an estimated half-life in blood plasma of 30 seconds to a few minutes (Samuelsson et al., 1975). The 15-hydroxy-prostaglandin dehydrogenase (15-PGDH or PGDH type I) and carbonyl reductase-1 (CR1 or PGDH type II) are key enzymes to inactivate prostaglandins (Ensor and Tai, 1995) as they mediate the first catabolic step, the oxidation of the 15(S)-hydroxyl group with subsequent high reduction of the prostaglandin activity (Anggard, 1966). 15-PGDH is a prostaglandin specific enzyme while CR1 has a low prostaglandin turn-down kinetics and a larger substrate profile, extending outside the eicosanoid family (Tai et al., 2002). 15-PGDH is an ubiquitous enzyme, but with its highest activity levels measured in the lungs (Piper et al., 1970). For the PGE2 metabolism, there are some reports showing a reciprocal regulation between COX-2 and 15-PGDH in inflammation with increased $\mathrm{PGE}_{2}$ production due to a coordinated up-regulation of COX-2 and down-regulation of 15-PGDH (Hahn et al., 1998; Ivanov et al., 2003; Tai et al., 2006).

\section{PGE2 transporters}

Prostaglandins are known to have a low membrane permeability capacity. Newly synthesized prostaglandins, protonated in the acidic cellular environment, are released by passive diffusion to become anionic at the higher extracellular $\mathrm{pH}$ levels thus losing their ability to readily cross membranes (reviewed in Schuster, 1998 and Schuster, 2002). These findings, originating during the 1960s and early 1970s, led to the search for prostaglandin transporters that would allow cellular influx of PGs and enzymatic degradation by PGDHs. In the CNS, the necessity of such transporters was inferred to be even greater than in other organs and tissues, as the brain was shown to have a low capacity to metabolize prostaglandins (Nakano et al., 1972), and also to have a high sensitivity to icv-injected PGE2 affecting body temperature (Feldberg and Saxena, 1971b), release of neurotransmitters (Bergström et al., 1973) and, at high doses, causing sedation and catatonia among other behavioral changes (Horton, 1964). Thus it was hypothesized that the CNS prostaglandin clearance was mainly achieved by barriertransporters that can act against an increased blood-brain prostaglandin gradient (active or 
facilitated transport) to protect the brain against the deleterious effects of high PG levels during conditions like infections or pregnancies (Bito et al., 1976). Influx/efflux prostaglandin transporters have been characterized in an ever growing number. The transporters were shown to allow prostaglandin outflow from the brain tissue by exerting their actions at the polarized CNS-blood barrier. It was also demonstrated that this process is slowed at the transporter level by $\beta$-lactam antibiotics like cefmetazole and cefazolin or during inflammation (Akanuma et al., 2010; Akanuma et al., 2011; Tachikawa et al., 2012). Prostaglandin influx transporters are found in both the solute carrier organic anion (Slco) transporter family and the cation (Slc) transporter family. Slco2a1, the very first one to be identified and thus also known as prostaglandin transporter (Slco2a1/PGT) (Kanai et al., 1995) and Slco2b1 (or multispecific organic anion transporter, moat1) (Nishio et al., 2000) are known to be widely expressed in almost every tissue, while Sclo3a1, also an ubiquitous transporter (or subtype D organic anion transporter OATP-D) (Adachi et al., 2003), Slco1a2 (Oatp3) and Slco1b2 (Oatp4) (Cattori et al., 2001), are transporters with very broad substrate specificity (Huber et al., 2007). Cation influx transporters shown so far to have prostaglandin affinity are Slc22a8 (Oat3) (Kobayashi et al., 2004) and Slc22a22, (Shiraya et al., 2010), with Slc22a22 mostly expressed in the kidneys. The best characterized efflux transporter is a membrane transport pump, Multi drug resistance-associated protein 4 or ATP-binding cassette transporter 4 (Mrp4/Abcc4) (Akanuma et al., 2010; Reid et al., 2003), but still more transporters might be expected to exist.

Another transportation modality, through nanovesicles also called exosomes, was recently shown functional for eicosanoids and their synthesizing enzymes. Exosomes are involved in cell-cell communication and transportation of several different RNAs and lipid molecules. For prostaglandins they were shown to allow transcellular prostaglandin synthesis through exosomes originating from mast cells (Record et al., 2014). The importance of the exosomes, believed to originate from all living cells, has not yet been tested in immune-to-brain signaling.

\section{PGE2 receptors}

Among prostanoids, PGE2 has the widest receptor profile with four subtypes EP1, EP2, EP3 and EP4 and several EP3 splicing isoforms at the C-terminal tail, allowing binding to different G-proteins. The number of EP3 splice isoforms is species specific, with 3 identified in mouse (EP3 $\alpha$, EP3 $\beta$ and EP3 $\gamma$ ) (Irie et al., 1993; Sugimoto et al., 1993), 4 in rat (Neuschaferrube et al., 1994; Oldfield et al., 2001; Takeuchi et al., 1993) and 9 isoforms (out of which 8 are functional) in humans (Kotani et al., 1997). The EP receptors bind $\mathrm{PGE}_{2}$ with varying affinities. In Chinese hamster ovary cells expressing stable levels of prostanoid receptors (Kiriyama et al., 1997) or in HEK cells (human embryonic kidney cells) expressing recombinant prostanoid receptors (Abramovitz et al., 2000) the highest affinity was shown by EP3 followed by EP4 
and then by low affinity receptors EP2 > EP1. In addition to its high affinity for PGE2, EP3 showed also a broad ligand binding profile not only among EP ligands but also for other prostanoids as e.g. the thromboxane analog $\mathrm{STA}_{2}$ or the prostacyclin analog iloprost (Kiriyama et al., 1997).

The versatile actions of $\mathrm{PGE}_{2}$, widely produced in the body, are controlled by the specific cellular EP profiles with their dynamic changes through receptor up-regulation (for EP2, EP4) and/or desensitization (for EP4, EP3), transactivation or cross-desensitization, and finally by the different signal transducing properties of each EP receptor (Sugimoto and Narumiya, 2007; Woodward et al., 2011). Thus, EP1 is a "contractile” receptor coupled to Gq that by its activation increases intracellular $\mathrm{Ca}^{2+}$ (Coleman and Kennedy, 1985; Coleman et al., 1985; Watabe et al., 1993). EP2 and EP4 are "relaxant” receptors coupled to stimulatory G proteins (Gs) mediating increases in intracellular cAMP (An et al., 1993; Coleman et al., 1994; Honda et al., 1993; Narumiya and FitzGerald, 2001). Reports from 2000s show that they were also able to mediate transcriptional activation through e. g. phosphokinase A-dependent pathway for EP2 or phosphatidylinositol 3-kinase-dependent pathway and other pathways for EP4 that in the latter case was shown to bind to a Gi protein (Fujino and Regan, 2006; Fujino et al., 2005; Fujino et al., 2002) (reviewed in Yokoyama et al., 2013). EP3, the only constitutive "inhibitory" receptor in the prostanoid receptor family (Narumiya and FitzGerald, 2001), is the most abundant $\mathrm{PGE}_{2}$ receptor subtype in the brain (Sugimoto and Narumiya, 2007). Its isoforms are constitutively coupled to inhibitory G-protein (Gi) decreasing cAMP but they can also activate other second messenger systems like inositol triphosphate with subsequent increase of intracellular calcium (Namba et al., 1993; Negishi et al., 1989), Rho to mediate cytoskeleton formation (Hasegawa et al., 1997), or, as shown for EP3 $\gamma$, by dual coupling to both Gi and Gs to modulate cAMP levels in an agonist-dependent manner (Irie et al., 1993; Negishi et al., 1996).

In the brain, EPs were mostly found to be associated with neuronal and glial cells (Batshake et al., 1995; Ek et al., 2000; Nakamura et al., 2000; Oka et al., 2000; Sugimoto et al., 1993; Zhang and Rivest, 1999). However, EP2 and EP4 were but recently reported to be expressed in the endothelium, and to be induced after stroke ( $\mathrm{Li}$ et al., 2008). Interestingly, the endothelial EP4 receptor was also reported together with the EP3 receptor to have perinuclear localization (Bhattacharya et al., 1999). In the latter case, the perinuclear EP3 receptors seemed to have an atypical downstream signaling that by PGE2 binding at the nuclear membrane could induce the expression of endothelial nitric oxide synthase (eNOS) (Gobeil et al., 2002). 


\section{Pathways for cytokine-to-brain signaling}

Several paradigms for immune-to-brain signaling have been tested and the number of substances suggested to participate in the process has increased tremendously. To the proinflammatory cytokines and prostaglandins have been added other cytokines (e.g. interferons) and eicosanoids, complement factors (e.g. C5a), chemokines (IL-8, CCL5, CXCL10, MIP-1), adhesion molecules, intracellular signaling molecules and many more (Rivest, 2009). Nonetheless, for the purpose of present thesis, only general issues will be addressed regarding the cytokine-to-brain signaling pathways, followed by a detailed characterization of PGE2 at the BBB in immune-to-brain signaling, particularly in the fever response.

The cytokine-to-brain signaling pathways can be divided into neuronal and humoral pathways. Depending on the extension of the inflammatory process these pathways may supplement each other. Thus with the knowledge we have today it can be hypothesized that tissue-released cytokines are primarily sensed by the afferent neurons while circulating cytokines activate the CNS through barrier-specific, humoral pathways (Quan, 2014). Evidence for the importance of both routes could be shown concurrently already during the dawn of this field (reviewed in Elmquist et al., 1997b; Hopkins and Rothwell, 1995; Rivest et al., 2000; Rothwell and Hopkins, 1995; Watkins et al., 1995b). However, the first assumptions were biased towards the neuronal autonomic pathways due to the classical view of the $\mathrm{BBB}$ as a strict barrier and further strengthened by the diffused distribution of BBB in the brain parenchyma, not being restricted to the immune responsive regions within the CNS (Quan, 2008; Watkins et al., 1995b). More recently, this view has been revised since BBB activation has been demonstrated by several convergent findings presented below.

\section{Afferent neuronal pathways}

The afferent neurons are the major input pathway for information from the peripheral tissues to the CNS. Acute phase responses could be elicited by stimulating both afferent fibers bundled with autonomic nerves that innervate the internal organs, and somatic afferents innervating the skin and the locomotor system.

The importance of the vagus nerve, conveying the autonomic afferents from the majority of the internal organs, emerged during the characterization of the brain immune responsive regions. The nucleus of the solitary tract (NTS), the central terminal nucleus of the vagal afferents, was activated showing cFOS labeling both after LPS (Wan et al., 1993) and iv IL-1 $\beta$ (Ericsson et al., 1994). These results led to the first vagotomy studies showing decreased cFOS labeling in NTS (Wan et al., 1994) as well as physiological effects like decreased hyperalgesia 
(Watkins et al., 1994) and fever responses (Watkins et al., 1995a) to ip IL-1 $\beta$ or LPS, hence confirming the vagal afferents as a major pathway for immune-to-brain signaling. Several other studies on vagotomized rats followed, dominating the field at the turn of the century (reviewed by Romanovsky, 2004). However, with our present knowledge on the importance of the humoral pathways, the conclusions of these studies have been given reduced importance. Nevertheless the contribution of the autonomic afferents cannot be dismissed completely as some critical findings have not been refuted, one example being immune activation of the NTS and of the vagal afferents (Ek et al., 1998) and the presence of TLR4, IL-1R1 and PGE2 receptors in the vagal nodose ganglion (Ek et al., 1998; Hosoi et al., 2005) or on the glomus cell of the vagal paraganglia (Goehler et al., 1997). The importance of the vagal signaling was furthermore verified by intraperitoneal (ip) administration of low doses of IL-1 $\beta$, reducing the risk for cytokine spill-over in the circulation, (Hansen et al., 2001; Konsman et al., 2000) and in a model of gut bacterial infection, with absence of circulating cytokines (Goehler et al., 2005).

The somatic afferents, particularly unmyelinated C-fibers, were shown to mediate the induction of acute phase responses like fever and hypermetabolism in a model of localized inflammation induced by subcutaneous turpentine (Cooper and Rothwell, 1991). While largely neglected at that time this study gained more attention when the antipyretic effect of local anesthetics blocking C-fiber-signaling was verified by Roth’s group (Ross et al., 2000; Roth and De Souza, 2001). Several models for local inflammation have been used, including subcutaneous turpentine (Cooper and Rothwell, 1991; Fantuzzi et al., 1997; Horai et al., 1998; Kozak et al., 1998; Lacroix and Rivest, 1998; Laflamme and Rivest, 1999; Leon et al., 1996), carrageenaninduced paw edema (Guay et al., 2004; Ibuki et al., 2003; Oka et al., 2007; Posadas et al., 2004; Prajapati et al., 2014), or immune stimuli administrated in artificial subcutaneous chambers (Cartmell et al., 2000; Miller et al., 1997; Rummel et al., 2005; Rummel et al., 2011; Zhang et al., 2008). However, most studies used local inflammation-models primarily to demonstrate an endotoxin-free cytokine-induced sickness syndrome (Horai et al., 1998; Kozak et al., 1998; Leon et al., 1996; Miller et al., 1997; Rivest et al., 2000) and not to investigate the role played by the afferent neurons. Thus, a humoral component was present in these models for local inflammation with measurable circulating cytokines (Horai et al., 1998; Kozak et al., 1998; Miller et al., 1997; Oka et al., 2007; Rummel et al., 2011) and brain expression of IkBa (Laflamme and Rivest, 1999), COX-2 (Horai et al., 1998; Ibuki et al., 2003; Lacroix and Rivest, 1998; Oka et al., 2007), and PGE2 (Guay et al., 2004; Ibuki et al., 2003; Oka et al., 2007). Consequently, to address the role of the afferent neurons in immune-to-brain signaling (Cooper and Rothwell, 1991; Ross et al., 2000), the study designs ought to limit the cytokine released into the bloodstream and better discriminate between local (tissue) or central (brain) cytokine and/or prostaglandin action sites. Accordingly, using LPS air-pouch as a model-system, it was shown that local IL-1 $\beta$ at low levels was critical for fever induction (Cartmell et al., 2000; 
Miller et al., 1997), although the response was also shown to be dependent on circulating IL-6 (Cartmell et al., 2000). Better models have been developed of so-called restricted local inflammation that do not induce brain COX-2 and have low to undetectable circulating cytokines. In these studies the fever response could be attenuated by very low doses of locally administrated diclofenac (Rummel et al., 2005) and could be shown to be dependent on the presence of TLR4, IL-1R1, IL-6 and COX-2 (Zhang et al., 2008).

The somatic and autonomic neuronal afferents, being able to gather information from any affected tissue, are certainly appealing signaling pathways. However, few older studies investigated the role of the afferent neurons in immune-to-brain signaling in animal models lacking a humoral component upon peripheral immune activation, and newer studies even dismiss the vagal contribution (Ootsuka et al., 2008) or its responsiveness to the proinflammatory cytokines (O'Connor et al., 2012). Still, in an endothelial-specific IL-1R1 KO mouse model impairing the immune signal transmission at the BBB, the discrepancy seen between iv and ip IL-1 $\beta$ treatments (no fever if iv, fever if ip) can best be explained by activation of the afferent somatic and/or autonomic neurons (Ching et al., 2007). Through their fast impulse signaling to the CNS the afferent neurons were also proposed to be responsible for the early phase of the sickness syndrome (Blatteis, 2006; Dantzer et al., 2008; Konsman et al., 2002; Quan, 2008; Romanovsky, 2004). Nevertheless, as NSAIDs are effective also in local inflammation, the neural pathway is still prostaglandin-dependent and thus dependent on de novo cytokine and prostaglandin enzyme production, i.e. time-consuming processes. Furthermore, little is known today about the central neuronal pathways activated by the somatic afferents. An immunological homunculus was proposed (Oke and Tracey, 2008) and recently partly demonstrated (Belevych et al., 2010) in an unique study, at least to the time of publication of this thesis. Hence, some topographical representation could be seen in the paraventricular nucleus (PVN) of the hypothalamus in the casein model for localized peripheral inflammation but not in subcutaneous or intramuscular LPS models that supposedly give rise to humoral responses (Belevych et al., 2010).

While peripheral mediators might signal to the brain through afferent neurons, the neuronal ascending pathways, which in the periphery translate the cytokine/prostaglandin signal into neuronal impulses within CNS, could still not account for the direct effect of the cytokines and prostaglandins injected icv or into the brain parenchyma, as shown already during the $1970^{\text {s. }}$. This discrepancy made the humoral signaling pathway a critical subject for research very early in the development of this field. 


\section{Humoral pathways}

Circulating cytokines engage the brain at the blood-brain interference regions: the BBB, the blood-cerebrospinal fluid barrier (BCSFB) and the arachnoid barrier. The latter two are believed to have a low impact on the central neuronal circuits in comparison with the large microvascular bed of the BBB. The calculated, total interface area of the BBB is $12-18 \mathrm{~m}^{2}$ for an average human adult brain, with neurons being rarely more than 8-20 $\mu \mathrm{m}$ away from the BBB (Abbott et al., 2010). The main function of the BBB is to maintain a stable ion and protein milieu in the brain parenchyma. This is achieved by a high impenetrability of the endothelial lining within the BBB, with tight junctions cementing the cells, and lack of intracellular fenestrations that, combined with low endocytic levels, limit both the paracellular and transcellular molecular and cellular trafficking. Peripheral episodic ion and/or protein fluctuations given by food ingestion are thus prevented from disturbing the neuronal transmission. For influx of nutrients and elimination of potentially harmful compounds, compensatory mechanisms act in form of specific transporters like solute carrier transporters, ATP-binding cassette transporters, and receptor-mediated transcytosis (Abbott et al., 2006).

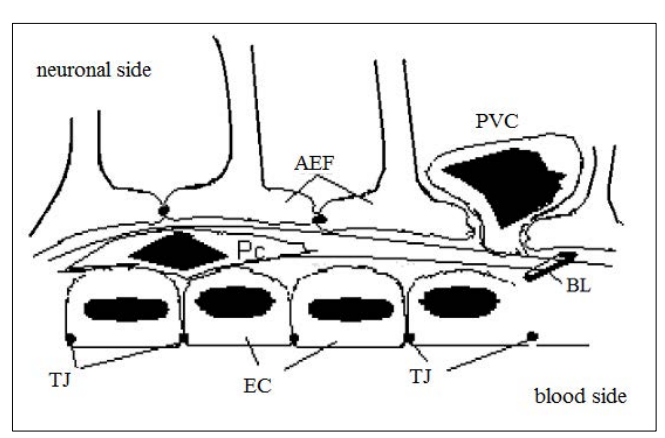

Figure 5. Structure of the Blood-Brain Barrier.
Apart from endothelial cells (ECs) with their tight junctions (TJ) (Figure 5), other BBB cellular constituents are pericytes (Pc) scattered along the ECs on the basal lamina (BL), astrocytic end-feet (AEF) bound by TJs or gap-junctions forming a second barrier (glia limitans), and perivascular cells (PVC) which are tissue macrophages at the vessel-parenchyma interface (the perivascular space).

The BBB and surrounding neuronal cells are also named the neurovascular unit (NVU) (Cohen et al., 1996). The BBB within the NVU adjusts to signals from both the abluminal (glial and neuronal) and luminal (blood) sides, and it plays a critical role in bidirectional humoral-signal transduction, which makes the BBB a dynamic barrier (Banks, 2009; Muldoon et al., 2013). Hence, while the $\mathrm{BBB}$ is mediating the immune signals in systemic inflammation, its characteristics are also changed by inflammation so that it becomes a more leaky barrier with decreased integrity of tight junctions (Hawkins and Davis, 2005; Huber et al., 2001) and increased endocytic processes (Banks and Erickson, 2010; Kastin and Pan, 2003) .

The cytokine-to-brain signaling at the BBB has been described as taking place by four potential mechanisms: i) direct diffusion and/or signal transduction at circumventricular organs (CVOs), ii) active cytokine transport, iii) increased immune cell trafficking, and iv) direct binding at the 
cognate receptors on the $\mathrm{BBB}$ with release of de novo cytokines or other central mediators such as prostaglandins (Haroon et al., 2012; Quan, 2014; Rivest, 2010; Turrin and Rivest, 2004). These mechanisms are validated to be functional and they are not mutually exclusive, but their individual importance might be correlated to the type and strength of the immunological signal. Accordingly, low levels of immune signals (cytokines or DAMPs) might be more easily detected and amplified by perivascular macrophages at CVOs, while higher levels can activate the endothelial cells and might result in a general BBB activation.

The circumventricular organs (CVOs) are leaky capillary structures within the BBB, already discovered by Paul Ehrlich (1885) as they allowed some trypan blue staining of the neighboring neuronal tissue. They were later shown to display looser endothelial lining and astroglial apposition than the general brain parenchyma, which creates a large and easily accessible perivascular space for blood macromolecules. The name CVOs denotes their periventricular positioning (Hofer, 1958), hence being tri-partner-meeting structures for blood, neuronal/glial and cerebrospinal fluid (CSF) signals (Johnson and Gross, 1993). Presenting fenestrated endothelial cells they were even called "windows of the brain” (Gross and Weindl, 1987), not only for their structural openings in the otherwise strict BBB, allowing the brain to "glimpse" into the periphery, but also metaphorically as "windows of opportunity", opening up new research avenues to study the neuro-humoral interaction. Thus, CVOs were a given target in cytokine-to-brain signaling research and (among) the first humoral pathways to be investigated (Roth et al., 2004). Of particular interest became the sensory CVOs, organum vasculosum of lamina terminalis (OVLT), subfornical organ and area postrema, located near the hypothalamic and brain stem structures regulating neurovegetative functions (Johnson and Gross, 1993). OVLT, situated in the anterior hypothalamus within the preoptic region that is the central thermoregulatory region, has been studied in the fever paradigm (Blatteis, 1992), starting with lesion studies initiated by Blatteis (Blatteis et al., 1983). Area postrema, situated at the bottom of the fourth ventricle near the NTS, the autonomic afferent nucleus relaying onto the PVN (Ericsson et al., 1994), was mostly investigated for its contribution to the activation of the HPAaxis (Ericsson et al., 1997; Lee et al., 1998). Several lesion studies were performed on the CVOs but they failed to provide any conclusive data as both the nearby BBB integrity and adjacent neuronal tissues could be damaged (Roth et al., 2004). Still, these studies contributed to giving increased attention to the CVOs as possible immune signal gateways and thus to their subsequently thorough characterization in terms of immune receptiveness. Accordingly, CVOs present LPS and cytokine receptors as shown for CD14 (Lacroix et al., 1998), TLR4 (Laflamme and Rivest, 2001), IL-1R1 (Cao et al., 1996; Cunningham et al., 1992; Ericsson et al., 1995), TNFRs (Nadeau and Rivest, 1999a) and IL-6R (Vallieres and Rivest, 1997). Also, in response to various immune stimuli, local de novo cytokine production was demonstrated as shown by up-regulated mRNA transcripts for TNF (Breder et al., 1994; Nadeau and Rivest, 1999b), IL6 (Vallieres and Rivest, 1997) and IL-1 $\beta$ (Eriksson et al., 2000; Quan et al., 1998) with IL-1 $\beta$ 
being expressed in immune cells apposing neuronal terminals (Goehler et al., 2006). Additionally, both vascular and neuronal activation was shown, such as induced vascular STAT3 (Harre et al., 2002; Konsman et al., 2000) and neuronal cFOS labeling, respectively (Ericsson et al., 1994; Herkenham et al., 1998; Nadeau and Rivest, 1999a). The cytokineinduced neuronal activity was also shown to be mediated by local COX-2 induction (Konsman et al., 2000) and PGE2 release (Matsuda et al., 1992; Ota et al., 1997).

Cytokine transporters, characterized by Banks and collaborators, are cytokine-binding sites at the $\mathrm{BBB}$, often different from the specific cytokine receptors but in some cases, such as for TNFR1, even believed to be a product of the same receptor gene (Banks and Erickson, 2010). Specific cytokine transporters were found for several cytokines, including IL-1, TNF $\alpha$, IL-6 (reviewed in Banks, 2005) but their contribution to the immune-to-brain signaling is believed to be limited as they show an easily saturated capacity, with an inflammation-insensitive, low rate kinetics (Banks and Erickson, 2010).

Increased trafficking of peripherally primed immune cells has recently been shown to contribute to the brain parenchymal release of cytokines (Aguliar-Valles et al., 2014; D'Mello et al., 2009; Wohleb et al., 2013), although not during the initial phase of the sickness syndrome. As cellular trafficking requires that there be pre-activated microglial cells after strong systemic immune challenge (Aguliar-Valles et al., 2014; Qin et al., 2007; Quan et al., 1998), long lasting liver inflammation (D'Mello et al., 2009), or social stress such as repeated social defeat (Wohleb et al., 2013), this pathway is considered a maladaptive response of the brain to chronic inflammation that by reinforcing an initial neuroinflammatory process (microglial activation) might eventually lead to behavioral dysfunctions (Dantzer et al., 2008; Quan, 2014).

\section{The BBB as an interface for immune signal-transduction}

The importance of the BBB for immune-to-brain signaling was acknowledged as the PGE2 synthesizing enzymes COX-2 and mPGES-1 were shown to be induced in the BBB by varying peripheral and central immune stimuli (Cao et al., 1995; Cao et al., 1996; Cao et al., 1998; Ek et al., 2001; Engblom et al., 2002), corroborating previous studies which suggested that BBB was a source of PGE2 (Bishai et al., 1987; Devries et al., 1995; Van Dam et al., 1993). Subsequently it was also demonstrated that the BBB is a cytokine target, presenting receptors for IL-1 $\beta$ (Ek et al., 2001; Ericsson et al., 1995; Konsman et al., 2004), IL-6 (Vallieres and Rivest, 1997) and TNF $\alpha$ (Nadeau and Rivest, 1999a) as well as intracellular cytokine activation markers like IkB $\alpha$ (Laflamme and Rivest, 1999; Quan et al., 1997) and SOCS3 (Lebel et al., 2000). Hence, the BBB displays all the elements needed for prostaglandin release in response to cytokine induction (Figure 6) leaving no doubt about its importance. Still, due to its cellular complexity, discrepant findings and hypotheses have been presented regarding the cell type 


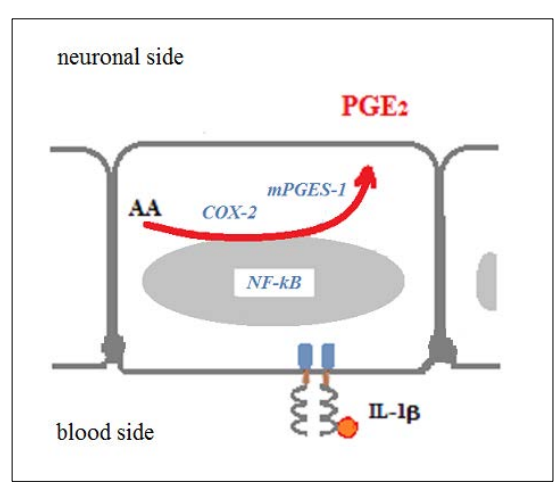

Figure 6. $\mathrm{PGE}_{2}$ production in cerebral endothelial cells. NF-kB activation by e.g. IL-1 $\beta$ up-regulates COX-2 and mPGES-1 allowing an increased production of $\mathrm{PGE}_{2}$. (AA arachidonic acid) critical for the inflammation-induced $\mathrm{PGE}_{2}$ production. Two main opposing views emerged, one supporting the endothelial cells (Cao et al., 1995; Ek et al., 2001; Matsumura et al., 1998; Yamagata et al., 2001) and the other favoring the perivascular macrophages (Breder and Saper, 1996; Elmquist et al., 1997a; Schiltz and Sawchenko, 2002). To address this question, we (paper I) (Eskilsson A 2014; Hamzic et al., 2013b; Matsuwaki et al., 2014; Wilhelms et al., 2014) and other groups (Chakravarty and Herkenham, 2005; Ching et al., 2007; Gosselin and Rivest, 2008; Ridder et al., 2011) have developed complex transgenic mice models that allowed in vivo analysis of one gene in a $\mathrm{BBB}$ cell population at a time (reviewed with paper I).

The humoral pathways described above thus provide several routes for the peripheral cytokines to pass the BBB and act centrally within the CNS. Accordingly, the proinflammatory cytokines can either be transported through or act on the cells of BBB and/or CVOs to induce local production of prostaglandins and/or cytokines, which eventually pass into the brain parenchyma. In the CNS, cytokine receptors were demonstrated to be present on the endothelial linings, glial cells and also neurons. IL-1R1, for example, was first reported to be expressed mostly on neurons and choroid plexus by affinity studies (Breder et al., 1988; Farrar et al., 1987; Takao et al., 1990 and several other studies). However, subsequent studies using in situ mRNA hybridization as well as immunohistological labeling with well characterized antibodies pointed out the brain microvessels as a major binding site for IL-1 $\beta$ (Ericsson et al., 1995; Konsman et al., 2004), but other studies reported parenchymal labeling in e.g. hypothalamus, hippocampus, anterior pituitary and cerebellum with inferred neuronal and/or glial representations (Cunningham et al., 1992; Wong and Licinio, 1994). Whether or not neurons express cytokine receptors is still a matter of debate (Dantzer et al., 2008; Quan, 2008). Several reports though, indicate that neuronal receptors contribute to normal neurophysiological processes like learning and memory at the hippocampal-amygdaloidal level, neuronal development and survival, or neuronal synchronization in specific cortical columns, reviewed in e.g. (Quan, 2014; Schultzberg et al., 2007). An in vitro model on microvessels showed that IL-1 $\beta$ binding to the endothelial lining induced release of IL- 6 and PGE2 (Van Dam et al., 1996), leading to the hypothesis that the neuronal IL-1R1 was not participating in mediating the sickness behavior. A contemporary study approached this issue in an in vivo model by looking at the downstream $\mathrm{IkB} \alpha$ mRNA up-regulation to trace the NF$\kappa \mathrm{B}$ induction in the brain after ip LPS. This study was able to reveal a spatio-temporal pattern 
of cytokine-induced activation, which is restricted to non-neuronal elements, starting at 30 minutes in the endothelial linings of the large vessels, choroid plexus and CVOs, followed at 1-2 h by small vessels (BBB) and astroglial cells throughout the entire brain, and then after 2 $\mathrm{h}$ by meningeal cells that finally reach ependymal cells after $12 \mathrm{~h}$ (Quan et al., 1997). Thus, for the sickness behavior the neuronal activation seen by means of cFOS labeling (Ericsson et al., 1994; Herkenham et al., 1998) is achieved indirectly by other molecules, like prostaglandin E (Ferri and Ferguson, 2005), a hypothesis that is also supported by the lack of double-labeling for cFOS and $\mathrm{IkB} \alpha$ in neurons (Ericsson et al., 1995).

In contrast to the cytokine receptors, EP receptors repeatedly have been reported on neurons and glia although vascular representation of EP receptors was also observed in a few studies as described in detail in the PGE2 receptor section. 
Prostaglandin $\mathrm{E}_{2}$ as a critical mediator in immune-to-brain signaling

\section{$\mathrm{PGE}_{2}$-sensitive CNS regions mediating sickness behavior}

EP receptors in the CNS are associated with both neuroprotective and toxic roles (Andreasson, 2010), and pathological and physiological processes, and are reported to play a role in sicknessinduced acute phase responses as well as in neural plasticity, learning and memory formation, and impulsive behavior (Furuyashiki and Narumiya, 2011). Accordingly, the four EPs have distinct distribution patterns (Batshake et al., 1995; Ek et al., 2000; Nakamura et al., 2000; Oka et al., 2000; Sugimoto et al., 1993; Zhang and Rivest, 1999). Hence they are not restricted to the typical CNS immune-responsive regions (Elmquist et al., 1996; Ericsson et al., 1994; Herkenham et al., 1998) but are also present in structures like the cerebral cortex, hippocampus, thalamus or cerebellar nuclei.

In immune-to-brain signaling, the representation of EP receptors in regions like the hypothalamic preoptic area (POA) and PVN, and in brain stem nuclei like NTS and the ventrolateral medulla (VLM) was in line with results from studies pointing out the same regions as highly responsive to locally administrated PGE2 (Ericsson et al., 1997; Oka et al., 1997; Scammell et al., 1996; Scammell et al., 1998). Hence, $\mathrm{PGE}_{2}$ is a central (brain) mediator of cytokine-induced sickness syndrome, although not the sole mediator. Inflammation-induced $\mathrm{PGE}_{2}$ was shown to be critical for the fever response (Engblom et al., 2003), but PGE2 was also shown to be one of several mediators contributing to the HPA-axis activation (Elander et al., 2009; Morimoto et al., 1989a), aversive behavioral changes (Fritz, 2012), hyperalgesia (Ferreira, 1972; Ferreira et al., 1973; Kamei et al., 2004; Trebino et al., 2003), and wakefulness (Huang et al., 2003).. However, it was found to have only a limited role in the anorectic response (Elander et al., 2007; Ruud et al., 2013a).

\section{Fever}

Fever is the prototypical PGE2 mediated response, demonstrated to be highly dependent on the inducible synthesizing enzymes COX-2 (Li et al., 1999) and mPGES-1 (Engblom et al., 2003) as well as on EP3 receptors (Ushikubi et al., 1998), particularly in the thermoregulatory region, the preoptic area (POA) (Lazarus et al., 2007) (Figure 7). Initially, other EP receptors were also considered febrigenic, such as EP1 and EP4. The idea of EP1 mediated fever was based on pharmacological tests using icv or intra-POA administered agonists and antagonists with low specificity for EP1 (Oka et al., 1997; Oka and Hori, 1994). The EP4 receptor was shown on neurons activated by immune challenges, an activation that also decreased in NSAIDs pretreated animals and contrasting to the non-activated EP3 neurons (Oka et al., 2000; Turrin 
and Rivest, 2004; Zhang and Rivest, 1999; Zhang and Rivest, 2000). Subsequent studies using highly selective agonists to each receptor (Oka et al., 2003b) as well as the introduction of transgenic mice lacking one of the EP1-3 receptors (Ushikubi et al., 1998) brought some clarity in this matter. Thus, EP3 was identified as the major fever mediating receptor (Ushikubi et al., 1998), whereas EP1 had but a minor contribution in the late phase of the fever response after intermediate doses of LPS (Oka et al., 2003a). EP4 was suggested to have a hypothermic effect (i.e. cryogenic receptor) upon agonist activation (Oka et al., 2003b).

\section{Stress-hormone release}

The finding that immune stimuli induced the activation of the hypothalamic-pituitary adrenal axis (HPA axis) with resulting stress hormone release was a major step in the development of the immune-to-brain signaling research field (Besedovsky et al., 1986; Sapolsky et al., 1987). Cortisol release from the adrenal glands is triggered by ACTH produced by the anterior adrenal gland, which in turn is released upon CRH stimulation from neurons of PVN. The prostaglandin contribution to the central activation of the HPA axis is complex. The initial phase seems to be dependent on COX-1 while the late phase is COX-2 driven (Elander et al., 2009; Elander et al., 2010; Garcia-Bueno et al., 2009). PGE2 has a direct central effect on the HPA-axis as seen from local administration of PGE2 in the brain parenchyma (Morimoto et al., 1989a). Its effect is mediated by EP1 and EP3, particularly in the central nucleus of amygdala (EP1) and POA (EP1 and EP3), but also in other regions projecting to PVN (Matsuoka et al., 2003; Saper et al., 2012; Ulrich-Lai and Herman, 2009). In contrast, EP2 and EP4 do not seem to be involved, since EP2 and EP4 KO mice display no disturbances in the activation of HPA axis (Matsuoka et al., 2003).

\section{Hyperalgesia}

Hyperalgesia represents an increased sensitivity to pain, due to sensitization of peripheral receptors or central neurons. Several inflammatory factors are involved in the pain modulation at the peripheral/tissue level and at central levels within the spinal cord, brain stem and forebrain. The PGE2 contribution was demonstrated both peripherally (Ferreira, 1972; Ferreira et al., 1973; Kamei et al., 2004; Trebino et al., 2003) and centrally at POA (Abe et al., 2001). The hypothesized central pathway for the regulation of pain sensitivity that involves prostaglandins originates in POA with EP3 expressing neurons (Hori et al., 2000; Oka et al., 2000; Ueno et al., 2001) that presumably project to the periaqueductal gray (Rizvi et al., 1996) to further reach medullary and spinal nociceptive-related structures. 


\section{Anorexia}

Sickness-induced anorexia has also been shown to be mediated by PGE2 (Pecchi et al., 2006), although not exclusively. While being reversed by COX-2 inhibitors (Johnson et al., 2002; Lugarini et al., 2002), the anorectic response driven by inflammation-induced PGE2 is dependent on the type of immune stimuli. Hence, IL-1 $\beta$ initiated a PGE2-dependent anorexia in contrast to LPS, which seems to be PGE 2 -independent (Elander et al., 2007; Pecchi et al., 2006). Among EPs, the strongest candidate is EP4 as demonstrated by the use of specific agonists and antagonists (Ohinata et al., 2006). EP4 is well represented in the hypothalamic and brain stem structures regulating feeding behavior (Williams and Elmquist, 2012; Zhang and Rivest, 1999) and an anorexic response was obtained when PGE2 was injected intraventricular (V3) or intra-PVN (Skibicka et al., 2011). However, contrasting results are seen in a tumor model for anorexia-cachexia where neither the neuronal EP4 nor global mPGES-1 deletions could rescue the tumor-induced appetite loss (Ruud et al., 2013a).

\section{Sleepiness}

Sleepiness, another typical component of the sickness behavior, was shown to be driven by $\mathrm{PGD}_{2}$ originating mostly from meninges and choroid plexus where its synthesizing enzyme LPGDS is expressed (Urade et al., 1993). PGD2 in the subarachnoid space can then act on its DP1 receptors enriched in meninges ventral to ventrolateral preoptic region (VLPO) and induce large and sustained increases in NREM (non-rapid eye movement) sleep (Matsumura et al., 1994). In contrast to PGD2, PGE2 has been suggested to be a wakening factor through its EP4 receptors in the tuberomammillary nucleus (TMN), activating histaminergic neurons (Huang et al., 2003; Onoe et al., 1992). 
Fever in acute systemic inflammation

\section{General considerations}

From ancient times to modern medicine, fever as a sign of disease has always fascinated physicians and scientists in search of cures. In immune-to-brain signaling, fever experiments are the prevailing models. The main inducers used are LPS, followed by different cytokines and other molecules, prostaglandins or DAMPs (Kluger, 1991).

\section{Central neuronal pathways for fever regulation}

Mammals maintain their body temperature within a strictly regulated range $\left(36.5\right.$ to $37.5^{\circ} \mathrm{C}$ in humans) through feedback mechanisms, collectively called thermoregulation. Thermoregulation encompasses neuronal circuits within the CNS that integrate central body temperature signals from brain warm-sensing neurons and peripheral temperature signals from cutaneous thermal receptors, and aims at restoring normal temperature through thermogenic (temperature increasing) or thermolytic (temperature decreasing) processes. Temperature changes are generated by cortical, conscious mechanisms generating adaptive behavioral actions (e.g. in rodents by changing environment), and by subcortical, diencephalic regions, i.e. unconscious mechanisms, that eventually employ the autonomic efferent pathways for temperature regulation (Morrison and Nakamura, 2011; Nakamura, 2011). In the latter case thermolysis is achieved in rodents by peripheral (cutaneous, tail) vasodilation, panting and saliva spreading, whereas thermogenesis is achieved by peripheral vasoconstriction (reducing heat loss through the skin) and non-shivering and shivering metabolic thermogenesis in brown adipose tissue (BAT) and skeletal muscle, respectively.

In fever, the thermoregulation process is switched by $\mathrm{PGE}_{2}$ towards an increased central body temperature by engaging thermogenic mechanisms. The anterior preoptic area (POA) of the hypothalamus was early identified to be highly sensitive to locally administrated PGE2 (Williams et al., 1977) and later on to express the febrigenic EP3 receptors (Ushikubi et al., 1998) in the median preoptic nucleus (MnPO) and the medial preoptic area (MPO) (Ek et al., 2000; Nakamura et al., 2000; Sugimoto et al., 1994) (paper III). Deletion of EP3 receptors specifically in MnPO has been shown to attenuate the febrile response (Lazarus et al., 2007). EP3 neurons within the POA are hypothesized to be GABAergic (Nakamura et al., 2002), which during normal conditions inhibit downstream neurons in the dorsomedial hypothalamic nucleus (DMH) (Nakamura et al., 2005) and raphe pallidus nucleus (RPa) (Nakamura et al., 2002). DMH neurons (glutamatergic) project as well to the RPa. Upon PGE2 binding to the EP3 receptor-bearing POA neurons, the GABAergic tonus in RPa is decreased allowing 
activation of the sympathetic preganglionic neurons in the spinal cord and subsequent peripheral vasoconstriction and increased metabolism in the BAT (Morrison and Nakamura, 2011; Saper and Lowell, 2014; Saper et al., 2012) (Figure 7).

Quite recently it was demonstrated that DMH also conveys the signaling pathways for stressinduced hyperthermia, a physiological (inflammation-free) elevation of body core temperature. $\mathrm{DMH}$ is thus a converging neural center for fever (POA) and psychological stress-induced hyperthermia (cortical) (Kataoka et al., 2014) and both the DMH and POA regulate mutually downstream RPa-sympathetic thermogenetic mechanism. Hyperthermia is thus not regulated from POA, but by cortical activation of the DMH (Kataoka et al., 2014) supporting the findings on hyperthermia being a PGE2 and EP3 independent process (Saha et al., 2005) (Figure 7).

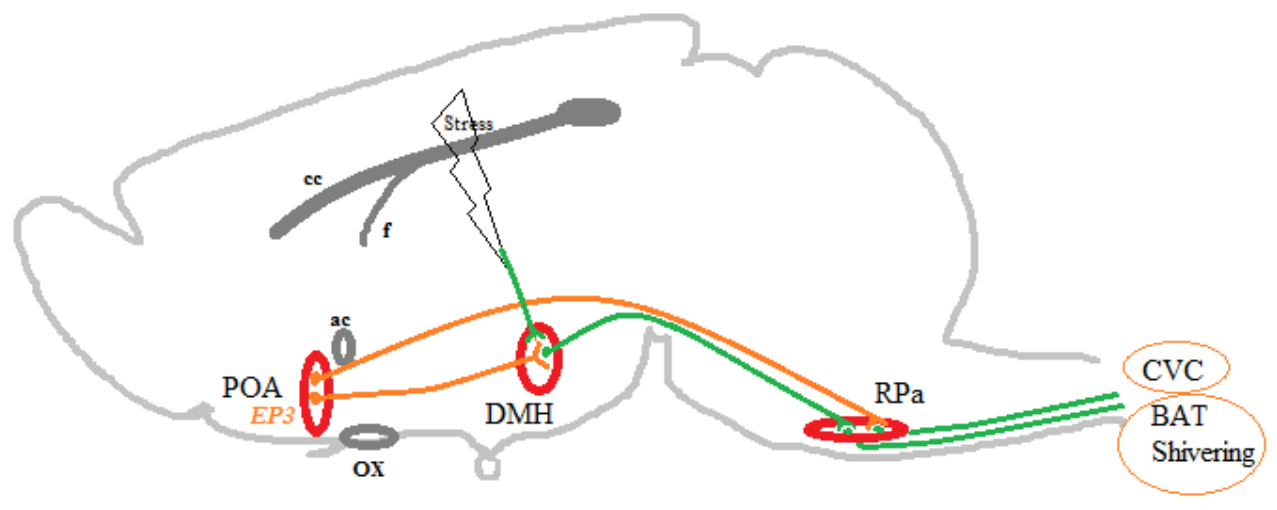

Figure 7. Central neuronal pathways of fever. Inflammation-induced PGE2 initiates the fever response by binding to EP3 expressing neurons of POA. The POA EP3 neurons are presumed to be GABAergic (orange colored), normally inhibiting the downstream pathway. PGE 2 binding to EP3 decreases the GABA-tonus on DMH and RPa These structure contain glutamatergic neurons (green colored), which activate the sympathetic preganglionic neurons in the spinal cord resulting in cutaneous vasoconstriction (CVC), brown adipose tissue (BAT) thermogenesis and the somatic motor neurons to elicit muscular shivering. Strong emotional-stress signals activate DMH neurons increasing body core temperature by BAT thermogenesis. ac $=$ anterior commissure, $\mathrm{cc}=$ corpus callosum, $\mathrm{f}=$ fornix, $\mathrm{ox}=$ optic chiasm. 


\section{Aims}

Inflammation-induced $\mathrm{PGE}_{2}$ has been shown to be a main mediator of the sickness syndrome, particularly of the fever response. The starting point for the research leading to this thesis was to further characterize the BBB contribution to the PGE2 production in acute peripheral inflammation and also to identify the PGE2 effect driving the fever response from the thermoregulation area.

Specific aims:

. To identify the cell type within the BBB critical for the fever response (paper I)

- To characterize the inflammatory profiles of the individual cell populations within the $\mathrm{BBB}$, in response to acute peripheral inflammation (paper II)

- To identify the EP3 receptor expressing region in the mouse preoptic area and to characterize the expression of the EP3 receptor isoforms in this region (paper III)

. To examine the gene regulatory effects of $\mathrm{PGE}_{2}$ in the preoptic area, during acute peripheral inflammation (paper IV) 


\title{
Methodology
}

\author{
Animal models
}

\section{Mice strains}

All experiments leading to the present thesis were conducted on mice, often transgenic mice (papers I, III and IV) but also chimeric mice (paper I) or wild-type mice (WT) (paper II), on a C57Bl/6 (papers I-III) or DBA1/lacJ background (paper IV).

Transgenic mice have allowed scientists to test in vivo the functions of many different proteins by manipulating the genes of the mice. The attractiveness of such an approach explains the driving force behind the development of more and more refined transgenic mice. The first largely used models were the global transgenic mice that have either a knocked-out (KO, i.e. deleted gene) or a knocked-in gene (overexpressed gene). The drawbacks of such a model are that the modified gene is expressed life-long, and in all cells (globally). In some cases this is incompatible with life, which renders this strategy useless for the genes in question. For other genes, the physiological implications of a global transgene risk appear to be too complex to comprehend. Newer developments have allowed the introduction of conditional transgenic mice. By using a versatile Cre-loxP recombination technology (Nagy, 2000), gene manipulations can be obtained in mice at a desired age, globally or in a tissue-restricted manner. In this thesis only global transgenic mice were used (Table 1); however several important studies in immune-to-brain signaling have used conditional transgenic mice (Eskilsson A 2014; Ridder et al., 2011; Wilhelms et al., 2014).

Table 1. Mice strains used in the present thesis

\begin{tabular}{llllll}
\hline Type & & Target Protein & Paper & Reference & Effect \\
\hline Ptges $^{-/-}$ & transgenic & mPGES-1 & I-IV & (Trebino et al., 2003) & Global \\
Ptgs2 $^{-/-}$ & transgenic & COX-2 & I & (Morham et al., 1995) & Global \\
EP3 $^{-/-}$ & transgenic & EP3 & III & (Fleming et al., 1998) & Global \\
GFP $^{+}$ & transgenic & GFP & I & (Okabe et al., 1997) & Global* \\
Ptges $^{+/} \leftrightarrow$ Ptges $^{-/-}$ & chimeric & mPGES-1 & I & (Turrin et al., 2007) & Hematopoietic \\
& & & & Paper I & vs. somatic \\
\hline
\end{tabular}

*Bone morrow cells from GFP+ (green fluorescent protein) WT or mPGES-1 KO mice were used for the generation of chimeric mice 
Chimeric mice were generated to differentiate between hematopoietic and non-hematopoietic production of PGE2. A chimeric organism is characterized by having genetically distinct cells either occurring spontaneously (extremely rare), or generated artificially during embryogenesis or induced by transplantations or blood transfusions at later time points.

In paper I chimeras were created by bone marrow transplantation. Bone marrow transplantations in laboratory mice are in general uncomplicated procedures as tissue-typing is not required in the very near-related mice. Also the risk of infections is limited in the pathogenfree environments the mice are kept in. However some complications have been reported related to the whole-body irradiation treatments, which can increase vascular permeability of the BBB the first days post-exposure (Diserbo et al., 2002). There may also be white-blood cells infiltration into the brain (Simard et al., 2006) and hippocampal dysfunction (Monje et al., 2002). Nonetheless, we and others have shown that the immune response both in the periphery and centrally (in the brain) are not compromised in chimeric mice, as measured by the release of cytokines like IL-1 $\beta$ (paper I) and IL-6 (Hamzic et al., 2013b) or by absence of white blood cell infiltration of the brain tissue (Turrin et al., 2007) (paper I).

The principles of creating mPGES-1 chimeric KO mice are described here, while the complete protocol for bone marrow transplantation in mice is given in paper I. Mice of both genotypes Ptges $^{+/+}$(WT) and Ptges ${ }^{-/-}$(KO) underwent a myeloablative whole-body $\gamma$-irradiation to deplete the hematopoietic cells in the recipient mice prior to transplantation with donor bone marrow. The degree of hematopoietic reconstitution was easily analyzed as bone marrow was harvested from $\mathrm{GFP}^{+}$(green fluorescent protein) mice of both mPGES-1 genotypes. At the time for LPS challenge, five months after transplantation, the hematopoietic reconstitution was around $90 \%$ in peripheral blood and brain, 67\% in liver, and 78\% in lung. There was little infiltration of $\mathrm{GFP}^{+}$cells in the brain parenchyma (Figure 1, A-C in paper I). Combining the two mPGES-1 genotypes between the recipient and donor mouse, four chimeric groups were generated, namely WT or KO bone marrow to WT mice (WT $\rightarrow$ WT and $\mathrm{KO} \rightarrow \mathrm{WT}$ ) and WT or KO bone marrow to $\mathrm{KO}$ mice $(\mathrm{KO} \rightarrow \mathrm{KO}$ and $\mathrm{WT} \rightarrow \mathrm{KO})$. At the $\mathrm{BBB}$ the chimeras may produce $\mathrm{PGE}_{2}$ either in perivascular macrophages $(\mathrm{WT} \rightarrow \mathrm{KO})$ or in the endothelium $(\mathrm{KO} \rightarrow \mathrm{WT})$. WT $\rightarrow \mathrm{WT}$ and $\mathrm{KO} \rightarrow \mathrm{KO}$ correspond genetically to the non-transplanted WT and $\mathrm{KO}$ littermates and were included as controls.

The same strategy has been used by others to investigate the contribution to the sickness syndrome of hematopoietic vs. non-hematopoietic expression of TLR4 (Chakravarty and Herkenham, 2005; Steiner et al., 2006a), MyD88 (Gosselin and Rivest, 2008; Ruud et al., 2013b), and IL-1R1 (Matsuwaki et al., 2014). 


\section{Induction stimuli for inflammation and stress hyperthermia}

The aim of the studies was to further characterize the role of PGE2 in acute systemic inflammation and thus the standard model for this thesis is intraperitoneal injection of LPS (papers I-IV) at a moderate dose of $120 \mu \mathrm{g} / \mathrm{kg}$ body weight. This model has been extensively used in our laboratory for the study of fever (Engblom et al., 2003; Hamzic et al., 2013b; Nilsberth et al., 2009a; Nilsberth et al., 2009b; Saha et al., 2005), HPA-activation (Elander et al., 2009; Elander et al., 2010), anorexia (Elander et al., 2007), and conditioned place aversion (Fritz, 2012). Other complementary models used in the present thesis were intravenous injections of either LPS or IL-1 $\beta$ (paper I) and cage exchange-induced stress hyperthermia (paper IV). The intravenous models were selected to test different stimuli-based hypothesis but also to allow investigation of the first phase of fever as the mice were implanted with catheters that allowed administration of the pyrogen without handling the animals, hence minimizing the initial injection-induced hyperthermia. The cage-exchange model was used to test the thermoregulatory capacity of mPGES-1 KO mice that do not mount a febrile response to LPS administration. The cage-exchange model induces a strong emotional stress as mice have an urge to mark and defend their territory. In the experiment, two adult male mice are removed from their littered home cages (marked cages) and placed in the cage of others (cage exchange). On detecting the smell from the other male mouse, in the home cage of the other mouse, the visiting mouse becomes agitated and starts exploring the new environment. Telemetric recordings indicate both a high locomotor activity and increased body core temperature during the first $2 \mathrm{~h}$ (Figure 2 in paper IV).

Telemetric recordings are done through intraperitoneally implanted transmitters, which permit long time measurements of both body core temperature and locomotor activity without disturbing the mice (papers I and IV).

Intraperitoneal injection of the LPS dose used in this research generates a typical tri-phasic fever that can be measured up to 7-8 h during the light diurnal period (Figure 8) (Romanovsky et al., 1998). The first phase of fever, up to 1-1.5 h after injection, coincides with the stressinduced hyperthermic peak. This temperature peak is followed by a slight hypothermic response that later evolves into the second phase of fever. In unstressed animals, for example animals injected through an indwelling iv catheter, the first fever response could be measured between 16 to 70 minutes after LPS injection (Romanovsky et al., 1998). This response is believed to be governed by mechanisms other than phase 2 and phase 3 fevers (Blatteis, 2006; Ivanov and Romanovsky, 2004). The second phase from 1.5 to $3 \mathrm{~h}$, peaking at approximately $2 \mathrm{~h}$, and the third phase are believed to depend on the same mechanisms but with the third phase being highly dependent on the LPS dose (Romanovsky, 2004). 


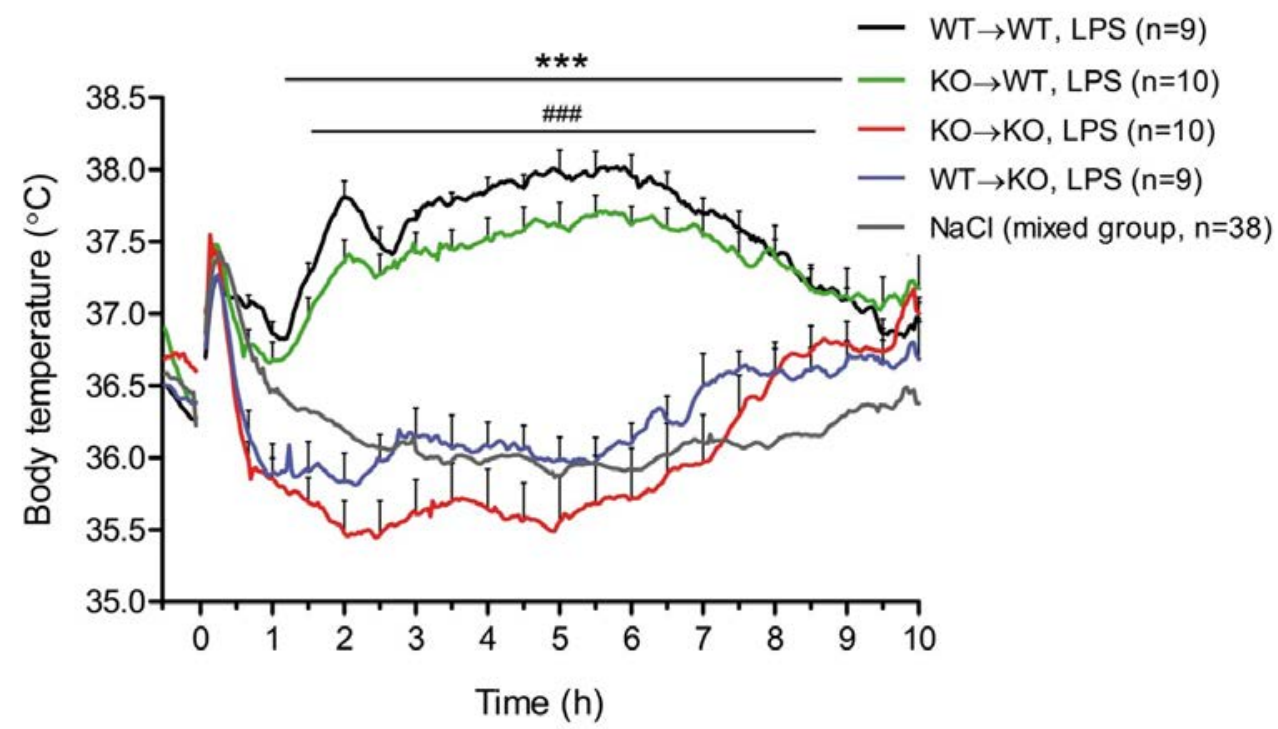

Figure 8. Fever curves after ip LPS or saline in chimeric mice. Saline treated mice are represented as an average for all transgenes.

Laser capture microdissection and enzymatic cell dissociation

Analysis of homogeneous cell populations or small regions from complex, solid tissues such as the brain is possible by using either laser microdissections methods or enzymatic tissue dissociation with subsequent magnetic cell isolation or fluorescent activated cell sorting (FACS) flow cytometry.

\section{Laser capture microdissection}

Two similar laser microdissection systems are commercially available. The one used in papers III and IV, Laser Capture Microdissection (LCM; Arcturus/Applied Biosystems) is based on a low energy laser that melts a plastic film above the desired region (capture method). The other method, Laser Microdissection (LMD; Leica Microsystems) uses a higher energy laser that causes lysis of the tissue around the desired region which then falls into the collecting vessel. There are advantages and disadvantages with each system. LCM is an easy and fast method for a manual tissue dissection (for each laser impulse one cell or a small region can be extracted), but it bears the risk of sample contamination. LMD on the other hand provides a contact and contamination-free technology but with a drawback of needing an automatized 
method that allows faster dissections as each target cell/region has to be encircled by the laser beam to detach from the section; this would be a terribly time-consuming and skill-demanding process with an operator-controlled laser.

Both systems can be used to dissect immunolabeled cells. Our initial aim for paper III was to label and analyze EP3-positive neurons. Lack of specificity of the commercially available EP3antibodies, tested on EP3 WT and KO mice, led us to approach another strategy and to investigate the general effect of PGE2 on the thermoregulation area by dissecting the whole anterior preoptic area of the hypothalamus (discussed with paper IV) instead of a specific $\mathrm{PGE}_{2}$ effect on the EP3 neurons.

\section{Enzymatic cell dissociation and magnetic isolation}

Tissue cell dissociation and magnetic isolation can also be used to separate homogenous cell groups, as shown in paper I for the $\mathrm{CD} 45^{+}$bone marrow cells. Magnetic isolation offers the advantage of simultaneous isolation of all specifically labeled cells from cell suspensions, like blood or cell suspensions generated after enzymatic cell dissociation of tissues. Magnetic isolation eliminates the need for microscopy and individual cell identification such as that needed by LCM, and is conveniently used for cell populations that can be characterized by one antigen, against which specific antibodies can be raised. There is a risk of antigen degradation by the enzymatic treatment, which should be considered whenever troubleshooting for lack of labeling by a specific antibody. The cell isolation depends on the intensity of the magnetic field, the size of the magnetic bead and the cellular abundance and availability of the antigen. Different strategies of negative and positive selections can be used to sort the cells. Future perspectives are to allow labeling for several consecutive positive selections, by enzymatically detaching the magnetic beads from the previous antibodies. However, for cells needing multiple positive labeling it is preferable to use FACS isolation, unless sterile conditions are desired. For the brain tissue this methodology cannot be applied for the branched and/or myelinated neurons, which are mechanically torn apart. On the other hand, enzymatic cell dissociation allows separation of the BBB cells, particularly endothelial cells and pericytes, which are otherwise technically difficult to dissect by LCM due to their near contact to each other and elongated morphology. Kits are provided by e.g. Miltenyi Biotec for easy and fast magnetic separation of endothelial cells, astroglia, neuronal progenitor cells or brain cancer cells. With an in house protocol developed by us, microglia (unpublished) and the BBB cells (papers I and II) were isolated by FACS flow cytometry. 


\section{Flow cytometry}

Flow cytometry offers many possibilities to analyze individual cells or particles in heterogeneous suspensions. Cellular characteristics of different types of cells and structures that can be labeled with fluorochromes are analyzed simultaneously and sorted accordingly into desired populations for further experiments. This versatility is given by the lasers and optical capacity of the instrument. The efficacy of such instruments is so high today that several 1000 cells/particles can be analyzed per second with up to 5 lasers, including measurement of 20 parameters per particle: 18 colors and 2 morphologic parameters (e.g. with BD LSRFortessa $\left.^{\mathrm{TM}} \mathrm{X}-20\right)$.

In the flow cytometer the stained cells are first lined-up into a single-cell stream by hydrodynamic focusing, allowing each cell to pass individually through several consecutive laser beams. Fluorochromes in the laser beam absorb light energy of a specific wavelength increasing their energy state in a process called excitation. The exited fluorochromes are unstable and emit light (emission) of longer wavelengths than the wavelength of the exciting laser. Light scatter (forward and side) and fluorochrome emission signals are gathered and analyzed in the collection optics and then individually converted from electrical impulses into digital data. Thus, each cell is eventually represented by two light scatter parameters (forward and side) and multiple color parameters, depending on the number of fluorochrome-labeled structures. Forward-scatter light (FSC) is proportional to the cell size and side-scatter light (SSC) to the intracellular complexity. Multiple staining, although appealing, increases the risk of spillover of the emission signals into several detectors, as the fluorochromes have rather broad emission spectra. To overcome this problem careful compensation programs are run, extracting for each fluorochrome used the percentage of the leaky signal from the wrong detectors.

In papers I and II, the cell sorters used were FACSAria III or II (BD), which, in addition to flow cytometry, can separate cells from the flow into single cell-droplets and deflect the desired cells/droplets from the stream into the collection devices.

In paper I white blood cells from chimeric mice were analyzed by flow cytometry for their GFP expression. Brain and liver tissues from LPS and saline treated WT animals were enzymatically dissociated and BBB cells and liver endothelial cells and macrophages were sorted and further analyzed by RT-qPCR for their mPGES-1 expression.

In paper II BBB cells from LPS and saline treated WT mice, were sorted into pericytes (CD45$\left.\mathrm{CD}^{-} 1^{-} \mathrm{CD} 140 \mathrm{~b}^{+}\right)$, endothelial cells $\left(\mathrm{CD} 45^{-} \mathrm{CD} 31^{+}\right)$, and perivascular macrophages $\left(\mathrm{CD} 45^{+} \mathrm{CD}^{206}{ }^{+}\right)$(Table 2, Cellular markers) and further analyzed by RT-qPCR on a 48-format TaqMan Low Density Arrays (48-TLDA). 


\section{Protein methods}

Proteins can be isolated, identified, quantified, and morphologically localized in tissues and cells with a tremendous variety of methods. In this thesis though few measurements were done at protein level as the LPS mouse model used (paper I-IV) has been extensively characterized in our laboratory for e.g. COX-2, lipocaline-2, cytokines and PGE2 expression, and cortisol release (Elander et al., 2009; Nilsberth et al., 2009a), and recently also for IL-1R1 (Matsuwaki et al., 2014) and mPGES-1 (Eskilsson et al., 2014).

The chimeric mice were characterized by in house immunohistochemistry methods for COX2 and cellular markers (Table 2), and by several commercially available immunoassays for PGE2 and IL-1 $\beta$ in plasma and CSF (methods presented in paper I).

Table 2. Cellular markers (papers I and II)

\begin{tabular}{llll}
\hline Name & Antigen & Cell type & Method \\
\hline CD45 & LCA & All hematopoietic cells & FACS \\
CD206 & MMR & Perivascular cells & FACS and immunohistochemistry \\
CD140b & PDGFR $\beta$ & Pericytes & FACS \\
CD31 & PECAM1 & Endothelial cells & FACS \\
vWF & vWF & Endothelial cells & Immunohistochemistry \\
Iba1 & Iba1 & Microglia & Immunohistochemistry \\
CD68 & Macrosialin & Lung macrophage & Immunohistochemistry \\
F4/80 & - & Pan-macrophage marker & FACS and immunohistochemistry \\
\hline
\end{tabular}

LCA: leukocyte common antigen; MMR: macrophage mannose receptor; PDGFR $\beta$ : platelet derived growth factor receptor, beta polypeptide; PECAM1: platelet endothelial cell adhesion molecule 1; vWF: von Willebrand Factor; Iba1: ionized calcium binding adapter molecule 1

\section{Messenger-RNA methods}

Molecular biology is another field that has experienced an extraordinary development in the past three decades. The advantages of detecting messenger-RNA molecules have turned the molecular biology in a good complementary methodology of characterizing proteins, allowing the detection of the cellular distribution of e.g. signaling molecules for which it has been difficult to develop good detection antibodies or that are expressed on cellular membranes or at long-distance from the cell body (as membrane receptors or neurotransmitters and synaptic proteins). Other advantages are given by the unlimited possibilities of developing different nucleotide sequences allowing the generation of any kind of probes for in situ hybridization (paper III), as well as assays for isolated RNA for further applications, here used with gene 
expression microarray (paper IV) and RT-qPCR (papers I-IV). The disadvantages coupled with an mRNA detection concern the low stability of the molecules and the relatively high abundance of degrading enzymes (RNases) that should be considered at any time. Another disadvantage is that the physiological impact of a detected transcript is uncertain, as the mRNA level is not directly proportional to the protein level due to post-translational regulating factors like RNA interference, which are gene/protein specific.

\section{In situ hybridization}

In situ hybridization was used in paper III for localization of the EP3 receptor in the anterior hypothalamus. The method employed is based on a radioisotope-labeled complementary RNA riboprobe (905 bp) for the EP3 mRNA that is hybridized on tissue slices ("in situ”). The probe is synthesized in plasmids in the presence of nucleotides labeled with an isotope (in paper III ${ }^{33} \mathrm{P}$ ). Tissue sections on slides are first fixed with paraformaldehyde and treated with proteinase $\mathrm{K}$ that by removing proteins increases tissue permeability for the probes (pre-hybridization). The probes are then hybridized at $58^{\circ} \mathrm{C}$ in a special hybridization solution that facilitates nucleotide binding. In the post-hybridization step, single-stranded RNAs are disintegrated by RNase treatment and unspecific probe-binding by rinses in a series of low salt buffers at high temperature $\left(72^{\circ} \mathrm{C}\right)$. Finally, the slides are prepared for autography. In situ hybridization was run both on WT mice showing a robust EP3 labeling in POA (Figure $1 \mathrm{~A}$ in paper III), and on EP3 KO mice that showed no signal in the corresponding area (Figure 1C in paper III). For regional localization, the sections adjacent to the in situ hybridized sections were stained with thionin (Figures $1 \mathrm{~B}$ and D in paper III).

\section{Gene expression microarray}

The technological progress and our increased knowledge of molecular biology have led researchers from the US and elsewhere around the world to the most ambitious project of our times, The Human Genome Project (1990-2003), aimed at mapping the whole human genome (Collins et al., 2003). Most of the mouse genome (one of the other species sequenced in the project) had already been mapped by the mid-1990s and at that time the first microarrays were already commercially available. This enabled the manufacturing of whole genome arrays which "catapulted many laboratories from studying the expression of one or two genes in a month to studying the expression of tens of thousands of genes in a single afternoon." (Collins et al., 2003; Nature, 2002)

In paper IV a microarray methodology was used to analyze the effect of PGE2 on the gene expression changes within the neuronal tissue of POA. The study was designed to analyze RNA 
samples from LCM dissected POAs (as in paper III) from both WT (n=5) and KO (n=5) genotypes, treated with LPS. The RNA samples were individually prepared and hybridized on the arrays.

For this study the oligonucleotide microarray GeneChip Mouse Genome 4302.0 Array was used, the array being the first whole transcriptome chip for the mouse developed by Affymetrix. In the workflow the isolated RNA was amplified, biotin-labeled, purified and fragmented in accordance with the instructions provided by the manufacturers of the kits (Affymetrix and Applied Biosystems; presented in paper IV). The resulting biotin-labeled complementary RNA (cRNA) was hybridized on the chip. The chip covers the whole mouse transcriptome, 39000 mouse transcripts, and has the advantage of having several probes (oligonucleotides) for one transcript (a probe-set per transcript), with a total of 45000 probe-sets for mouse and control transcripts on each chip. The oligonucleotides are 25-base long probes synthesized on the chip through photolithography during the chip manufacturing process. The probes are designed to bind with similar affinities to the cRNA fragments and to either match perfectly (perfect-match probes: PM) or to differ at one base (miss-match probes: MM), which can be used to estimate the tendency for cross-hybridization. Both PM and MM probes are distributed along the whole length of the transcript from the 5'-end to 3'-end allowing estimations of the mRNA integrity (3'/5' signal ratio should be less than 3). The chip is also provided with probes for chip intensity controls ("control spikes”) and external controls (transcripts of prokaryotic origin). The control spikes (bioB, bioC, bioD, cre) provide chip-specific quality control measurements. The external controls (dap, lys, phe, thr) are standardized poly-A RNAs that are added to the sample RNA to be treated together in the pre-hybridization process. In this way the controls become an effective tool for the normalization process within and between the arrays. After hybridization, the samples are stained on the chip, scanned and analyzed. The raw data of each probe are analyzed with the GenChip Operating Software (GCOS), normalized within the project, and saved in CEL files for further functional genomics data analysis. In paper IV GeneSpring (Agilent) or Ingenuity Pathway Analysis System (Sigma) were used.

\section{RT-qPCR,}

Gene expression changes were quantified with a two-step RT-qPCR method. For this purpose commercially available kits were used both for RNA extractions (Arcturus or Qiagen), cDNA synthesis (Applied Biosystems) and TaqMan RT-qPCR chemistry (Applied Biosystems). The kits were chosen on the basis of their recommended usage, in that several different RNeasy kits were used for the RNA purification depending on the type and amount of tissue used. A DNA elimination step was employed on all occasions. The purified RNA was reversely transcribed with High Capacity cDNA Reverse Transcription Kits (Applied Biosystems), a kit 
recommended for the pre-amplification step and TLDAs. Several check-points were used, such as mRNA integrity controls with 2100 Bioanalyser, Agilent RNA 6000 Pico, or Nano Assays (papers III and IV), and RNA quantitative measurements with NanoDrop spectrophotometer (papers III and IV). The RNA levels were expected to correlate with the amount of tissue used in the RNA extraction step, when comparing similar tissues. The RNA values were used to synthesize cDNA with similar concentrations, which in the RT-qPCR also resulted in similar Cq values for GAPDH, the control (housekeeping) gene used in the present studies. In papers I and II neither 2100 Bioanalyser nor NanoDrop could be used for the BBB cells due to their low numbers. As a quality control the GAPDH Cq values were expected to be similar when starting with cDNA loading volumes that were calculated based on the cell counts used in the RNA extraction step and aimed to yield same "cell loading counts” in the RT-qPCR reaction. Most of the assays (except those used in paper III, see below) used in RT-qPCR were inventoried TaqMan assays, and, whenever possible, assays were chosen that span exons to eliminate the risk of interference from genomic DNA. Linearity and efficiency were controlled for several genes and also for the pre-amplification step. Quantitative measurements were done by calculating $\Delta \Delta \mathrm{Cq}$, comparing the degree of gene expression variation for each gene against the reference gene and between treated and control animals.

In paper III PCR primers and RT-qPCR assays were designed in house, with the exception of the GAPDH assay. To test the specificity of our assays, specific transcripts were reversely transcribed, amplified and purified to prepare individual standard curves for each EP3 isoform and GAPDH. The assays were then tested individually against each standard curve. They showed high efficacy with correlation coefficient over 0.99 for each assay, and displayed no cross-reactivity. 


\section{Results and Discussions}

\section{Lipopolysaccharide-induced fever depends on prostaglandin E2 production specifically in brain endothelial cells}

In paper I the cellular origin of the inflammation-induced $\mathrm{PGE}_{2}$ at the $\mathrm{BBB}$ was analyzed in chimeric mice that lacked mPGES-1 either in non-hematopoietic cells, i.e. endothelial cells within $\mathrm{BBB}(\mathrm{KO} \rightarrow \mathrm{WT})$, or in hematopoietic cells, i.e. perivascular macrophages within BBB $(\mathrm{WT} \rightarrow \mathrm{KO})$. Non-irradiated/non-transplanted mice and $\mathrm{WT} \rightarrow \mathrm{WT}$ and $\mathrm{KO} \rightarrow \mathrm{KO}$ mice were used as controls. The febrile response to ip LPS was similar throughout to that displayed by the background genotype, irrespective of whether the mice were transplanted with KO or WT bone marrow (Figure 8 ). Thus, $\mathrm{WT} \rightarrow \mathrm{WT}$ and $\mathrm{KO} \rightarrow \mathrm{WT}$ mice had a fever curve characteristic for the WT genotype, demonstrating that the ablation of mPGES-1 in the hematopoietic cells $(\mathrm{KO} \rightarrow \mathrm{WT})$ is not critical for the pyrogenic response to peripheral immune challenge. Similarly, $\mathrm{KO} \rightarrow \mathrm{KO}$ and $\mathrm{WT} \rightarrow \mathrm{KO}$ mice showed a temperature response characteristic for the KO genotype, implying that mPGES-1 in the transplanted perivascular cells and hematopoietic cells was not rescuing the KO genotype either by local PGE2 production in the BBB or by peripheral release of PGE2. Similar patterns were seen also after iv LPS injections, a treatment that by minimizing the handling-induced stress allows analysis of the first phase of fever. The telemetric findings were largely consistent with the PGE2 levels in CSF, but not with the plasma levels of PGE2. Hence, hematopoietic mPGES-1 (WT $\rightarrow \mathrm{KO}$ ) could rescue the peripheral production of $\mathrm{PGE}_{2}$, but not the fever response. Immunohistochemical staining of the liver for COX-2 showed immune-induced labeling of immune cells like Kupffer cells, and this was also seen in mice in which these cells derived from the transplanted cells. In contrast, staining of lung and brain tissue showed immune-induced COX-2 labeling in endothelial cells. Apart from the standard LPS dose of $120 \mu \mathrm{g} / \mathrm{kg}$ ip, a low dose of LPS $(1 \mu \mathrm{g} / \mathrm{kg}$ iv as in Schiltz and Sawchenko, 2002) or a moderate dose of IL-1 $\beta(30 \mu \mathrm{g} / \mathrm{kg}$ iv as in Givalois et al., 1994) were also tested, since these stimuli have been reported to induce COX-2 expression preferentially in perivascular macrophages. However, these stimuli also resulted in COX-2 labeling exclusively in endothelial cells. A critical issue for determining in which cells PGE2 production takes place was the identification of mPGES-1 expressing cells in the mouse. At the time when this study was performed, no specific antibody for mouse mPGES-1 was available, and in situ hybridization did not yield any specific signal (unpublished). Therefore, we instead developed a method to dissociate and isolate endothelial cells and macrophages from the brain and the liver, and subsequently analyze their gene expression by RT-qPCR. The induction patterns in the $\mathrm{BBB}$ were distinct and opposite from those seen in the liver cells. While endothelial cells within the $\mathrm{BBB}$ expressed much higher levels of mPGES-1 transcripts than perivascular 
macrophages, and also showed a prominent upregulation after immune stimulation (9 times; $P$ $<0.05$ ), the PGE2 production in the liver took place in Kupffer cells, whereas liver endothelial cells had no detectable mPGES-1 transcripts.

\section{Discussion:}

The data shown in paper I demonstrate that PGE2 synthesis by non-hematopoietic cell is critical for the febrile response to LPS, whereas PGE2 synthesis in hematopoietic cells does not seem to be involved. These functional data, when taken together with our demonstration of mPGES-1 expression in brain endothelial cells but not in perivascular macrophages, identify the brain endothelial cells as the cells responsible for the PGE2 production that underlies the febrile response.

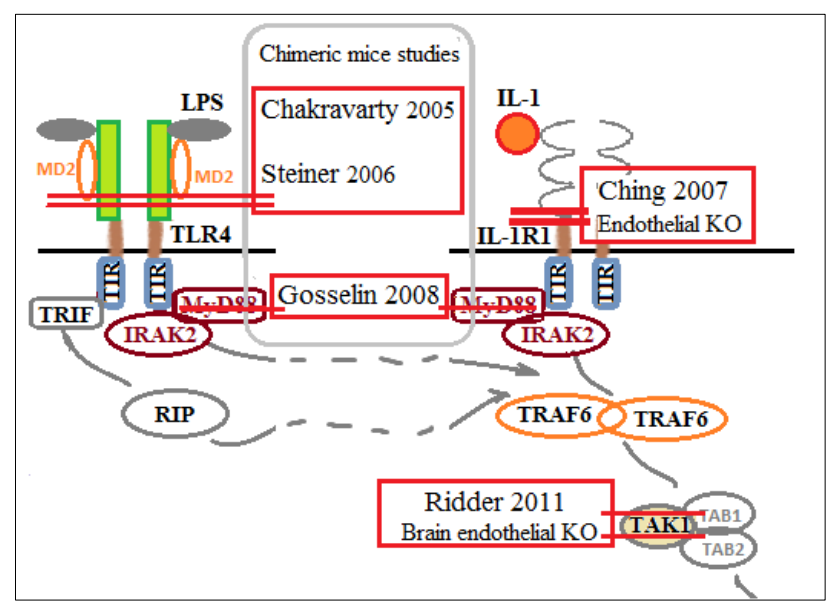

Figure 9. Studies on the TLR4 and IL-1R1 signaling.
While paper I is the first study that identifies the $\mathrm{PGE}_{2}$ producing cells critical for fever, several other studies have addressed the contribution of the BBB cells in immune-tobrain signaling by examining other levels of the signal transduction pathway. These studies include work on TLR4 chimeric mice (Chakravarty and Herkenham, 2005; Steiner et al., 2006b), endothelial specific IL-1R1 KO mice

(Ching et al., 2007), brain endothelial TAK1 KO mice, i.e. specific brain endothelial IL-1 signaling blockage (Ridder et al., 2011), and MyD88 chimeric mice (Gosselin and Rivest, 2008) (Figure 9).

While some controversies exist for the first phase of fever, particularly regarding the importance of TLR4 on hematopoietic cells (see below) (Steiner et al., 2006a), data from the abovementioned studies regarding IL-1-signaling are concordant. Hence, endothelial cells are strongly responsive to IL- $1 \beta$, while IL- $1 \beta$ signaling in perivascular macrophages does not rescue the IL-1 KO genotype (Ching et al., 2007; Gosselin and Rivest, 2008). Blood-borne IL$1 \beta$ signaling to CNS is completely dependent on endothelial IL-1R1 (Ching et al., 2007), which at BBB was also shown to be highly expressed on endothelial cells and not on perivascular cells (Konsman et al., 2004). A later study in which the brain endothelial IL- $1 \beta$ signaling was specifically targeted by TAK1 deletion in brain endothelial cells resulted in blunted fever 
response and decreased locomotion (lethargy) (Ridder et al., 2011). However, intraperitoneally injected IL-1 $\beta$ may signal to CNS through other pathways, probably by activating peripheral macrophages (Ching et al., 2007).

In the study by Steiner et al., (2006) it was reported that the presence of functional TLR4 in hematopoietic cells in mice with a TLR4 KO background rescued the initial febrile response. Their data thus suggested a critical role for hematopoietic cells for the initiation of fever which may seem to be in contrast to our finding, which showed intact initial fever in mice lacking $\mathrm{PGE}_{2}$ production in hematopoietic cells. However, the obvious reconciling interpretation is that intact TLR4 in hematopoietic cells foster the release of proinflammatory cytokines which in turn act on endothelial cells in the brain to induce PGE2 release and subsequent fever.

The critical role of endothelial cells for the PGE2 production that elicits fever has recently also been demonstrated by targeted deletion of COX-2 and mPGES-1 in brain endothelial cells (Wilhelms et al., 2014). Taken together these studies should end a long controversy concerning this issue (Saper et al., 2012).

\section{Immune challenge by intraperitoneal administration of lipopolysaccharide directs gene expression in distinct blood-brain barrier cells towards an enhanced prostaglandin $E_{2}$ signaling}

In paper II, with the method developed in paper I, FACS isolated BBB cells (Figure 10) and subsequent TLDA RT-qPCR analysis, we aimed at analyzing the effect of peripheral immune stimulation on gene transcripts related to inflammatory signaling in each BBB cell population in WT mice. We thus analyzed 48 gene-transcripts representing enzymes and proteins for prostaglandin metabolism and transport, cytokines, chemokines and lipocalin-2 with associated receptors, cytokine signaling molecules, peroxidase proliferator activated receptors, and celltype specific molecules (Tables 1 and 2 in paper II). The emerging picture (Figure 11) was that each cell population had a distinct transcriptional profile at base line and after ip LPS. The investigated endothelial and perivascular cell-type markers showed high specificity, but not the pericyte markers, discussed below. Down-regulation of endothelial and pericyte molecules known to participate in cell-to-cell contact suggested a decreased integrity of the barrier in response to LPS. Among prostaglandins, all the production at the BBB was switched towards an increase of PGE2 both by increased synthesis through inducible COX-2 and mPGES-1 in endothelial cells but also by decreased degradation in endothelial cells and perivascular macrophages, coupled with decreased production in the latter for other prostanoids. An interesting finding was the high, LPS-stable level of L-PGDS in the pericytes as the $\mathrm{PGD}_{2}$ 
synthesis previously has been assigned to the leptomeninges, choroid plexus and oligodendrocytes (Urade et al., 1993) but not to BBB.

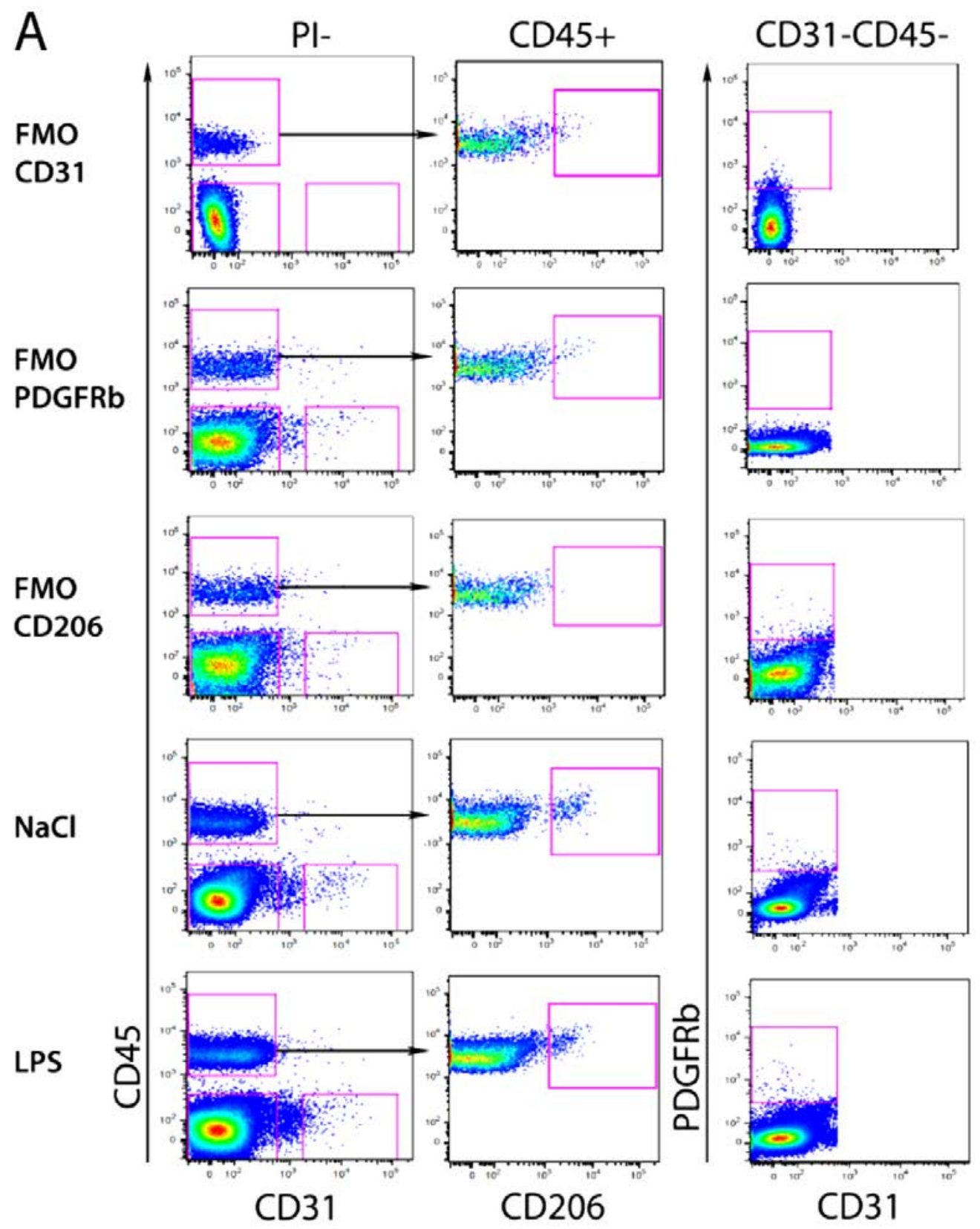



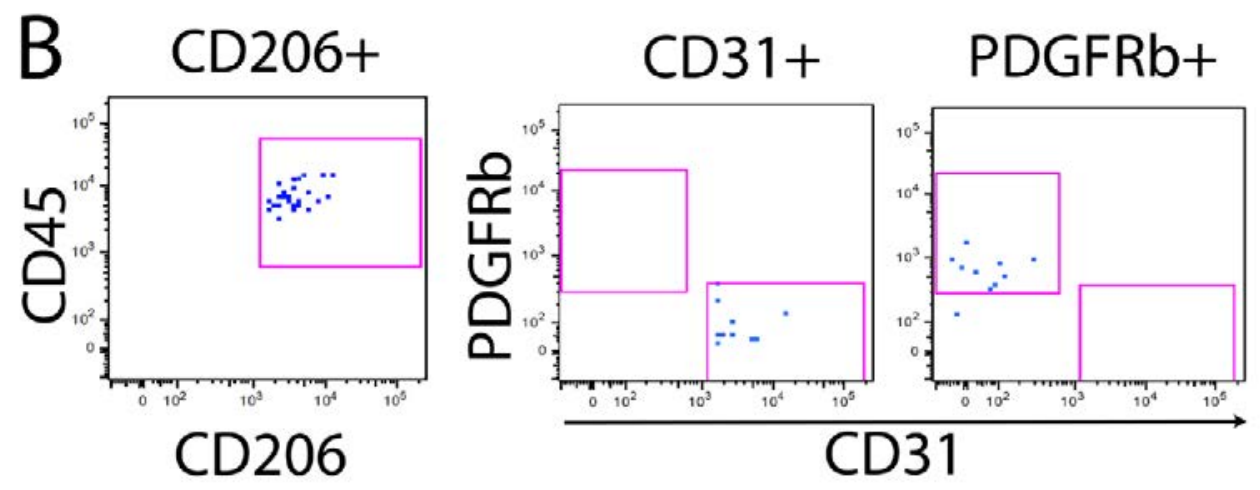

Figure 10. FACS sorting of endothelial cells (CD45-CD31+), perivascular macrophages (CD45+CD206+), and pericytes (CD45-CD31-PDGFRb+). (A) The cell populations were gated based on fluorescent minus one (FMO) controls in which the antibodies against CD31, CD206, and PDGFRb (CD140b) were omitted (FMO CD31, FMO CD206, and FMO PDGFRb, respectively). The left column shows gating for CD31 and CD45, and identifies three populations (red boxes): CD45-CD31+ cells, CD45+CD31- cells, and CD45-CD31- cells. Note that the gate used for CD31+ cells is defined according to FMO CD31 control (top panel) where no signal was observed in the gate. The middle column shows gating of CD206+ cells within the CD45+CD31- population. Note that the gate used for CD206+ cells contains only a single background event (accounting for $0.05 \%$ of total CD45+ cells) in the FMO CD206 control (third panel from top). The right column shows gating for PDGFRb+ cells among the CD45CD31- population. Note that the gate used for the PDGFRb+ cells is devoid of any signal in the FMO PDGFRb control (second panel from top). (B) Purity analysis of the sorted cell populations CD45+CD206+, CD45-CD31+, and CD140b/PDGFRb+. Note that the sorted CD31+ cells (ECs) were negative for PDGFRb and that the pericytes (PDGFRb+) were negative for CD31 (right).

Some of the prostaglandin transporters were up-regulated in endothelial cells (Abcc4 and Slco2b1) and down-regulated in perivascular cells (Slco2b1). As regards cytokine signaling, there was a clear up-regulation in the endothelial cells of IL-1R1, TLR4, IL-6R $\alpha$, whereas the perivascular cells responded with up-regulation of IL-6 and the pericytes with increased TNF expression, although the latter at low levels. Both endothelial cells and perivascular cells showed signs of cytokine activation as seen by induced expression of downstream signaling molecules such as IkB $\alpha$, MyD88, STAT3, Akt1 in endothelial cells and Myd88 or SOCS3 in perivascular cells, or of immediate early genes like lipocalin-2 and CXCL10, in both endothelial cells and perivascular cells.

\section{Discussion:}

Because the method used to examine the inflammatory transcriptome in BBB cell is novel, it is of interest to note that several of the transcripts now studied by RT-qPCR were previously shown in the same BBB cell populations by in situ hybridization or at protein level by immunohistochemistry. Some examples are COX-2 (Cao et al., 1995; Engström et al., 2012; 


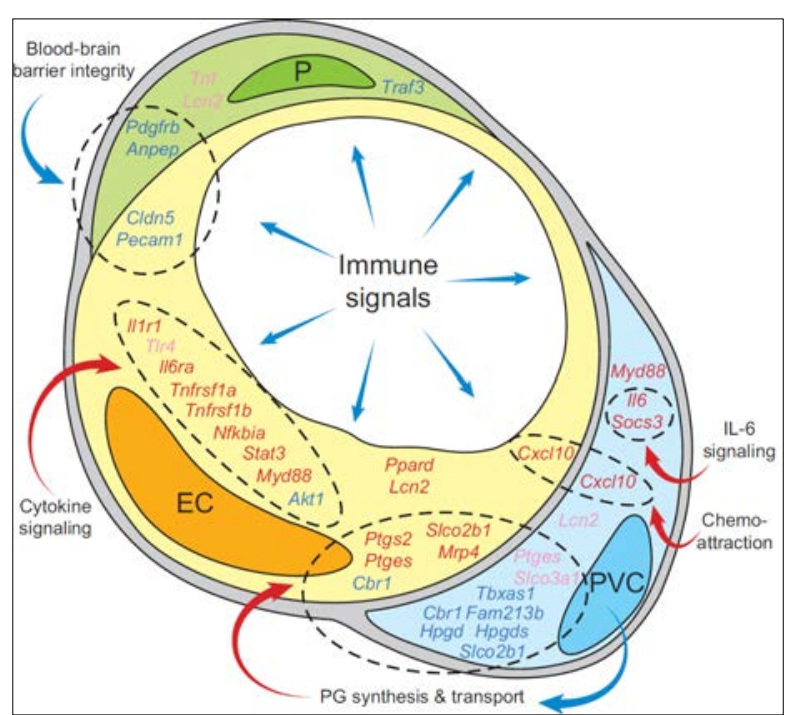

Figure 11. Gene expression changes in the BBB. Significant changes are represented for each cell type. Up-regulated genes in red (high expression) or pink text (low expression), and down-regulated genes in blue. Genes are group by dashed line into functional groups: BBB integrity, cytokine signaling in endothelial cells (ECs), prostaglandins synthesis and transport in ECs and perivascular cells (PVCs), chemoattraction and IL6 signaling in PVCs.

Inoue et al., 2002), mPGES-1 (Ek et al., 2001; Eskilsson et al., 2014), IL-1R1 (Cao et al., 2001; Ek et al., 2001; Konsman et al., 2004; Matsuwaki et al., 2014), $\operatorname{IkB} \alpha$ (Laflamme et al., 1999; Quan et al., 1997), and inducible lipocalin-2 (Hamzic et al., 2013a) in endothelial cells, and thromboxane-A synthases-1 (Tbxas1) in perivascular macrophages (Cyrus et al., 2010; Gabrielsen et al., 2010). Furthermore, functional coupling of increased production (COX-2, mPGES-1) and decreased degradation (15-PGDH) as revealed here was also previously reported to occur for PGE2 (Hahn et al., 1998; Tai et al., 2006). Thus, while providing a novel and comprehensive view of the inflammatory transcriptome in the $\mathrm{BBB}$, our data corroborate several observations in earlier studies underlining the feasibility of the present method. Still, several considerations ought to be addressed regarding the methodology and present results.

\section{Methodological limitations.}

The periyte-specific markers Anpep (CD13) and Pdgfrb (Armulik et al., 2010; Daneman et al., 2010; Eskilsson et al., 2014) showed in our RT-qPCR similar expression levels in endothelial cells as in pericytes suggesting a pericyte contamination of the endothelial cell population. However, this possibility can be dismissed by the flow cytometric controls such as CD31/PGDFRb gated FMO (fluorescence minus one) controls and purity controls (Figure 10) or SSC-H/SSC-W and FSC-H/FSC-W gating strategy (Figure 1 in paper II) to eliminate doublets in case of an incomplete dissociation of pericytes from endothelial cells. Moreover, a pericyte contamination would have generated a generalized effect on RT-qPCR data from endothelial cells and that was not seen for the highly expressed pericyte transcripts, Slc22a17 and L-PGDS. Thus, the expression of the pericyte markers by the endothelial cells is rather a phenomenon limited to the transcript-assay interaction depending either on a cross-reactivity 
of the used assays (Anpep and Pdgfrb) with other transcripts expressed in endothelial cells or on that the transcripts detected are largely un-translated in endothelial cells.

A potential limitation in the present study is the risk of activating the cells during the long processing time needed for enzymatic dissociation and FACS isolation. Although the cells were processed at $4^{\circ} \mathrm{C}$ to minimize this risk, several results that differ from those reported in previous studies were noted particularly as regards the perivascular cells, such as high COX-2, IL-1 $\beta$ and TNF $\alpha$ mRNAs levels both in saline and LPS treated samples. These results are in strong contrast to those obtained in morphological studies, pointing out endothelial cells as the cells expressing immune-induced COX-2 (both as protein and mRNA) (Engblom et al., 2002; Engström et al., 2012). They also differ from results from studies showing absence of cytokine expression in perivascular cells in naïve animals (Nadeau and Rivest, 1999b; Quan et al., 1998). Hence, some in vitro activation of transcripts cannot be excluded. However, this potential limitation does not invalidate the general conclusions of the study, which was based on the comparison of saline and LPS treated animals, since any in vitro effect should have affected both groups equally.

Another limitation of our study is analytical. The analyzed cells were shown to present different GAPDH levels (Table 1 in paper II), which was expected due to their different sizes and structural characteristics (Schmidt and Schibler, 1995). However, this implies that direct quantitative or qualitative comparisons of target genes between different cell-types may be uncertain. The present results are accordingly presented only as relative expressions in each cell population and treatment, and differences were calculated only between saline and LPS samples within the same cell-type (Table 1 in paper II). Nevertheless, for each cell-type, transcripts belonging to a protein family (as prostaglandin enzymes or cytokine receptors) are expected to reflect the relative abundance of the corresponding protein. Taking as an example IL-1R1 and TLR4, respectively, it may be inferred from comparing the relative mRNA expressions that endothelial cells express more IL-1R1 protein than TLR4, and furthermore, that perivascular cells express more TLR4 than endothelial cells. This inference is supported by the expression in these cells of their adaptor molecules TRIF and MyD88. Thus, TRIF (Ticam1) is much more abundantly expressed in perivascular cells than in endothelial cells, whereas Myd88 is about equally abundant in both cell types, which is what is to be expected by the canonical signaling pathways of TLR4 and IL-1R1, respectively (Figure 3).

Regarding results that conflict with results from previous reports, our data do not support the production of IL-6 and TNF $\alpha$ in endothelial cells (Verma et al., 2006). Instead we found an upregulation of IL-6 and TNFa in PVCs and pericytes, respectively. Another finding contrasting to those previously reported in the literature is the responsiveness of the different BBB cell populations to immune stimuli. It has been proposed that perivascular cells are the cells sensing low levels of IL-1 $\beta$, whereas endothelial cells have been proposed to respond 
mostly to LPS (Saper et al., 2012; Schiltz and Sawchenko, 2002; Serrats et al., 2010). These proposals contrasts strongly with our interpretations based on our data, which demonstrate that endothelial cells have high expression of IL-1R1, in agreement with other studies on the endothelial IL-1 signaling (Ching et al., 2007; Ek et al., 2001; Gosselin and Rivest, 2008) and IL-1R1 representation (Konsman et al., 2004; Matsuwaki et al., 2014). Perivascular cells, in contrast, displayed very little IL-1R1, compared to their high levels of TNFRs, IL-6R $\alpha$ and TLR4.

In conclusion, our study demonstrates that both endothelial cells and perivascular cells are responsive to immune stimuli, but that the two cell types respond in often opposing, yet complementary ways. Endothelial cells increased their cytokine sensitivity (receptor expression) while perivascular cells were contributing through an in situ cytokine production of IL-6. There was also increased prostaglandin transport and production that was switched towards more $\mathrm{PGE}_{2}$ through increased synthesis in endothelial cells, decreased degradation in endothelial cells and perivascular cells, and decreased synthesis of other prostanoids in perivascular cells.

\section{Expression of $\mathrm{PGE}_{2} \mathrm{EP} 3$ receptor subtypes in the mouse preoptic region.}

In paper III we aimed at characterizing the constitutive and LPS-induced expressions of the mouse EP3 isoforms (EP3 $\alpha, \mathrm{EP} 3 \beta$, and EP3 $\gamma$ ) in the preoptic region. For this purpose we first identified the EP3 expressing region in the anterior hypothalamus by in situ hybridization (Figure $1 \mathrm{~A}, \mathrm{C}$ in paper III). This region was mapped relative to the third ventricle, anterior commissure and optic nerve structures. With the anatomical landmarks we obtained we could specifically extract the EP3-rich preoptic region by laser capture microdissection and use it for RT-qPCR analysis of EP3 isoforms. We found that EP3 $\alpha$ was the most abundant isoform, followed by EP3 $\gamma$, and very low levels of EP3 $\beta$. None of the isoforms changed its expression $5 \mathrm{~h}$ after ip LPS (Figure 3 in paper III).

\section{Discussion:}

EP3 receptors within the preoptic area are critical for the fever response (Engblom et al., 2003; Lazarus et al., 2007; Ushikubi et al., 1998). Our findings suggest that the predominant effect of PGE2 on the EP3 isoforms would be an increased activity at Gi, through the dominant EP3 $\alpha$ isoform, but, in an agonist-dependent manner, there could also be an activation of Gs through the EP3 $\gamma$, with opposing effect on the cellular cAMP levels. Other processes governing fever regulation downstream of the EP receptors within the preoptic region are yet little elucidated. The EP4 receptors, also highly expressed in POA, are constitutively coupled to Gs and 
recognized as a hypothermic receptor (Oka et al., 2003b), thus opposing the general EP3 effect. However, the interaction between EP3 isoforms and EP4 in POA or their possible colocalization at neuronal level are issues that have not yet been addressed.

\section{Minor changes in gene expression in the mouse preoptic hypothalamic region by inflammation-induced prostaglandin E2}

In paper IV the gene regulatory effect of inflammation-induced $\mathrm{PGE}_{2}$ was investigated in the EP rich thermoregulatory region of the hypothalamus. LPS treated animals that were able to (WT) or unable to $(\mathrm{KO})$ produce inflammation-induced $\mathrm{PGE}_{2}\left(\mathrm{iPGE}_{2}\right.$ ) were compared with respect to their gene expression changes within the mouse preoptic area. The time point for analyzing the iPGE2 effect was set at $5 \mathrm{~h}$, that is about $2 \mathrm{~h}$ after the PGE2 peak in the CSF, which corresponded to a robust transcriptional up-regulation of the PGE2 synthesizing enzymes, COX-2 and mPGES-1 (Figure 1 in paper IV). The microarray analysis yielded a list of 253 unique genes that displayed significantly changed transcripts between genotypes. The genes could be grouped into neural-specific and cAMP dependent pathways, yet, no pathway was significantly changed in an integrated pathway analysis (Ingenuity Pathway Analysis System). As the changes in general were small, and no particular process was identified by pathway analysis, a smaller number of genes were selected for further analysis, based on the transcript's fold change (FC) and significance levels, or on previous studies. Hence, 47 genes and 1 reference gene (Gapdh) that displayed a FC of at least $2(P<0.05)$ or a FC between 1.5 and $2(P<0.01)$, as well as some other genes of interest, were analyzed by RT-qPCR. The validation step was run on new LPS or saline treated WT and KO mice, but following the same LCM and RNA-extraction protocols as the samples used for microarray analyses. Of the 47 genes examined, we could validate significant differences between genotypes only for HSPa1b and Hspa1a (together HSPs) encoding inducible forms of heat-shock proteins (HSP) of the HSP70 family (Tables 2 and 3 in paper IV). Analyses of cDNA from our time-course study on WT mice (Figure 1 in paper IV) suggested that the expression of the HSPs was dependent on $\mathrm{PGE}_{2}$ since they were induced at a later time point than the PGE2 synthesizing enzymes (COX2, mPGES-1). Furthermore, they were either more abundantly expressed in the hypothalamus (an EP rich region) than in striatum (an EP low expressing region), or they showed a stronger up-regulation in hypothalamus than in striatum. Nonetheless, the fever response is a major confounder in our model, as LPS-treated KO animals produce neither iPGE2 nor mount a fever response. Accordingly, the expression of HSPs was investigated in a cage exchange-induced hyperthermia paradigm. In response to emotional stress and in the absence of iPGE2 (Figure 2 in paper IV), both WT and KO mice displayed increased core body temperature and an up- 
regulation of HSPs. In conclusion, HSPs were independent of $\mathrm{iPGE}_{2}$, but dependent on the increased body temperature, which implied that inflammation-induced PGE2 regulates few, if any, of the gene expression changes that are seen in the CNS during systemic inflammation (Hamzic et al., 2013a; Mastronardi et al., 2007; Reyes et al., 2003).

\section{Discussion:}

In the model used, both WT and KO mice display most of the inflammation-induced characteristics upstream of PGE2 (i.e. cytokine production, BBB activation) (Nilsberth et al., 2009b). The critical difference is that KO mice lack iPGE2 and thus display no fever (Engblom et al., 2003) and they also show attenuated HPA activation (Elander et al., 2009), and abolished conditioned place aversion (Fritz, 2012). The very low fold changes that was seen in induced gene expression between the two genotypes differ from the strong LPS effect seen in the mouse brain (Hamzic et al., 2013a; Mastronardi et al., 2007; Reyes et al., 2003). To control that the small differences seen in induced gene expression between genotypes were not due to a general lack of responsiveness to the LPS treatment, we also examined the LPS-induced induction by comparing gene expression in LPS-treated WT mice with that in saline injected WT mice. Genes known to be strongly induced by LPS such as CXCL-10, COX-2 and lipocaline-2 (Hamzic et al., 2013a; Reyes et al., 2003) were all strongly up-regulated also in the present material (Table 3 in paper IV). Thus, as we could not find any $\mathrm{PGE}_{2}$-dependent genes, despite a strong LPS effect as such, the present data imply that the gene expression changes that take place in the hypothalamus/brain in systemic inflammation are not necessary for the PGE2 dependent sickness behavior, as they are not regulated by PGE2 but by some other, unknown pathway.

A potential limitation of our study concerns the chosen time point that could be set too late to allow detection of immediate-early genes like c-FOS, shown to be highly expressed in POA after ip LPS (Elander et al., 2009; Elmquist et al., 1996). According to some previous studies c-FOS expression in several autonomic relay regions of the brain is dependent on induced PGE2 production (Dallaporta et al., 2007; Zhang et al., 2003), however this was not confirmed in a subsequent study from our laboratory (Elander et al., 2009). While gene expression changes may also occur at time points later than $5 \mathrm{~h}$ post LPS injection, these are unlikely to be PGE2 driven since PGE2 levels in the CSF peak at $3 \mathrm{~h}$ post LPS injection to subsequently fall back and reach baseline levels at $12 \mathrm{~h}$ (Inoue et al., 2002).

Another limitation is the heterogeneous cell population analyzed from POA, a highly vascularized region encompassing the OVLT. The consequence of extracting the entire POA might be that any effect of PGE 2 on gene expression in neurons, if present, could be diluted and hence undetected due the presence of a large number of vascular and glial cells. Another approach would have been to dissect individual cells expressing EP receptors like shown for EP3 positive neurons (Tsuchiya et al., 2008). Nonetheless, even in that model, in which the 
gene regulatory effects were examined briefly after icv injection of PGE2, few genes were identified that were changed by the stimulus, and these genes generally displayed low fold changes (between 1.5 and 2). However, in that study (Tsuchiya et al., 2008) it was reported that the GABAA transcript was attenuated by PGE2, a finding that could not be verified in our present work.

In conclusion, very few, if any, gene-expression changes can be attributed to mPGES-1 induced PGE2. This implies that the centrally-elicited disease symptoms controlled by PGE2 are mostly generated by regulating the neuronal excitability through intracellular transcriptionalindependent cascades affecting the membrane potential. 


\section{Concluding remarks and future perspectives}

The search for immune-to-brain signaling pathways started more than 40 years ago as the endogenous pyrogens (Atkins and Bodel, 1971; Moore et al., 1970; Wood, 1962) proved to be too large to penetrate the BBB (Dinarello et al., 1974). Complementary to the pro-inflammatory cytokines, PGE2 emerged at the same time as a critical mediator in inflammation as the mechanism behind aspirin was revealed (Vane, 1971). Since that time, the missing links between cytokines and prostaglandins have been filled in by the identification of cytokine receptors and down-stream intracellular signaling molecules (e.g. NF-kB, STAT3, AP1) as well as by the identification of prostaglandin synthesizing enzymes (COX-2, mPGES-1) and PGE2 receptors (EPs). As a result, the sites for cytokine-prostaglandin interactions could be mapped in the periphery and in the brain with strongly compelling data pointing out the BBB as an active immune-to-brain interface region.

\section{Inflammation-induced $\mathrm{PGE}_{2}$ produced by the endothelial cells of the $\mathrm{BBB}$, a critical mechanism in imunne-to-brain signaling}

From the idea of an immune privileged brain with its impenetrable barriers, through the discovery of cytokines and prostaglandins, newer functions of the BBB were revealed that changed our view on the interactions between the immune system and the central nervous system. Today the immune privilege is considered relative and specialized (Muldoon et al., 2013). Thus, leukocytes have been shown to pass back and forth across the barriers much more easily than was initially considered possible, and the brain barriers, particularly the BBB, have been shown to be sensitive to circulating cytokines. Hence, in light of the data we present, the BBB production of inflammation-induced intermediates, like PGE2, can be added to the classical barrier properties.

Conflicting data have pointed out different cells as PGE2 producers within the BBB, i.e. endothelial cells (Cao et al., 1995; Ek et al., 2001; Matsumura et al., 1998; Yamagata et al., 2001) vs. perivascular cells (Breder and Saper, 1996; Elmquist et al., 1997b; Schiltz and Sawchenko, 2002). In paper I we demonstrate for the first time that endothelial cells are critical for the inflammation-induced $\mathrm{PGE}_{2}$ and the febrile response. Our findings are in agreement with other similar functional studies showing that the brain endothelial lining is highly responsive to IL-1 and that the IL-1 signaling cascade in the endothelium is critical for the brain-mediated acute phase responses (Ching et al., 2007; Gosselin and Rivest, 2008; Matsuwaki et al., 2014; Ridder et al., 2011) or microglia activation (Wohleb et al., 2014; Wohleb et al., 2013). These data corroborate the hypothesis of an IL-1-induced PGE2 production in endothelial cells that was previously inferred from morphological studies 
localizing COX-2, mPGES-1 and IL-1 signaling elements to the endothelial cells (Cao et al., 2001; Cao et al., 1995; Ek et al., 2001) (Figure 6), and refute the idea of critical PGE2 production in perivascular cells (Breder and Saper, 1996; Elmquist et al., 1997b; Schiltz and Sawchenko, 2002). However, the perivascular cells are not completely inert to peripheral inflammation as shown in paper II. We found them to respond to inflammation by CXCL10, lipocalin-2 and cytokine production (IL6) and decreased synthesis of other prostanoids. We also demonstrated that the perivascular cells express high levels of TNFRs and TLR4 but moderate levels of IL6R, and very little mRNA for IL-1R1. On the other hand they express high levels of cytokine mRNAs and can probably provide an amplification loop within the BBB upon activation. Several functional studies analyzing the role of the barrier TLR4signaling might be worth undertaking here.

In the TLR4 chimeric models discussed in paper I, brain cytokine and peripheral cortisol levels after LPS challenge were more dependent on a TLR4 ${ }^{+}$endothelial cell activation $(\mathrm{KO} \rightarrow \mathrm{WT}$ mice) than on a TLR4 ${ }^{+}$perivascular cell activation (WT $\rightarrow \mathrm{KO}$ mice). Still, $\mathrm{TLR}^{+}$in perivascular cells or peripheral LPS-sensitized macrophages was found to be contributing to the stress hormone release response (Chakravarty and Herkenham, 2005). The fever response in the same chimeric mice lacking TLR4 on hematopoietic cells (Steiner et al., 2006a) showed a 30 minute delay in its development, but the mice displayed normal fevers at later phases. From this study it could be similarly inferred that endothelial cell activation without activation of hematopoietic cells gives rise to a fever response, though at a later time point. Thus, TLR $4^{+}$ non-hematopoietic cells alone can mount acute phase responses and cytokine release, but at a slower pace. An important observation was that the endothelial TLR4 seemed to be redundant, since mice lacking TLR4 on endothelial cells displayed a fever response that was not significantly different from that of WT mice (Figure 2 in Steiner et al., 2006a)].

In conclusion, paper I and II and the above mentioned studies reveal the endothelial immune activation at BBB to be critical for the brain's adaptive responses like fever and release of stress hormones. The endothelial cells are highly responsive to IL-1 $\beta$, while the TLR4 signaling has but a low impact on the endothelial activation. Clinically this can give an answer to why simple bacteremia (i.e. circulating LPS) does not induce sickness symptoms. Bacteremia, in contrast to sepsis, is an inflammation-free bacterial passage in the blood stream, i.e. no IL-1 $\beta$ is released and thus there is no activation of the brain endothelial cells. In our LPS model, TNF $\alpha$, IL-1 $\beta$ and IL-6 were detected in plasma at distinct time points, each with its own specific kinetics (Elander et al., 2009). Thus, in our present studies the BBB was activated by several circulating cytokines which resulted in an up-regulation of the cytokine receptors and several cytokine intracellular signaling pathways in endothelial cells. Nonetheless, there are also indications of an activation of perivascular cells, either by LPS at TLR4 or by other cytokines, resulting in an IL-6 in-situ production that might provide an intra-barrier regulatory loop. Perivascular cells 
might be directly activated by LPS at CVOs, regions known to have a more accessible perivascular region and shown earlier to express immune-induced IL-1 $\beta$ in its perivascular cells and to be among the first structures activated by immune stimuli (Goehler et al., 2006; Quan et al., 1998). This activation of perivascular cell within CVOs could thus be the first event at the $\mathrm{BBB}$ until an IL-1 $\beta$ response is raised to engage the endothelial cells and induce a generalized BBB activation. Such an activation, as shown above in paper II, would bring about several functional changes like an increased cytokine sensitivity in endothelial cells and at the prostaglandin level a switch towards an increased production of PGE2 in endothelial cells and decreased synthesis of other prostanoids both in endothelial cells and perivascular cells.

\section{Brain $\mathrm{PGE}_{2}$ as a mediator of fever at the preoptic region}

Inflammation-induced PGE2 levels in CSF after ip LPS were significantly increased already at 40 minutes (paper I), even though at that time point only COX-2 mRNA, but not mPGES-1, was up-regulated in the brain (paper IV) or specifically in dissociated barrier cells (unpublished data). This discrepancy was seen also in rats (Ivanov et al., 2002) but in those studies no clear PGE2 increase in CSF was seen 45 minutes after LPS injection (Inoue et al., 2002). As peripheral organs like liver and lungs displayed an earlier up-regulation of the enzyme transcripts (Ivanov et al., 2002) than the brain, it was suggested that peripheral PGE2 was responsible for the first phase of fever (Ivanov and Romanovsky, 2004). This idea was further supported by a study from the same group showing that the fever response was suppressed after administration of blocking antibodies against PGE 2 (Blatteis, 2006; Steiner et al., 2006b). In mice, however, we found that non-hematopoietic (i.e. endothelial in CNS) production of $\mathrm{PGE}_{2}$, which was associated with an early rise of the PGE2 level in CSF, is needed also for the first phase of fever as demonstrated in paper I (Figure 2B in paper I). Hence, at least in mice we could dismiss a peripheral hematopoietic origin of PGE2 as responsible for fever. Nonetheless, the PGE2 elevation in CSF precedes the up-regulation of the mPGES-1 transcript. Several explanations for this apparent contradiction could be considered, such as the presence of a preexisting PGE2 pool in, for example, the cell components of the neuro-vascular unit (Tachikawa et al., 2012), or an initial effect mediated by constitutively expressed enzymes coupled transiently to rapidly produce and release PGE2 (Turrin and Rivest, 2004). The latter hypothesis is supported by studies identifying a COX-1 dependency of the early behavior changes (Swiergiel and Dunn, 2002), the initiation of fever (Zhang et al., 2003), the hypothermic response after the first phase of fever (Steiner et al., 2009), and the HPA-activation (Elander et al., 2009; Elander et al., 2010). It is also supported in mouse by the presence of constitutive expression of mPGES-1 in the brain endothelial cells (Eskilsson et al., 2014b). For the inconsistency between the rapid releases of PGE2 in the absence of induced mPGES-1 expression at the same time point, there are also methodological considerations to be addressed, such as different sensitivity levels for methods in general and 
for protein vs mRNA methods in particular. As an example, measuring PGE2 levels and mPGES-1 immunoreactivity, Inoue et al. (2002) reported an earlier increase of PGE2 than of mPGES-1. In the same study, another contradiction discussed by the authors was the early drop of PGE2 in CSF despite remaining high levels of COX-2 and mPGES-1. This as yet unsolved problem might have been answered in paper II by the up-regulation of the prostaglandin transporters in the barrier that by their suggested functions and cellular membrane localizations would contribute to the brain PGE2 clearance (Akanuma et al., 2010; Tachikawa et al., 2012).

Once released in the neuronal parenchyma $\mathrm{PGE}_{2}$ binds to its receptors and initiates different acute phase responses. The preoptic region of the anterior hypothalamus was shown to mediate the fever response and to participate to the HPA-activation (Saper et al., 2012; Ulrich-Lai and Herman, 2009) and hyperalgesia (Abe et al., 2001). Despite a high representation of EPs in this region we could not identify any of the inflammation-induced gene expression changes to be regulated by PGE2 (paper IV), which seems to be in line with the sparse evidence in the literature (Tsuchiya et al., 2008), and which suggests that most of the effects of PGE2 are nontranscriptional.

\section{Future perspectives}

The methodological arsenal available together with the multitude of transgenic animal models that exist today offer hope to elucidate the complex interactions between the BBB cells and their specific contribution in both physiological and pathological conditions, e.g. immune-tobrain signaling and sepsis, depressive disorders, multiple sclerosis and Alzheimer's disease, to name a few. By dissociating vascular cells from the brain and sorting them in specific populations we could analyze cellular specific characteristics and responses to immune stimuli. In immune-to-brain signaling most of the focus of our work was towards the PGE2 production in the barrier and the roles played by IL- $1 \beta$ or IL- 6 but the contributions of several other cytokines await characterization, as well as the effect of the cytokines on other properties of the BBB, such as the role of IL-6 in barrier integrity, or the effect of different cytokines on the prostaglandin transporters.

We here examined 48 transcripts (paper II) but the sensitivity of the methods has increased and whole transcriptome analyses are already provided even for low cell counts, at more accessible prices. Enzymatic cell dissociation and cell isolation by FACS flow cytometry might be the way to go to characterize cells like pericytes that are otherwise difficult to isolate by e.g. LCM due to their localization, apposing endothelial cells. Dissociation and FACS-sorting is also possible for glial cells, although not for neurons. Analyzing glial cells would provide much information on the parenchymal response to peripheral inflammation and could help to elucidate the mechanisms underlying a persistent activation and neuroinflammation. 


\section{Acknowledgments}

This work was carried out at the Division of Cell Biology and during the final years was even given support from the Division of Clinical Immunology and Transfusion Medicine. Both divisions are part of the Department of Clinical and Experimental Medicine within the Faculty of Health Sciences in Linköping. As the soul of each system (divisions, faculties, or societies) is yet its people, and as no great achievement is done in solitude, I would like to express my gratitude to all of you that helped and encouraged me to reach this dear moment in my life.

Dr Camilla Nilsberth, my supervisor, you have been an island of serenity during these intensive years for us both. I don't think that any of us knew that we would achieve that much during these 11 years on the $11^{\text {th }}$ floor. I am extremely thankful that despite your own work and me being away a lot, you still have had time for me and showed a good sense of who I am.

Professor Sivert Lindström and Professor Fredrik Elinder, my co-supervisors, for being openminded and not questioning my mental-health as I went for my extreme choices in life. Thank you for your support!

Professor Anders Blomqvist for your dedication to good quality science and life in general and most of all for inspiring me to get three new lives: research, work, and private life, far away from Bucharest.

To the earlier AB-group with whom I learned most of the methods I have used. Special thanks to Ludmila Mackerlova, Linda Engström Ruud, Louise Elander, Johan Ruud and David Engblom. Thank you David for all your good advice and for trying to save the EP3 project by creating transgenic mice. It is impressive to see how you always find some time for people in need!

Assistant Professor Hong Qian, thank you for your dedication to your research and your skillfulness in the lab. You have saved me from a cell-by-cell dissection and sent me fast forward to hundreds of cells at once! Mind blowing technology! (... not only because we worked with brain samples)

Over the years many people have come and gone from, or just remained on the $11^{\text {th }}$ floor in Cell Biology and contributed to enjoyable discussions over the coffee breaks and lunches. Thank you all! Simin Mohseni, Namik, and Josefine, David and collaborators, students in Fredrik Elinders group, Björn Granseth and his group and the new AB-group. Special thanks to Unn for all your lab support to me, although I'm a CN not an AB. 
Many thanks to the technicians in the animal facility! Anna, Linda, Nettan, Cissy, Petra and Björn, Anders, Emma and everyone else thank you for your day by day contribution to my projects.

Papers III and IV were quite a challenging race between the labs with samples to be kept on dry ice and to be sectioned, ultra-thin! To Håkan Wiktander who rescued several samples in the process by finding dry ice and also for improving life in the labs! And to Florence Sjögren for your support with the cryostat, an instrument that forced me to practice meditation while working. It took me some years, but now the studies are done and printed!

To Åsa Schippert and Annette Molbaek who give molecular biology a warm soul! Always nice to be working in Cellkärnan!

To my colleagues from the Blood Bank. Crazy year this last year, but how nice it is to be one among you!

To Professor Gösta Berlin who gave me courage to come to the clinical lab. To Professor Jan Ernerudh and Professor Thomas Skogh for taking immunology to the bedside level and for your inspiring lectures... one (almost) angry granulocyte has even made it to the front cover of the present issue. Please notice the T and B-lymphocytes as well!

And I wouldn't still be here without the warm encouragement from: Bodil, Lotta, Agneta, Gittan, Karin, Sofia, Nahreen, Marie, Laila, Saad, Bengt and Mima, Anne, Eva, Carina and Christina, Inger, Tina, Annika, Berith, Ingrid, Khilis, Christine, Maria, Maria, Marie, Carina, Lena, Annika, Tina, Ina , Ann, Charlotte and many others. Yes, it is a great place to be working at thanks to you all! (and I am not totally lost, we do have Carina x 2 or Maria x N)

To my friends here in Sweden, in Romania or elsewhere. Although I like my private moments, I am happy to be with or hear from you and get some fresh news from the real life outside my "green-house" where my pumpkins are growing.

To Lena, Josefine and Anna, Claudia, Karina and Adi, Lillemor and Dick, Anne, Dag, and Peter who have put my life in motion again.

To Magda, Mirela, Victoria, and Andrei for still remembering me and the wonderful days we spent hiking. May the future bring some more!

Last but not least, to my dear, dear family my father and brother, uncles and aunts, cousins and family friends! I must have been the luckiest child on Earth to have had you around me during the red, communistic years in Romania. I was surrounded by joy and love and learned from you that there is no better foundation for solid relationships than trust. When forced to live in lies the joy is running thin! My heart will always be in Fagaras, near the beautiful Carpathian Mountains and near my mother and grandparents resting under the big oak tree. 
Till Cecilia, Johan och Carl! Ni är det bästa som har hänt mig i detta konstiga liv som tar en från ett läge till ett annat (ibland på nolltid). Jag är så glad att vi får dröja kvar tillsammans en lång stund till!

"Denna dagen, ett livt”....gånger några tusen dagar till... 


\section{Literature cited}

Abbott, N.J., A.A. Patabendige, D.E. Dolman, S.R. Yusof, and D.J. Begley. 2010. Structure and function of the blood-brain barrier. Neurobiol Dis. 37:13-25.

Abbott, N.J., L. Rönnback, and E. Hansson. 2006. Astrocyte-endothelial interactions at the blood-brain barrier. Nat Rev Neurosci 7:41-53.

Abe, H., T. Takeshita, K. Nagata, T. Arita, Y. Endo, T. Fujita, H. Takayama, M. Kubo, and K. Sugamura. 1999. Molecular cloning, chromosome mapping and characterization of the mouse CRTH2 gene, a putative member of the leukocyte chemoattractant receptor family. Gene 227:7177.

Abe, M., T. Oka, T. Hori, and S. Takahashi. 2001. Prostanoids in the preoptic hypothalamus mediate systemic lipopolysaccharide-induced hyperalgesia in rats. Brain Res 916:41-49.

Abramovitz, M., M. Adam, Y. Boie, M.-C. Carrière, D. Denis, C. Godbout, S. Lamontagne, C. Rochette, N. Sawyer, N.M. Tremblay, M. Belley, M. Gallant, C. Dufresne, Y. Gareau, R. Ruel, H. Juteau, M. Labelle, N. Ouimet, and K.M. Metters. 2000. The utilization of recombinant prostanoid receptors to determine the affinities and selectivities of prostaglandins and related analogs. BBA- Mol Cell Biol L 1483:285-293.

Adachi, H., T. Suzuki, M. Abe, N. Asano, H. Mizutamari, M. Tanemoto, T. Nishio, T. Onogawa, T. Toyohara, S. Kasai, F. Satoh, M. Suzuki, T. Tokui, M. Unno, T. Shimosegawa, S. Matsuno, S. Ito, and T. Abe. 2003. Molecular characterization of human and rat organic anion transporter OATP-D. Am J Physiol-Renal 285:F1188-1197.

Aggarwal, B.B. 2003. Signalling pathways of the TNF superfamily: A double-edged sword. Nat Rev Immunol 3:745-756.

Aggarwal, B.B., W.J. Kohr, P.E. Hass, B. Moffat, S.A. Spencer, W.J. Henzel, T.S. Bringman, G.E. Nedwin, D.V. Goeddel, and R.N. Harkins. 1985. Human tumor necrosis factor. Production, purification, and characterization. J Biol Chem 260:2345-2354.

Aguliar-Valles, A., J. Kim, S. Jung, B. Woodside, and G.N. Luheshi. 2014. Role of brain transmigrating neutrophils in depression-like behavior during systemic infection. Mol Psychiatry 19:599-606.

Akanuma, S., K. Hosoya, S. Ito, M. Tachikawa, T. Terasaki, and S. Ohtsuki. 2010. Involvement of multidrug resistance-associated protein 4 in efflux transport of prostaglandin $\mathrm{E}(2)$ across mouse blood-brain barrier and its inhibition by intravenous administration of cephalosporins. $J$ Pharmacol Exp Ther 333:912-919.

Akanuma, S., Y. Uchida, S. Ohtsuki, M. Tachikawa, T. Terasaki, and K. Hosoya. 2011. Attenuation of prostaglandin E2 elimination across the mouse blood-brain barrier in lipopolysaccharide-induced inflammation and additive inhibitory effect of cefmetazole. Fluids Barriers CNS 8:24.

Akira, S., S. Uematsu, and O. Takeuchi. 2006. Pathogen Recognition and Innate Immunity. Cell 124:783-801.

Algire, G.H., F.Y. Legallais, and B.F. Anderson. 1952. Vascular reactions of normal and malignant tissues in vivo. V. The role of hypotension in the action of a bacterial polysaccharide on tumors. J Natl Cancer Inst 12:1279-1295.

Alheim, K., and T. Bartfai. 1998. The interleukin-1 system: receptors, ligands, and ICE in the brain and their involvement in the fever response. Ann N Y Acad Sci 840:51-58.

Alheim, K., Z. Chai, G. Fantuzzi, H. Hasanvan, D. Malinowsky, E. Di Santo, P. Ghezzi, C.A. Dinarello, and T. Bartfai. 1997. Hyperresponsive febrile reactions to interleukin (IL) 1alpha and IL-1beta, and altered brain cytokine mRNA and serum cytokine levels, in IL-1beta-deficient mice. $P$ Natl Acad Sci USA 94:2681-2686. 
An, S.Z., J.H. Yang, M.H. Xia, and E.J. Goetzl. 1993. Cloning and expression of the EP2 subtype of human receptors for prostaglandin-E2. Biochem Biophys Res Co 197:263-270.

An, Y., N. Belevych, Y.F. Wang, H. Zhang, H. Herschman, Q. Chen, and N. Quan. 2014. Neuronal and Nonneuronal COX-2 Expression Confers Neurotoxic and Neuroprotective Phenotypes in Response to Excitotoxin Challenge. J Neurosci 92:486-495.

Andreasson, K. 2010. Emerging roles of PGE2 receptors in models of neurological disease. Prostag Oth Lipid M 91:104-112.

Anggard, E. 1966. The biological activities of three metabolites of prostaglandin E 1. Acta Physiol Scand 66:509-510.

Arend, W.P. 2002. The balance between IL-1 and IL-1Ra in disease. Cytokine Growth Factor Rev 13:323-340.

Armulik, A., G. Genove, M. Mae, M.H. Nisancioglu, E. Wallgard, C. Niaudet, L. He, J. Norlin, P. Lindblom, K. Strittmatter, B.R. Johansson, and C. Betsholtz. 2010. Pericytes regulate the bloodbrain barrier. Nature 468:557-561.

Atkins, E. 1984. Fever: the old and the new. J Infect Dis 149:339-348.

Atkins, E. 1988. On new concepts on the pathogenesis of fever. Rev Infect Dis 10:190.

Atkins, E., and P.T. Bodel. 1971. Role of leucocytes in fever. Ciba F Symp 81-100.

Atkins, E., and W.B. Wood, Jr. 1955. Studies on the pathogenesis of fever. II. Identification of an endogenous pyrogen in the blood stream following the injection of typhoid vaccine. J Exp Med 102:499-516.

Auron, P.E., A.C. Webb, L.J. Rosenwasser, S.F. Mucci, A. Rich, S.M. Wolff, and C.A. Dinarello. 1984. Nucleotide-sequence of human monocyte interleukin-1 precursor cDNA. P Natl Acad Sci USA 81:7907-7911.

Banks, W.A. 2005. Blood-brain barrier transport of cytokines: A mechanism for neuropathology. Curr Pharm Design 11:973-984.

Banks, W.A. 2009. The blood-brain barrier in psychoneuroimmunology. Immunol Allergy Clin 29:223228.

Banks, W.A., and M.A. Erickson. 2010. The blood-brain barrier and immune function and dysfunction. Neurobiol Dis. 37:26-32.

Batshake, B., C. Nilsson, and J. Sundelin. 1995. Molecular characterization of the mouse prostanoid EP(1) receptor gene. Eur J Biochem 231:809-814.

Belevych, N., K. Buchanan, Q. Chen, M. Bailey, and N. Quan. 2010. Location-specific activation of the paraventricular nucleus of the hypothalamus by localized inflammation. Brain Behav Immun 24:1137-1147.

Bennett, I.L., Jr., and P.B. Beeson. 1953. Studies on the pathogenesis of fever. I. The effect of injection of extracts and suspensions of uninfected rabbit tissues upon the body temperature of normal rabbits. J Exp Med 98:477-492.

Bentivoglio, M., and K. Kristensson. 2014. Tryps and trips: cell trafficking across the 100-year-old blood-brain barrier. Trends Neurosci 37:325-333.

Bergström, S. 1967. Prostaglandins: members of a new hormonal system. These physiologically very potent compounds of ubiquitous occurrence are formed from essential fatty acids. Science 157:382-391.

Bergström, S., L.O. Farnebo, and K. Fuxe. 1973. Effect of prostaglandin E 2 on central and peripheral catecholamine neurons. Eur J Pharmacol 21:362-368.

Bergström, S., and B. Samuelsson. 1965. Prostaglandins. Annu Rev Biochem 34:101-108. 
Berkenbosch, F., J. van Oers, A. del Rey, F. Tilders, and H. Besedovsky. 1987. Corticotropin-releasing factor-producing neurons in the rat activated by interleukin-1. Science 238:524-526.

Bernheim, H.A., L.H. Block, and E. Atkins. 1979. Fever: Pathogenesis, Pathophysiology, and Purpose. Ann Int Med 91:261-270.

Besedovsky, H., A. del Rey, E. Sorkin, and C.A. Dinarello. 1986. Immunoregulatory feedback between interleukin-1 and glucocorticoid hormones. Science 233:652-654.

Besedovsky, H., and E. Sorkin. 1977. Network of immune-neuroendocrine interactions. Clin Exp Immunol 27:1-12.

Beutler, B., D. Greenwald, J.D. Hulmes, M. Chang, Y.C. Pan, J. Mathison, R. Ulevitch, and A. Cerami. 1985. Identity of tumour necrosis factor and the macrophage-secreted factor cachectin. Nature 316:552-554.

Beutler, B., and E.T. Rietschel. 2003. Innate immune sensing and its roots: the story of endotoxin. Nat Rev Immunol 3:169-176.

Bhattacharya, M., K. Peri, A. Ribeiro-da-Silva, G. Almazan, H. Shichi, X. Hou, D.R. Varma, and S. Chemtob. 1999. Localization of functional prostaglandin E-2 receptors EP3 and EP4 in the nuclear envelope. J Biol Chem 274:15719-15724.

Bishai, I., C.A. Dinarello, and F. Coceani. 1987. Prostaglandin formation in feline cerebral microvessels-effect of endotoxin and interleukin-1. Can J Physiol Pharmac 65:2225-2230.

Bito, L.Z., H. Davson, and J.R. Hollingsworth. 1976. Facilitated transport of prostaglandins across the blood—cerebrospinal fluid and blood—brain barriers. J Physiol 256:273-285.

Blatteis, C.M. 1992. Role of the OVLT in the febrile response to circulating pyrogens. Prog Brain Res 91:409-412.

Blatteis, C.M. 2006. Endotoxic fever: new concepts of its regulation suggest new approaches to its management. Phamacol Therapeut 111:194-223.

Blatteis, C.M., S.L. Bealer, W.S. Hunter, J.Q. Llanos, R.A. Ahokas, and T.A. Mashburn Jr. 1983. Suppression of fever after lesions of the anteroventral third ventricle in guinea pigs. Brain Res Bull 11:519-526.

Bluthe, R.M., S. Laye, B. Michaud, C. Combe, R. Dantzer, and P. Parnet. 2000. Role of interleukin-1 beta and tumour necrosis factor-alpha in lipopolysaccharide-induced sickness behaviour: a study with interleukin-1 type I receptor-deficient mice. Eur J Neurosci 12:4447-4456.

Bradley, J.R. 2008. TNF-mediated inflammatory disease. J Pathol 214:149-160.

Breder, C.D., D. Dewitt, and R.P. Kraig. 1995. Characterization of inducible cyclooxigenase in ratbrain. J Comp Neurol 355:296-315.

Breder, C.D., C.A. Dinarello, and C.B. Saper. 1988. Interleukin-1 immunoreactive innervation of the human hypothalamus. Science 240:321-324.

Breder, C.D., C. Hazuka, T. Ghayur, C. Klug, M. Huginin, K. Yasuda, M. Teng, and C.B. Saper. 1994. Regional induction of tumor-necrosis-factor alpha expression in the mouse-brain after systemic lipopolysaccharide administration. P Natl Acad Sci USA 91:11393-11397.

Breder, C.D., and C.B. Saper. 1996. Expression of inducible cyclooxygenase mRNA in the mouse brain after systemic administration of bacterial lipopolysaccharide. Brain Res 713:64-69.

Cao, C., K. Matsumura, N. Shirakawa, M. Maeda, I. Jikihara, S. Kobayashi, and Y. Watanabe. 2001. Pyrogenic cytokines injected into the rat cerebral ventricle induce cyclooxygenase-2 in brain endothelial cells and also upregulate their receptors. Eur J Neurosci 13:1781-1790.

Cao, C.Y., K. Matsumura, K. Yamagata, and Y. Watanabe. 1995. Induction by lipopolysaccharide of cyclooxigenase-2 messenger-RNA in rat brain- its possible role in the febrile response. Brain Res 697:187-196. 
Cao, C.Y., K. Matsumura, K. Yamagata, and Y. Watanabe. 1996. Endothelial cells of the rat brain vasculature express cyclooxygenase-2 mRNA in response to systemic interleukin-1 beta: A possible site of prostaglandin synthesis responsible for fever. Brain Res 733:263-272.

Cao, C.Y., K. Matsumura, K. Yamagata, and Y. Watanabe. 1998. Cyclooxygenase-2 is induced in brain blood vessels during fever evoked by peripheral or central administration of tumor necrosis factor. Mol Brain Res 56:45-56.

Carswell, E.A., L.J. Old, R.L. Kassel, S. Green, N. Fiore, and B. Williamson. 1975. An endotoxininduced serum factor that causes necrosis of tumors. P Natl Acad Sci USA 72:3666-3670.

Cartmell, T., S. Poole, A.V. Turnbull, N.J. Rothwell, and G.N. Luheshi. 2000. Circulating interleukin6 mediates the febrile response to localised inflammation in rats. $J$ Physiol 526 Pt 3:653-661.

Casanova, J.L., L. Abel, and L. Quintana-Murci. 2011. Human TLRs and IL-1Rs in host defense: natural insights from evolutionary, epidemiological, and clinical genetics. Annu Rev Immunol 29:447-491.

Cattori, V., J.E. van Montfoort, B. Stieger, L. Landmann, D.K. Meijer, K.H. Winterhalter, P.J. Meier, and B. Hagenbuch. 2001. Localization of organic anion transporting polypeptide 4 (Oatp4) in rat liver and comparison of its substrate specificity with Oatp1, Oatp2 and Oatp3. Pflug Arch Eur J Phy 443:188-195.

Cerami, A., Y. Ikeda, N. Le Trang, P.J. Hotez, and B. Beutler. 1985. Weight loss associated with an endotoxin-induced mediator from peritoneal macrophages: the role of cachectin (tumor necrosis factor). Immunol Lett 11:173-177.

Chai, Z., S. Gatti, C. Toniatti, V. Poli, and T. Bartfai. 1996. Interleukin (IL)-6 gene expression in the central nervous system is necessary for fever response to lipolysaccharide or IL-1 beta: A study on IL-6-deficient mice. J Exp Med 183:311-316.

Chakravarty, S., and M. Herkenham. 2005. Toll-like receptor 4 on nonhematopoietic cells sustains CNS inflammation during endotoxemia, independent of systemic cytokines. J Neurosci 25:1788-1796.

Chalaris, A., B. Rabe, K. Paliga, H. Lange, T. Laskay, C.A. Fielding, S.A. Jones, S. Rose-John, and J. Scheller. 2007. Apoptosis is a natural stimulus of IL6R shedding and contributes to the proinflammatory trans-signaling function of neutrophils. Blood 110:1748-1755.

Chen, Q., D.T. Fisher, K.A. Clancy, J.M.M. Gauguet, W.C. Wang, E. Unger, S. Rose-John, U.H. von Andrian, H. Baumann, and S.S. Evans. 2006. Fever-range thermal stress promotes lymphocyte trafficking across high endothelial venules via an interieukin 6 trans-signaling mechanism. Nat Immunol 7:1299-1308.

Ching, S., H. Zhang, N. Belevych, L. He, W. Lai, X.A. Pu, L.B. Jaeger, Q. Chen, and N. Quan. 2007. Endothelial-specific knockdown of interleukin-1 (IL-1) type 1 receptor differentially alters CNS responses to IL-1 depending on its route of administration. J Neurosci 27:10476-10486.

Chou, C.T. 2013. How to Translate Basic Knowledge into Clinical Application of Biologic Therapy in Spondyloarthritis. Clin Dev Immunol 2013:369202.

Cohen, Z., G. Bonvento, P. Lacombe, and E. Hamel. 1996. Serotonin in the regulation of brain microcirculation. Prog Neurobiol 50:335-362.

Coleman, R.A., S.P. Grix, S.A. Head, J.B. Louttit, A. Mallett, and R.L.G. Sheldrick. 1994. A novel inhibitory prostanoid receptor in piglet saphenous-vein. Prostaglandins 47:151-168.

Coleman, R.A., and I. Kennedy. 1985. Characterization of the prostanoid receptors mediating contraction of guinea-pig isolated trachea. Prostaglandins 29:363-375.

Coleman, R.A., I. Kennedy, and R.L.G. Sheldrick. 1985. AH-6809 6 isopropoxy-9-oxoxanthene-2carboxylic-acid a prostanoid EP-1 receptor blocking drug. Brit J Pharmacol 85:273P.

Coley, W. 1893. The treatment of malignant tumors by repeated inoculations of erysipelas: with a report of ten original cases. Am J Med Sci 105:487-510. 
Collins, F.S., E.D. Green, A.E. Guttmacher, and M.S. Guyer. 2003. A vision for the future of genomics research. Nature 422:835-847.

Cooper, A.L., and N.J. Rothwell. 1991. Mechanisms of early and late hypermetabolism and fever after localized tissue injury in rats. Am J Physiol 261:E698-705.

Couzin-Frankel, J. 2010. Inflammation Bares a Dark Side. Science 330:1621-1621.

Creagan, E.T., J.S. Kovach, C.G. Moertel, S. Frytak, and L.K. Kvols. 1988. A phase-I clinical-trial of recombinant human-tumor necrosis factor. Cancer 62:2467-2471.

Crofford, L.J., B. Tan, C.J. McCarthy, and T. Hla. 1997. Involvement of nuclear factor kappa B in the regulation of cyclooxygenase-2 expression by interleukin-1 in rheumatoid synoviocytes. Arthritis Rheum 40:226-236.

Cunningham, E.T., Jr., E. Wada, D.B. Carter, D.E. Tracey, J.F. Battey, and E.B. De Souza. 1992. In situ histochemical localization of type I interleukin-1 receptor messenger RNA in the central nervous system, pituitary, and adrenal gland of the mouse. J Neurosci 12:1101-1114.

D'Mello, C., T. Le, and M.G. Swain. 2009. Cerebral Microglia Recruit Monocytes into the Brain in Response to Tumor Necrosis Factor alpha Signaling during Peripheral Organ Inflammation. $J$ Neurosci 29:2089-2102.

Dallaporta, M., E. Pecchi, C. Jacques, F. Berenbaum, A. Jean, S. Thirion, and J.D. Troadec. 2007. cFos immunoreactivity induced by intraperitoneal LPS administration is reduced in the brain of mice lacking the microsomal prostaglandin E synthase-1 (mPGES-1). Brain Behav Immun 21:1109-1121.

Daneman, R., L. Zhou, D. Agalliu, J.D. Cahoy, A. Kaushal, and B.A. Barres. 2010. The mouse bloodbrain barrier transcriptome: a new resource for understanding the development and function of brain endothelial cells. PLoS One 5:e13741.

Dantzer, R., R.M. Bluthe, G. Gheusi, S. Cremona, S. Laye, P. Parnet, and K.W. Kelley. 1998. Molecular basis of sickness behavior. In Mol Mechanisms of Fever. M.J. Kluger, T. Bartfai, and C.A. Dinarello, editors. 132-138.

Dantzer, R., J.C. O'Connor, G.G. Freund, R.W. Johnson, and K.W. Kelley. 2008. From inflammation to sickness and depression: when the immune system subjugates the brain. Nat Rev Neurosci 9:46-57.

De Bosscher, K., W. Vanden Berghe, and G. Haegeman. 2003. The interplay between the glucocorticoid receptor and nuclear factor-kappaB or activator protein-1: molecular mechanisms for gene repression. Endocr Rev 24:488-522.

Deutschman, Clifford S., and Kevin J. Tracey. 2014. Sepsis: Current Dogma and New Perspectives. Immunity 40:463-475.

Devries, H.E., K.H. Hoogendoorn, J. Vandijk, F.J. Zijlstra, A.M. Vandam, D.D. Breimer, T.J.C. Vanberkel, A.G. Deboer, and J. Kuiper. 1995. Eicosanoid production by rat cerebral endothelialcells -stimulation by lipopolysaccharide, interleukin-1 and interleukin-6. J Neuroimmunol 59:18.

Diaz-Munoz, M.D., I.C. Osma-Garcia, C. Cacheiro-Llaguno, M. Fresno, and M.A. Iniguez. 2010. Coordinated up-regulation of cyclooxygenase- 2 and microsomal prostaglandin E synthase 1 transcription by nuclear factor kappa B and early growth response-1 in macrophages. Cell Signal 22:1427-1436.

Dinarello, C.A. 1996. Biologic basis for interleukin-1 in disease. Blood 87:2095-2147.

Dinarello, C.A., J.G. Cannon, and S.M. Wolff. 1988. New concepts on the pathogenesis of fever. Rev Infect Dis 10:168-189. 
Dinarello, C.A., J.G. Cannon, S.M. Wolff, H.A. Bernheim, B. Beutler, A. Cerami, I.S. Figari, M.A. Palladino, and J.V. Oconnor. 1986. Tumor-necrosis-factor (cachectin) is an endogenous pyrogen and induces production of interleukin-1. J Exp Med 163:1433-1450.

Dinarello, C.A., N.P. Goldin, and S.M. Wolff. 1974. Demonstration and characterization of two distinct human leukocytic pyrogens. J Exp Med 139:1369-1381.

Dinarello, C.A., A. Simon, and J.W. van der Meer. 2012. Treating inflammation by blocking interleukin-1 in a broad spectrum of diseases. Nat Rev Drug Discov 11:633-652.

Diserbo, M., A. Agin, I. Lamproglou, J. Mauris, F. Staali, E. Multon, and C. Amourette. 2002. Bloodbrain barrier permeability after gamma whole-body irradiation: an in vivo microdialysis study. Can J Physiol Pharmac 80:670-678.

Dubois, R.N., S.B. Abramson, L. Crofford, R.A. Gupta, L.S. Simon, L.B.A. Van De Putte, and P.E. Lipsky. 1998. Cyclooxygenase in biology and disease. Faseb J 12:1063-1073.

Ehrlich, P. 1885. Das sauerstufbudurfnis des organismus. Eine Farbenanalytische Studie Hirschwald, Berlin:

Ek, M., C. Arias, P. Sawchenko, and A. Ericsson-Dahlstrand. 2000. Distribution of the EP3 prostaglandin E-2 receptor subtype in the rat brain: Relationship to sites of interleukin-1-induced cellular responsiveness. J Comp Neurol 428:5-19.

Ek, M., D. Engblom, S. Saha, A. Blomqvist, P.J. Jakobsson, and A. Ericsson-Dahlstrand. 2001. Inflammatory response: pathway across the blood-brain barrier. Nature 410:430-431.

Ek, M., M. Kurosawa, T. Lundeberg, and A. Ericsson. 1998. Activation of vagal afferents after intravenous injection of interleukin-1beta: role of endogenous prostaglandins. J Neurosci 18:9471-9479.

Elander, L., L. Engström, M. Hallbeck, and A. Blomqvist. 2007. IL-1 beta and LPS induce anorexia by distinct mechanisms differentially dependent on microsomal prostaglandin E synthase-1. Am J Physiol-Reg I 292:R258-R267.

Elander, L., L. Engström, J. Ruud, L. Mackerlova, P.J. Jakobsson, D. Engblom, C. Nilsberth, and A. Blomqvist. 2009. Inducible prostaglandin E2 synthesis interacts in a temporally supplementary sequence with constitutive prostaglandin-synthesizing enzymes in creating the hypothalamicpituitary-adrenal axis response to immune challenge. J Neurosci 29:1404-1413.

Elander, L., J. Ruud, M. Korotkova, P.-J. Jakobsson, and A. Blomqvist. 2010. Cyclooxygenase-1 mediates the immediate corticosterone response to peripheral immune challenge induced by lipopolysaccharide. Neurosci Lett 470:10-12.

Elmquist, J.K., C.D. Breder, J.E. Sherin, T.E. Scammell, W.F. Hickey, D. Dewitt, and C.B. Saper. 1997a. Intravenous lipopolysaccharide induces cyclooxygenase 2-like immunoreactivity in rat brain perivascular microglia and meningeal macrophages. J Comp Neurol 381:119-129.

Elmquist, J.K., T.E. Scammell, C.D. Jacobson, and C.B. Safer. 1996. Distribution of Fos-like immunoreactivity in the rat brain following intravenous lipopolysaccharide administration. $J$ Comp Neurol 371:85-103.

Elmquist, J.K., T.E. Scammell, and C.B. Saper. 1997b. Mechanisms of CNS response to systemic immune challenge: the febrile response. Trends Neurosci 20:565-570.

Engblom, D., M. Ek, I.M. Andersson, S. Saha, M. Dahlström, P.J. Jakobsson, A. Ericsson-Dahlstrand, and A. Blomqvist. 2002. Induction of microsomal prostaglandin E synthase in the rat brain endothelium and parenchyma in adjuvant-induced arthritis. J Comp Neurol 452:205-214.

Engblom, D., S. Saha, L. Engström, M. Westman, L.P. Audoly, P.J. Jakobsson, and A. Blomqvist. 2003. Microsomal prostaglandin E synthase-1 is the central switch during immune-induced pyresis. Nat Neurosci 6:1137-1138. 
Engström, L., J. Ruud, A. Eskilsson, A. Larsson, L. Mackerlova, U. Kugelberg, H. Qian, A.M. Vasilache, P. Larsson, D. Engblom, M. Sigvardsson, J.I. Jonsson, and A. Blomqvist. 2012. Lipopolysaccharide-induced Fever depends on prostaglandin e2 production specifically in brain endothelial cells. Endocrinology 153:4849-4861.

Ensor, C.M., and H.-H. Tai. 1995. 15-Hydroxyprostaglandin dehydrogenase. J Lipid Mediat Cell 12:313-319.

Ericsson, A., C. Arias, and P.E. Sawchenko. 1997. Evidence for an intramedullary prostaglandindependent mechanism in the activation of stress-related neuroendocrine circuitry by intravenous interleukin-1. J Neurosci 17:7166-7179.

Ericsson, A., K.J. Kovacs, and P.E. Sawchenko. 1994. A functional anatomical analysis of central pathways subserving the effects of interleukin-1 on stress-related neuroendocrine neurons. $J$ Neurosci 14:897-913.

Ericsson, A., C. Liu, R.P. Hart, and P.E. Sawchenko. 1995. Type 1 interleukin-1 receptor in the rat brain: distribution, regulation, and relationship to sites of IL-1-induced cellular activation. $J$ Comp Neurol 361:681-698.

Eriksson, C., S. Nobel, B. Winblad, and M. Schultzberg. 2000. Expression of interleukin 1 alpha and beta, and interleukin 1 receptor antagonist mRNA in the rat central nervous system after peripheral administration of lipopolysaccharides. Cytokine 12:423-431.

Eskilsson A , M.E., Dufour S, Schwaninger M, Engblom D , Blomqvist A. 2014. Immune-induced fever is mediated by IL-6 receptors on brain endothelial cells coupled to STAT3 dependent induction of brain endothelial prostaglandin synthesis. J Neurosci 34:15957-15961.

Eskilsson, A., M. Tachikawa, K.I. Hosoya, and A. Blomqvist. 2014. Distribution of microsomal prostaglandin E synthase-1 in the mouse brain. J Comp Neurol 522:3229-3244.

Fantuzzi, G., and C.A. Dinarello. 1996. The inflammatory response in interleukin-1 beta-deficient mice: Comparison with other cytokine-related knock-out mice. J Leukocyte Biol 59:489-493.

Fantuzzi, G., G. Ku, M.W. Harding, D.J. Livingston, J.D. Sipe, K. Kuida, R.A. Flavell, and C.A. Dinarello. 1997. Response to local inflammation of IL-1 beta-converting enzyme- deficient mice. J Immunol 158:1818-1824.

Farooqui, A.A., H.C. Yang, T.A. Rosenberger, and L.A. Horrocks. 1997. Phospholipase A(2) and its role in brain tissue. $J$ Neurochem 69:889-901.

Farrar, W.L., P.L. Kilian, M.R. Ruff, J.M. Hill, and C.B. Pert. 1987. Visualization and characterization of interleukin-1 receptors in brain. J Immunol 139:459-463.

Feldberg, W., and K.P. Gupta. 1973. Pyrogen fever and prostaglandin-like activity in cerebrospinal fluid. J Physiol 228:41-53.

Feldberg, W., and P.N. Saxena. 1971a. Fever produced by prostaglandin E1. J Physiol 217:547-556.

Feldberg, W., and P.N. Saxena. 1971b. Fever produced in rabbits and cats by prostaglandin E1 injected into the cerebral ventricles. J Physiol 215:23P-24P.

Ferreira, S.H. 1972. Prostaglandins aspirin-like drugs and analgesia. Nat New Biol 240:200-203.

Ferreira, S.H., S. Moncada, and J.R. Vane. 1973. Prostaglandins and the mechanism of analgesia produced by aspirin-like drugs. Brit J Pharmacol 49:86-97.

Ferri, C.C., and A.V. Ferguson. 2005. Prostaglandin E-2 mediates cellular effects of interleukin-1 beta on parvocellular neurones in the paraventricular nucleus of the hypothalamus. $J$ Neuroendocrinol 17:498-508.

Fleming, E.F., K. Athirakul, M.I. Oliverio, M. Key, J. Goulet, B.H. Koller, and T.M. Coffman. 1998. Urinary concentrating function in mice lacking EP(3) receptors for prostaglandin $\mathrm{E}(2)$. Am $J$ Physiol-Renal 275:F955-F961. 
Fritz, M.K., AM.; Wilhems, D.; Örtegren, U.; Ridder, DA.; Hamzic, N.; Nilsberth, C.; Schwaninger, M.; Blomqvist, A.; Engblom, D. 2012. The affective component of systemic inflammation-a new role for prostaglandins. Soc Neurosci Abstr 587:

Fujino, H., and J.W. Regan. 2006. EP4 prostanoid receptor coupling to a pertussis toxin-sensitive inhibitory G protein. Mol Pharmacol 69:13-18.

Fujino, H., S. Salvi, and J.W. Regan. 2005. Differential regulation of phosphorylation of the cAMP response element-binding protein after activation of EP2 and EP4 prostanoid receptors by prostaglandin E-2. Mol Pharmacol 68:251-259.

Fujino, H., K.A. West, and J.W. Regan. 2002. Phosphorylation of glycogen synthase kinase-3 and stimulation of T-cell factor signaling following activation of EP2 and EP4 prostanoid receptors by prostaglandin E-2. J Biol Chem 277:2614-2619.

Furuyashiki, T., and S. Narumiya. 2011. Stress responses: the contribution of prostaglandin E(2) and its receptors. Nat Rev Endocrinol 7:163-175.

Garcia-Bueno, B., J. Serrats, and P.E. Sawchenko. 2009. Cerebrovascular Cyclooxygenase-1 Expression, Regulation, and Role in Hypothalamic-Pituitary-Adrenal Axis Activation by Inflammatory Stimuli. J Neurosci 29:12970-12981.

Garlanda, C., C.A. Dinarello, and A. Mantovani. 2013. The interleukin-1 family: back to the future. Immunity 39:1003-1018.

Gery, I., R.K. Gershon, and B.H. Waksman. 1972. Potentiation of the T-lymphocyte response to mitogens. I. The responding cell. J Exp Med 136:128-142.

Givalois, L., J. Dornand, M. Mekaouche, M.D. Solier, A.F. Bristow, G. Ixart, P. Siaud, I. Assenmacher, and G. Barbanel. 1994. Temporal cascade of plasma-level surges in ACTH, corticosterone, and cytokines in endotoxin-challenged rats. Am J Physiol 267:R164-R170.

Gobeil, F., I. Dumont, A.M. Marrache, A. Vazquez-Tello, S.G. Bernier, D. Abran, X. Hou, M.H. Beauchamp, C. Quiniou, A. Bouayad, S. Choufani, M. Bhattacharya, S. Molotchnikoff, A. Ribeiro-da-Silva, D.R. Varma, G. Bkaily, and S. Chemtob. 2002. Regulation of eNOS expression in brain endothelial cells by perinuclear EP3 receptors. Circ Res 90:682-689.

Goehler, L.E., A. Erisir, and R.P. Gaykema. 2006. Neural-immune interface in the rat area postrema. Neuroscience 140:1415-1434.

Goehler, L.E., R.P.A. Gaykema, N. Opitz, R. Reddaway, N. Badr, and M. Lyte. 2005. Activation in vagal afferents and central autonomic pathways: Early responses to intestinal infection with Campylobacter jejuni. Brain Behav Immun 19:334-344.

Goehler, L.E., J.K. Relton, D. Dripps, R. Kiechle, N. Tartaglia, S.F. Maier, and L.R. Watkins. 1997. Vagal Paraganglia Bind Biotinylated Interleukin-1 Receptor Antagonist: A Possible Mechanism for Immune-to-Brain Communication. Brain Res Bull 43:357-364.

Goldmann, E.E. 1913. Vitalfarbung am Zentralnervensystem. Beitrag zur Physio-Pathologie des Plexus Chorioideus und der Hirnhäute. Abhandl Konigl Preuss Akad Wiss 1:1-60.

Gosselin, D., and S. Rivest. 2008. MyD88 signaling in brain endothelial cells is essential for the neuronal activity and glucocorticoid release during systemic inflammation. Mol Psychiatry 13:480-497.

Gross, P.M., and A. Weindl. 1987. Peering Through the Windows of the Brain. J Cereb Blood F Met 7:663-672.

Guay, J., K. Bateman, R. Gordon, J. Mancini, and D. Riendeau. 2004. Carrageenan-induced paw edema in rat elicits a predominant prostaglandin E2 (PGE2) response in the central nervous system associated with the induction of microsomal PGE2 synthase-1. J Biol Chem 279:24866-24872. 
Hahn, E.L., K.D. Clancy, H.H. Tai, J.D. Ricken, L.K. He, and R.L. Gamelli. 1998. Prostaglandin E2 alterations during sepsis are partially mediated by endotoxin-induced inhibition of prostaglandin 15-hydroxydehydrogenase. J Trauma 44:777-781; discussion 781-772.

Hamberg, M., J. Svensson, T. Wakabayashi, and B. Samuelsson. 1974. Isolation and structure of two prostaglandin endoperoxides that cause platelet aggregation. P Natl Acad Sci USA 71:345-349.

Hamzic, N., A. Blomqvist, and C. Nilsberth. 2013a. Immune-Induced Expression of Lipocalin-2 in Brain Endothelial Cells: Relationship with Interleukin-6, Cyclooxygenase-2 and the Febrile Response. J Neuroendocrinol 25:271-280.

Hamzic, N., Y. Tang, A. Eskilsson, U. Kugelberg, J. Ruud, J.-I. Jönsson, A. Blomqvist, and C. Nilsberth. 2013b. Interleukin-6 primarily produced by non-hematopoietic cells mediates the lipopolysaccharide-induced febrile response. Brain Behav Immun 33:123-130.

Hansen, M.K., K.A. O'Connor, L.E. Goehler, L.R. Watkins, and S.F. Maier. 2001. The contribution of the vagus nerve in interleukin-1beta-induced fever is dependent on dose. Am J Physiol-Reg I 280:R929-934.

Haroon, E., C.L. Raison, and A.H. Miller. 2012. Psychoneuroimmunology Meets Neuropsychopharmacology: Translational Implications of the Impact of Inflammation on Behavior. Neuropsychopharmacol 37:137-162.

Harre, E.M., J. Roth, U. Pehl, M. Kueth, R. Gerstberger, and T. Hubschle. 2002. Molecular biology of thermoregulation - Selected contribution: Role of IL-6 in LPS-induced nuclear STAT3 translocation in sensory circumventricular organs during fever in rats. J Appl Physiol 92:26572666.

Hart, B.L. 1988. Biological basis of the bahavior of sick animals. Neurosci Biobehav Rev 12:123-137.

Hasegawa, H., M. Negishi, H. Katoh, and A. Ichikawa. 1997. Two isoforms of prostaglandin EP3 receptor exhibiting constitutive activity and agonist-dependent activity in Rho-mediated stress fiber formation. Biochem Biophys Res Co 234:631-636.

Hawkins, B.T., and T.P. Davis. 2005. The Blood-Brain Barrier/Neurovascular Unit in Health and Disease. Pharmacol Rev 57:173-185.

Hayden, M.S., and S. Ghosh. 2008. Shared principles in NF-kappaB signaling. Cell 132:344-362.

Heinrich, P.C., I. Behrmann, S. Haan, H.M. Hermanns, G. Muller-Newen, and F. Schaper. 2003. Principles of interleukin (IL)-6-type cytokine signalling and its regulation. Biochem J 374:1-20.

Herkenham, M., H.Y. Lee, and R.A. Baker. 1998. Temporal and spatial patterns of c-fos mRNA induced by intravenous interleukin-1: a cascade of non-neuronal cellular activation at the blood-brain barrier. J Comp Neurol 400:175-196.

Hirai, H., K. Tanaka, O. Yoshie, K. Ogawa, K. Kenmotsu, Y. Takamori, M. Ichimasa, K. Sugamura, M. Nakamura, S. Takano, and K. Nagata. 2001. Prostaglandin D2 selectively induces chemotaxis in T helper type 2 cells, eosinophils, and basophils via seven-transmembrane receptor CRTH2. $J$ Exp Med 193:255-261.

Hofer, H. 1958. Zur Morphologie der circumventricularen Organe des Zwischenhirnes der Saugetiere. Verh Dtsch Zool Ges 8:202-251.

Honda, A., Y. Sugimoto, T. Namba, A. Watabe, A. Irie, M. Negishi, S. Narumiya, and A. Ichikawa. 1993. Cloning and expression of a cDNA for mouse prostaglandin-E receptor EP2 subtype. $J$ Biol Chem 268:7759-7762.

Hopkins, S.J., and N.J. Rothwell. 1995. Cytokines and the nervous system. I: Expression and recognition. Trends Neurosci 18:83-88.

Horai, R., M. Asano, K. Sudo, H. Kanuka, M. Suzuki, M. Nishihara, M. Takahashi, and Y. Iwakura. 1998. Production of mice deficient in genes for interleukin (IL)-1 alpha, IL-1 beta, IL-1 
alpha/beta, and IL-1 receptor antagonist shows that IL-1 beta is crucial in turpentine-induced fever development and glucocorticoid secretion. J Exp Med 187:1463-1475.

Hori, T., T. Oka, M. Hosoi, M. Abe, and K. Oka. 2000. Hypothalamic mechanisms of pain modulatory actions of cytokines and prostaglandin E-2. In Neuroimmunomodulation: Perspectives at the New Millennium. A. Conti, G.J.M. Maestroni, S.M. McCann, E.M. Sternberg, J.M. Lipton, and C.C. Smith, editors. New York Acad Sciences, New York. 106-120.

Horton, E.W. 1964. Actions of prostaglandins E1, E2 and E3 on the central nervous system. Brit J Pharmacol Chemother 22:189-192.

Hosoi, T., Y. Okuma, T. Matsuda, and Y. Nomura. 2005. Novel pathway for LPS-induced afferent vagus nerve activation: Possible role of nodose ganglion. Auton Neurosci Basic 120:104-107.

Huang, Z.L., Y. Sato, T. Mochizuki, T. Okada, W.M. Qu, A. Yamatodani, Y. Urade, and O. Hayaishi. 2003. Prostaglandin E-2 activates the histaminergic system via the EP4 receptor to induce wakefulness in rats. J Neurosci 23:5975-5983.

Huber, J.D., R.D. Egleton, and T.P. Davis. 2001. Molecular physiology and pathophysiology of tight junctions in the blood-brain barrier. Trends Neurosci 24:719-725.

Huber, R.D., B. Gao, M.A. Sidler Pfandler, W. Zhang-Fu, S. Leuthold, B. Hagenbuch, G. Folkers, P.J. Meier, and B. Stieger. 2007. Characterization of two splice variants of human organic anion transporting polypeptide 3A1 isolated from human brain. Am J Physiol-Cell Ph 292:C795-806.

Hurst, S.M., T.S. Wilkinson, R.M. McLoughlin, S. Jones, S. Horiuchi, N. Yamamoto, S. Rose-John, G.M. Fuller, N. Topley, and S.A. Jones. 2001. IL-6 and its soluble receptor orchestrate a temporal switch in the pattern of leukocyte recruitment seen during acute inflammation. Immunity 14:705714.

Ibuki, T., K. Matsumura, Y. Yamazaki, T. Nozaki, Y. Tanaka, and S. Kobayashi. 2003. Cyclooxygenase-2 is induced in the endothelial cells throughout the central nervous system during carrageenan-induced hind paw inflammation; its possible role in hyperalgesia. $J$ Neurochem 86:318-328.

Inoue, W., K. Matsumura, K. Yamagata, T. Takemiya, T. Shiraki, and S. Kobayashi. 2002. Brainspecific endothelial induction of prostaglandin E-2 synthesis enzymes and its temporal relation to fever. Neurosci Res 44:51-61.

Irie, A., Y. Sugimoto, T. Namba, A. Harazono, A. Honda, A. Watabe, M. Negishi, S. Narumiya, and A. Ichikawa. 1993. 3rd isoform of the prostaglandin-E- receptor EP3 subtype with different Cterminal tail coupling to both stimulation and inhibition of adenylate-cyclase. Eur $J$ Biochem 217:313-318.

Isaacs, A., and J. Lindenmann. 1957. Virus interference. I. The interferon. P Roy Soc Lond B Bio 147:258-267.

Ivanov, A.I., R.S. Pero, A.C. Scheck, and A.A. Romanovsky. 2002. Prostaglandin E-2-synthesizing enzymes in fever: differential transcriptional regulation. Am J Physiol-Reg I 283:R1104-R1117.

Ivanov, A.I., and A.A. Romanovsky. 2004. Prostaglandin E2 as a mediator of fever: synthesis and catabolism. Front Biosci 9:1977-1993.

Ivanov, A.I., A.C. Scheck, and A.A. Romanovsky. 2003. Expression of genes controlling transport and catabolism of prostaglandin E-2 in lipopolysaccharide fever. Am J Physiol-Reg I 284:R698-R706.

Jakobsson, P.J., S. Thoren, R. Morgenstern, and B. Samuelsson. 1999. Identification of human prostaglandin E synthase: A microsomal, glutathione-dependent, inducible enzyme, constituting a potential novel drug target. P Natl Acad Sci USA 96:7220-7225.

Johnson, A.K., and P.M. Gross. 1993. Sensory circumventricular organs and brain homeostatic pathways. Faseb J 7:678-686. 
Johnson, P.M., S.K. Vogt, M.W. Burney, and L.J. Muglia. 2002. COX-2 inhibition attenuates anorexia during systemic inflammation without impairing cytokine production. Am J Physiol 282:E650E656.

Kamei, D., K. Yamakawa, Y. Takegoshi, M. Mikami-Nakanishi, Y. Nakatani, S. Oh-ishi, H. Yasui, Y. Azuma, N. Hirasawa, K. Ohuchi, H. Kawaguchi, Y. Ishikawa, T. Ishii, S. Uematsu, S. Akira, M. Murakami, and I. Kudo. 2004. Reduced pain hypersensitivity and inflammation in mice lacking microsomal prostaglandin E synthase-1. J Biol Chem 279:33684-33695.

Kanai, N., R. Lu, J.A. Satriano, Y. Bao, A.W. Wolkoff, and V.L. Schuster. 1995. Identification and characterization of a prostaglandin transporter. Science 268:866-869.

Kastin, A.J., and W. Pan. 2003. Peptide transport across the blood-brain barrier. Prog Drug Res 61:79100.

Kataoka, N., H. Hioki, T. Kaneko, and K. Nakamura. 2014. Psychological Stress Activates a Dorsomedial Hypothalamus-Medullary Raphe Circuit Driving Brown Adipose Tissue Thermogenesis and Hyperthermia. Cell Metab 20:346-358.

Kerr, J.F., A.H. Wyllie, and A.R. Currie. 1972. Apoptosis: a basic biological phenomenon with wideranging implications in tissue kinetics. Brit J Cancer 26:239-257.

Kiriyama, M., F. Ushikubi, T. Kobayashi, M. Hirata, Y. Sugimoto, and S. Narumiya. 1997. Ligand binding specificities of the eight types and subtypes of the mouse prostanoid receptors expressed in Chinese hamster ovary cells. Brit J Pharmacol 122:217-224.

Kluger, M.J. 1991. Fever -role of pyrogens and cryogens. Physiol Rev 71:93-127.

Kobayashi, Y., N. Ohshiro, A. Tsuchiya, N. Kohyama, M. Ohbayashi, and T. Yamamoto. 2004. Renal transport of organic compounds mediated by mouse organic anion transporter 3 (mOat3): further substrate specificity of mOat3. Drug Metab Dispos 32:479-483.

Konsman, J.P., G.N. Luheshi, R.M. Bluthe, and R. Dantzer. 2000. The vagus nerve mediates behavioural depression, but not fever, in response to peripheral immune signals; a functional anatomical analysis. Eur J Neurosci 12:4434-4446.

Konsman, J.P., P. Parnet, and R. Dantzer. 2002. Cytokine-induced sickness behaviour: mechanisms and implications. Trends Neurosci 25:154-159.

Konsman, J.P., S. Vigues, L. Mackerlova, A. Bristow, and A. Blomqvist. 2004. Rat brain vascular distribution of interleukin-1 type-1 receptor immunoreactivity: relationship to patterns of inducible cyclooxygenase expression by peripheral inflammatory stimuli. J Comp Neurol 472:113-129.

Kotani, M., I. Tanaka, Y. Ogawa, T. Usui, N. Tamura, K. Mori, S. Narumiya, T. Yoshimi, and K. Nakao. 1997. Structural organization of the human prostaglandin EP(3) receptor subtype gene (PTGER3). Genomics 40:425-434.

Kozak, W., M.J. Kluger, D. Soszynski, C.A. Conn, K. Rudolph, and H. Zheng. 1998. IL-6 and IL-1 beta in fever - Studies using cytokine-deficient (knockout) mice. In Mol Mechanisms of Fever. M.J. Kluger, T. Bartfai, and C.A. Dinarello, editors. New York Acad Sciences, New York. 3347.

Kozak, W., V. Poli, D. Soszynski, C.A. Conn, L.R. Leon, and M.J. Kluger. 1997. Sickness behavior in mice deficient in interleukin-6 during turpentine abscess and influenza pneumonitis. Am $J$ Physiol-Reg I 272:R621-R630.

Kujubu, D.A., B.S. Fletcher, B.C. Varnum, R.W. Lim, and H.R. Herschman. 1991. TIS10, a phorbol ester tumor promoter-inducible messenger-RNA from swiss 3T3 cells, encodes a novel prostaglandin synthase cyclooxygenase homolog. J Biol Chem 266:12866-12872.

Kumar, A., Y. Takada, A.M. Boriek, and B.B. Aggarwal. 2004. Nuclear factor-kappa B: its role in health and disease. J Mol Med-JMM 82:434-448. 
Kumar, H., T. Kawai, and S. Akira. 2011. Pathogen Recognition by the Innate Immune System. Int Rev Immunol 30:16-34.

Lacroix, S., D. Feinstein, and S. Rivest. 1998. The bacterial endotoxin lipopolysaccharide has the ability to target the brain in upregulating its membrane CD14 receptor within specific cellular populations. Brain Pathology 8:625-640.

Lacroix, S., and S. Rivest. 1998. Effect of acute systemic inflammatory response and cytokines on the transcription of the genes encoding cyclooxygenase enzymes (COX-1 and COX-2) in the rat brain. J Neurochem 70:452-466.

Laflamme, N., and S. Rivest. 1999. Effects of systemic immunogenic insults and circulating proinflammatory cytokines on the transcription of the inhibitory factor kappaB alpha within specific cellular populations of the rat brain. $J$ Neurochem 73:309-321.

Laflamme, N., and S. Rivest. 2001. Toll-like receptor 4: the missing link of the cerebral innate immune response triggered by circulating gram-negative bacterial cell wall components. Faseb J 15:155163.

Lazarus, M., K. Yoshida, R. Coppari, C.E. Bass, T. Mochizuki, B.B. Lowell, and C.B. Saper. 2007. EP3 prostaglandin receptors in the median preoptic nucleus are critical for fever responses. Nat Neurosci 10:1131-1133.

Lebel, E., L. Vallieres, and S. Rivest. 2000. Selective involvement of interleukin-6 in the transcriptional activation of the suppressor of cytokine signaling-3 in the brain during systemic immune challenges. Endocrinology 141:3749-3763.

Lee, H.Y., M.B. Whiteside, and M. Herkenham. 1998. Area postrema removal abolishes stimulatory effects of intravenous interleukin- $1 \beta$ on hypothalamic-pituitary-adrenal axis activity and c-fos mRNA in the hypothalamic paraventricular nucleus. Brain Res Bull 46:495-503.

Leon, L.R., C.A. Conn, M. Glaccum, and M.J. Kluger. 1996. IL-1 type I receptor mediates acute phase response to turpentine, but not lipopolysaccharide, in mice. Am J Physiol-Reg I 271:R1668R1675.

Leon, L.R., W. Kozak, J. Peschon, and M.J. Kluger. 1997. Exacerbated febrile responses to LPS, but not turpentine, in TNF double receptor knockout mice. Am J Physiol-Reg I 272:R563-R569.

Levesque, H., and O. Lafont. 2000. Aspirin throughout the ages: a historical review. Rev Med Interne 21 Suppl 1:8s-17s.

Li, J., X. Liang, Q. Wang, R.M. Breyer, L. McCullough, and K. Andreasson. 2008. Misoprostol, an anti-ulcer agent and PGE2 receptor agonist, protects against cerebral ischemia. Neurosci Lett 438:210-215.

Li, S., Y. Wang, K. Matsumura, L.R. Ballou, S.G. Morham, and C.M. Blatteis. 1999. The febrile response to lipopolysaccharide is blocked in cyclooxygenase-2(-/-), but not in cyclooxygenase1(-/-) mice. Brain Res 825:86-94.

Lindenmann, J. 2007. 50 years ago: how prepared were our minds? Biochimie 89:719-720.

Long, N.C., S.L. Kunkel, A.J. Vander, and M.J. Kluger. 1990. Antiserum against tumor-necrosis-factor enhances lipopolysaccharide fever in rats. Am J Physiol 258:R332-R337.

Lugarini, F., B.J. Hrupka, G.J. Schwartz, C.R. Plata-Salaman, and W. Langhans. 2002. A role for cyclooxygenase-2 in lipopolysaccharide-induced anorexia in rats. Am J Physiol-Reg I 283:R862R868.

March, C.J., B. Mosley, A. Larsen, D.P. Cerretti, G. Braedt, V. Price, S. Gillis, C.S. Henney, S.R. Kronheim, K. Grabstein, P.J. Conlon, T.P. Hopp, and D. Cosman. 1985. Cloning, sequence and expression of 2 distinct human interleukin-1 complementary DNAs. Nature 315:641-647. 
Mariathasan, S., K. Newton, D.M. Monack, D. Vucic, D.M. French, W.P. Lee, M. Roose-Girma, S. Erickson, and V.M. Dixit. 2004. Differential activation of the inflammasome by caspase-1 adaptors ASC and Ipaf. Nature 430:213-218.

Mastronardi, C., F. Whelan, O.A. Yildiz, J. Hannestad, D. Elashoff, S.M. McCann, J. Licinio, and M.L. Wong. 2007. Caspase 1 deficiency reduces inflammation-induced brain transcription. $P$ Natl Acad Sci USA 104:7205-7210.

Mathison, J.C., E. Wolfson, and R.J. Ulevitch. 1988. Participation of tumor necrosis factor in the mediation of gram-negative bacterial lipopolysaccheride-induced injury in rabbits. J Clin Invest 81:1925-1937.

Matsuda, T., T. Hori, and T. Nakashima. 1992. Thermal and PGE2 sensitivity of the organum vasculosum lamina terminalis region and preoptic are in rat-brain slices. $J$ Physiol 454:197-212.

Matsumura, H., T. Nakajima, T. Osaka, S. Satoh, K. Kawase, E. Kubo, S.S. Kantha, K. Kasahara, and O. Hayaishi. 1994. Prostaglandin D2-sensitive, sleep-promoting zone defined in the ventral surface of the rostral basal forebrain. P Natl Acad Sci USA 91:11998-12002.

Matsumura, K., C. Cao, M. Ozaki, H. Morii, K. Nakadate, and Y. Watanabe. 1998. Brain endothelial cells express cyclooxygenase-2 during lipopolysaccharide-induced fever: light and electron microscopic immunocytochemical studies. J Neurosci 18:6279-6289.

Matsuoka, Y., T. Furuyashiki, H. Bito, F. Ushikubi, Y. Tanaka, T. Kobayashi, S. Muro, N. Satoh, T. Kayahara, M. Higashi, A. Mizoguchi, H. Shichi, Y. Fukuda, K. Nakao, and S. Narumiya. 2003. Impaired adrenocorticotropic hormone response to bacterial endotoxin in mice deficient in prostaglandin E receptor EP1 and EP3 subtypes. P Natl Acad Sci USA 100:4132-4137.

Matsuwaki, T., A. Eskilsson, U. Kugelberg, J.I. Jonsson, and A. Blomqvist. 2014. Interleukin-1 beta induced activation of the hypothalamus-pituitary-adrenal axis is dependent on interleukin-1 receptors on non-hematopoietic cells. Brain Behav Immun 40:166-173.

Matzinger, P. 2002. The danger model: A renewed sense of self. Science 296:301-305.

McDermott, M.F., I. Aksentijevich, J. Galon, E.M. McDermott, B.W. Ogunkolade, M. Centola, E. Mansfield, M. Gadina, L. Karenko, T. Pettersson, J. McCarthy, D.M. Frucht, M. Aringer, Y. Torosyan, A.M. Teppo, M. Wilson, H.M. Karaarslan, Y. Wan, I. Todd, G. Wood, R. Schlimgen, T.R. Kumarajeewa, S.M. Cooper, J.P. Vella, C.I. Amos, J. Mulley, K.A. Quane, M.G. Molloy, A. Ranki, R.J. Powell, G.A. Hitman, J.J. O'Shea, and D.L. Kastner. 1999. Germline mutations in the extracellular domains of the $55 \mathrm{kDa}$ TNF receptor, TNFR1, define a family of dominantly inherited autoinflammatory syndromes. Cell 97:133-144.

McGonagle, D., and M.F. McDermott. 2006. A proposed classification of the immunological diseases. PLoS Med 3:e297.

McKay, L.I., and J.A. Cidlowski. 1999. Molecular control of immune/inflammatory responses: interactions between nuclear factor-kappa B and steroid receptor-signaling pathways. Endocr Rev 20:435-459.

Medzhitov, R., and C.A. Janeway. 2002. Decoding the patterns of self and nonself by the innate immune system. Science 296:298-300.

Menkin, V. 1944. Chemical basis of fever. Science 100:337-338.

Miller, A.J., S.J. Hopkins, and G.N. Luheshi. 1997. Sites of action of IL-1 in the development of fever and cytokine responses to tissue inflammation in the rat. Br J Pharmacol 120:1274-1279.

Milton, A.S., and S. Wendlandt. 1971. The effect of different environmental temperatures on the hyperpyrexia produced by the intraventricular injection of pyrogen, 5-hydroxytryptamine and prostaglandin E 1 in the conscious cat. J Physiol (Paris) 63:340-342. 
Mizel, S.B., J.J. Oppenheim, and D.L. Rosenstreich. 1978. Characterization of lymphocyte-activating factor (LAF) produced by macrophage cell line, P388D1.1. Enhancement of LAF production by activated T-lymphocytes. J Immunol 120:1497-1503.

Monje, M.L., S. Mizumatsu, J.R. Fike, and T.D. Palmer. 2002. Irradiation induces neural precursor-cell dysfunction. Nat Med 8:955-962.

Moore, D.M., S.F. Cheuk, J.D. Morton, R.D. Berlin, and W.B. Wood, Jr. 1970. Studies on the pathogenesis of fever. 18. Activation of leukocytes for pyrogen production. J Exp Med 131:179188.

Morham, S.G., R. Langenbach, C.D. Loftin, H.F. Tiano, N. Vouloumanos, J.C. Jennette, J.F. Mahler, K.D. Kluckman, A. Ledford, C.A. Lee, and O. Smithies. 1995. Prostaglandin synthase 2 gene disruption causes severe renal pathology in the mouse. Cell 83:473-482.

Morimoto, A., N. Murakami, T. Nakamori, Y. Sakata, and T. Watanabe. 1989a. Possible involvement of prostaglandin-E in development of ACTH response in rats induced by human recombinant interleukin-1. J Physiol 411:245-256.

Morimoto, A., Y. Sakata, T. Watanabe, and N. Murakami. 1989b. Characteristics of fever and acutephase response induced in rabbits by IL-1 and TNF. Am J Physiol 256:R35-R41.

Morrison, S.F., and K. Nakamura. 2011. Central neural pathways for thermoregulation. Front Biosci 16:74-104

Muldoon, L.L., J.I. Alvarez, D.J. Begley, R.J. Boado, G.J. Del Zoppo, N.D. Doolittle, B. Engelhardt, J.M. Hallenbeck, R.R. Lonser, J.R. Ohlfest, A. Prat, M. Scarpa, R.J. Smeyne, L.R. Drewes, and E.A. Neuwelt. 2013. Immunologic privilege in the central nervous system and the blood-brain barrier. J Cereb Blood F Met 33:13-21.

Murakami, M., K. Nakashima, D. Kamei, S. Masuda, Y. Ishikawa, T. Ishii, Y. Ohmiya, K. Watanabe, and I. Kudo. 2003. Cellular prostaglandin E2 production by membrane-bound prostaglandin E synthase-2 via both cyclooxygenases-1 and -2. J Biol Chem 278:37937-37947.

Murakami, M., H. Naraba, T. Tanioka, N. Semmyo, Y. Nakatani, F. Kojima, T. Ikeda, M. Fueki, A. Ueno, S. Oh-ishi, and I. Kudo. 2000. Regulation of prostaglandin E-2 biosynthesis by inducible membrane-associated prostaglandin E-2 synthase that acts in concert with cyclooxygenase-2. $J$ Biol Chem 275:32783-32792.

Nadeau, S., and S. Rivest. 1999a. Effects of circulating tumor necrosis factor on the neuronal activity and expression of the genes encoding the tumor necrosis factor receptors (p55 and p75) in the rat brain: a view from the blood-brain barrier. Neuroscience 93:1449-1464.

Nadeau, S., and S. Rivest. 1999b. Regulation of the gene encoding tumor necrosis factor alpha (TNFalpha) in the rat brain and pituitary in response in different models of systemic immune challenge. J Neuropathol Exp Neurol 58:61-77.

Nagy, A. 2000. Cre recombinase: The universal reagent for genome tailoring. Genesis 26:99-109.

Nakamura, K. 2011. Central circuitries for body temperature regulation and fever. Am J Physiol-Reg I 301:R1207-R1228.

Nakamura, K., T. Kaneko, Y. Yamashita, H. Hasegawa, H. Katoh, and M. Negishi. 2000. Immunohistochemical localization of prostaglandin EP3 receptor in the rat nervous system. $J$ Comp Neurol 421:543-569.

Nakamura, K., K. Matsumura, T. Kaneko, S. Kobayashi, H. Katoh, and M. Negishi. 2002. The rostral raphe pallidus nucleus mediates pyrogenic transmission from the preoptic area. J Neurosci 22:4600-4610.

Nakamura, Y., K. Nakamura, K. Matsumura, S. Kobayashi, T. Kaneko, and S.F. Morrison. 2005. Direct pyrogenic input from prostaglandin EP3 receptor-expressing preoptic neurons to the dorsomedial hypothalamus. Eur J Neurosci 22:3137-3146. 
Nakano, J., A.V. Prancan, and S.E. Moore. 1972. Metabolism of prostaglandin E 1 in the cerebral cortex and cerebellum of the dog and rat. Brain Res 39:545-548.

Namba, T., Y. Sugimoto, M. Negishi, A. Irie, F. Ushikubi, A. Kakizuka, S. Ito, A. Ichikawa, and S. Narumiya. 1993. Aletrnative splicing of C-terminal tail of prostaglandin-E receptor subtype-EP3 determines G-protein specificity. Nature 365:166-170.

Narumiya, S., and G.A. FitzGerald. 2001. Genetic and pharmacological analysis of prostanoid receptor function. J Clin Invest 108:25-30.

Nature, T.C.F.I. 2002. The Chipping Forecast II. Nat Genet 32:461-552.

Nauts, H.C., W.E. Swift, and B.L. Coley. 1946. The treatment of malignant tumors by bacterial toxins as developed by the late William B. Coley, M.D., reviewed in the light of modern research. Cancer Res 6:205-216.

Negishi, M., H. Hasegawa, and A. Ichikawa. 1996. Prostaglandin E receptor EP3 gamma isoform, with mostly full constitutive Gi activity and agonist-dependent Gs activity. Febs Lett 386:165-168.

Negishi, M., S. Ito, and O. Hayaishi. 1989. Prostaglandin-E receptors in bovine adrenal-medulla are coupled to adenylate-cyclase via $\mathrm{Gi}$ and to phosphoinositide metabolism in a pertussis toxininsensitive manner. J Biol Chem 264:3916-3923.

Neuschaferrube, F., C. Devries, K. Hanecke, K. Jungermann, and G.P. Puschel. 1994. Molecularcloning and expression of a prostaglandin E2 receptor of the EP(3-beta) subtype from rat hepatocytes. Febs Lett 351:119-122.

Nilsberth, C., L. Elander, N. Hamzic, M. Norell, J. Lonn, L. Engstrom, and A. Blomqvist. 2009a. The role of interleukin-6 in lipopolysaccharide-induced fever by mechanisms independent of prostaglandin E2. Endocrinology 150:1850-1860.

Nilsberth, C., N. Hamzic, M. Norell, and A. Blomqvist. 2009b. Peripheral lipopolysaccharide administration induces cytokine mRNA expression in the viscera and brain of fever-refractory mice lacking microsomal prostaglandin E synthase-1. J Neuroendocrinol 21:715-721.

Nishio, T., H. Adachi, R. Nakagomi, T. Tokui, E. Sato, M. Tanemoto, K. Fujiwara, M. Okabe, T. Onogawa, T. Suzuki, D. Nakai, K. Shiiba, M. Suzuki, H. Ohtani, Y. Kondo, M. Unno, S. Ito, K. Iinuma, K. Nunoki, S. Matsuno, and T. Abe. 2000. Molecular identification of a rat novel organic anion transporter moat1, which transports prostaglandin $\mathrm{D}(2)$, leukotriene $\mathrm{C}(4)$, and taurocholate. Biochem Biophys Res Co 275:831-838.

O'Connor, E.T., K.D. O'Halloran, and J.F.X. Jones. 2012. Pro-inflammatory cytokines do not affect basal or hypoxia-stimulated discharge of rat vagal paraganglia. Exp Physiol 97:1203-1210.

O'Neill, L.A. 2008. The interleukin-1 receptor/Toll-like receptor superfamily: 10 years of progress. Immunol Rev 226:10-18.

O'Neill, L.A.J., D. Golenbock, and A.G. Bowie. 2013. The history of Toll-like receptors - redefining innate immunity. Nat Rev Immunol 13:453-460.

Ohinata, K., K. Suetsugu, Y. Fujiwara, and M. Yoshikawa. 2006. Activation of prostaglandin E receptor EP4 subtype suppresses food intake in mice. Prostag Oth Lipid M 81:31-36.

Oka, K., T. Oka, and T. Hori. 1997. Prostaglandin E-2 may induce hyperthermia through EP1 receptor in the anterior wall of the third ventricle and neighboring preoptic regions. Brain Res 767:92-99.

Oka, T., and T. Hori. 1994. EP1- receptor mediation of prostaglandin E2- induced hyperthermia in rats. Am J Physiol 267:R289-R294.

Oka, T., K. Oka, T. Kobayashi, Y. Sugimoto, A. Ichikawa, F. Ushikubi, S. Narumiya, and C.B. Saper. 2003a. Characteristics of thermoregulatory and febrile responses in mice deficient in prostaglandin EP1 and EP3 receptors. J Physiol 551:945-954. 
Oka, T., K. Oka, and C.B. Saper. 2003b. Contrasting effects of E type prostaglandin (EP) receptor agonists on core body temperature in rats. Brain Res 968:256-262.

Oka, T., K. Oka, T.E. Scammell, C. Lee, J.F. Kelly, F. Nantel, J.K. Elmquist, and C.B. Saper. 2000. Relationship of EP(1-4) prostaglandin receptors with rat hypothalamic cell groups involved in lipopolysaccharide fever responses. J Comp Neurol 428:20-32.

Oka, Y., T. Ibuki, K. Matsumura, M. Namba, Y. Yamazaki, S. Poole, Y. Tanaka, and S. Kobayashi. 2007. Interleukin-6 is a candidate molecule that transmits inflammatory information to the CNS. Neuroscience 145:530-538.

Okabe, M., M. Ikawa, K. Kominami, T. Nakanishi, and Y. Nishimune. 1997. 'Green mice' as a source of ubiquitous green cells. Febs Lett 407:313-319.

Oke, S.L., and K.J. Tracey. 2008. From CNI-1493 to the immunological homunculus: physiology of the inflammatory reflex. J Leukocyte Biol 83:512-517.

Oldfield, S., B.D. Grubb, and L.F. Donaldson. 2001. Identification of a prostaglandin E2 receptor splice variant and its expression in rat tissues. Prostag Oth Lipid M 63:165-173.

Onoe, H., Y. Watanabe, K. Ono, Y. Koyama, and O. Hayaishi. 1992. Prostaglandin-E2 exerts an awakening effect in the posterior hypothalamus at a site distinct from that mediating its febrile action in the anterior hypothalamus. J Neurosci 12:2715-2725.

Ootsuka, Y., W.W. Blessing, A.A. Steiner, and A.A. Romanovsky. 2008. Fever response to intravenous prostaglandin E2 is mediated by the brain but does not require afferent vagal signaling. Am $J$ Physiol-Reg I 294:R1294-1303.

Oppenheim, J.J., E.J. Kovacs, K. Matsushima, and S.K. Durum. 1986. There is more than one interleukin-1. Immunol Today 7:45-56.

Ota, K., T. Katafuchi, A. Takaki, and T. Hori. 1997. AV3V neurons that send axons to hypothalamic nuclei respond to the systemic injection of IL-1 beta. Am J Physiol-Reg I 272:R532-R540.

Palsson-McDermott, E.M., and L.A.J. O'Neill. 2004. Signal transduction by the lipopolysaccharide receptor, Toll-like receptor-4. Immunology 113:153-162.

Pecchi, E., M. Dallaporta, S. Thirion, C. Salvat, F. Berenbaum, A. Jean, and J.D. Troadec. 2006. Involvement of central microsomal prostaglandin E synthase-1 in IL-1 beta-induced anorexia. Physiol Genomics 25:485-492.

Philipp-Dormston, W.K., and R. Siegert. 1974. Identification of prostaglandin E by radioimmunoassay in cerebrospinal fluid during endotoxin fever. Naturwissenschaften 61:134-135.

Piper, P.J., J.R. Vane, and J.H. Wyllie. 1970. Inactivation of prostaglandins by the lungs. Nature 225:600-604.

Poltorak, A., X.L. He, I. Smirnova, M.Y. Liu, C. Van Huffel, X. Du, D. Birdwell, E. Alejos, M. Silva, C. Galanos, M. Freudenberg, P. Ricciardi-Castagnoli, B. Layton, and B. Beutler. 1998a. Defective LPS signaling in C3H/HeJ and C57BL/10ScCr mice: Mutations in Tlr4 gene. Science 282:2085-2088.

Poltorak, A., I. Smirnova, X.L. He, M.Y. Liu, C. Van Huffel, D. Birdwell, E. Alejos, M. Silva, X. Du, P. Thompson, E.K.L. Chan, J. Ledesma, B. Roe, S. Clifton, S. Vogel, and B. Beutler. 1998b. Genetic and physical mapping of the Lps locus: Identification of the Toll-4 receptor as a candidate gene in the critical region. Blood Cell Mol Dis 24:340-355.

Posadas, I., M. Bucci, F. Roviezzo, A. Rossi, L. Parente, L. Sautebin, and G. Cirino. 2004. Carrageenaninduced mouse paw oedema is biphasic, age-weight dependent and displays differential nitric oxide cyclooxygenase-2 expression. Br J Pharmacol 142:331-338.

Prajapati, V.D., P.M. Maheriya, G.K. Jani, and H.K. Solanki. 2014. Carrageenan: A natural seaweed polysaccharide and its applications. Carbohyd Polym 105:97-112. 
Qin, L.Y., X.F. Wu, M.L. Block, Y.X. Liu, G.R. Bresse, J.S. Hong, D.J. Knapp, and F.T. Crews. 2007. Systemic LPS causes chronic neuroinflammation and progressive neurodegeneration. Glia 55:453-462.

Quan, N. 2008. Immune-to-brain signaling: How important are the blood-brain barrier-independent pathways? Mol Neurobiol 37:142-152.

Quan, N. 2014. In-depth conversation: Spectrum and kinetics of neuroimmune afferent pathways. Brain Behav Immun

Quan, N., M. Whiteside, and M. Herkenham. 1998. Time course and localization patterns of interleukin1 beta messenger RNA expression in brain and pituitary after peripheral administration of lipopolysaccharide. Neuroscience 83:281-293.

Quan, N., M. Whiteside, L. Kim, and M. Herkenham. 1997. Induction of inhibitory factor kappaBalpha mRNA in the central nervous system after peripheral lipopolysaccharide administration: an in situ hybridization histochemistry study in the rat. P Natl Acad Sci USA 94:10985-10990.

Record, M., K. Carayon, M. Poirot, and S. Silvente-Poirot. 2014. Exosomes as new vesicular lipid transporters involved in cell-cell communication and various pathophysiologies. BBA- Mol Cell Biol L 1841:108-120.

Reid, G., P. Wielinga, N. Zelcer, I. van der Heijden, A. Kuil, M. de Haas, J. Wijnholds, and P. Borst. 2003. The human multidrug resistance protein MRP4 functions as a prostaglandin efflux transporter and is inhibited by nonsteroidal antiinflammatory drugs. P Natl Acad Sci USA 100:9244-9249.

Reimann, H.A. 1949. Periodic disease; periodic fever, periodic abdominalgia, cyclic neutropenia, intermittent arthralgia, angioneurotic edema, anaphylactoid purpura and periodic paralysis. $J \mathrm{Am}$ Med Assoc 141:175-183.

Reyes, T.M., J.R. Walker, C. DeCino, J.B. Hogenesch, and P.E. Sawchenko. 2003. Categorically distinct acute stressors elicit dissimilar transcriptional profiles in the paraventricular nucleus of the hypothalamus. J Neurosci 23:5607-5616.

Ridder, D.A., M.F. Lang, S. Salinin, J.P. Roderer, M. Struss, C. Maser-Gluth, and M. Schwaninger. 2011. TAK1 in brain endothelial cells mediates fever and lethargy. J Exp Med 208:2615-2623.

Rivest, S. 2009. Regulation of innate immune responses in the brain. Nat Rev Immunol 9:429-439.

Rivest, S. 2010. Interactions between the immune and neuroendocrine systems. Prog Brain Res 181:4353.

Rivest, S., S. Lacroix, L. Vallieres, S. Nadeau, J. Zhang, and N. Laflamme. 2000. How the blood talks to the brain parenchyma and the paraventricular nucleus of the hypothalamus during systemic inflammatory and infectious stimuli. P Soc Exp Biol Med 223:22-38.

Rizvi, T.A., A.Z. Murphy, M. Ennis, M.M. Behbehani, and M.T. Shipley. 1996. Medial preoptic area afferents to periaqueductal gray medullo-output neurons: A combined Fos and tract tracing study. J Neurosci 16:333-344.

Romanovsky, A.A. 2004. Signaling the brain in the early sickness syndrome: are sensory nerves involved? Front Biosci 9:494-504.

Romanovsky, A.A., V.A. Kulchitsky, C.T. Simons, and N. Sugimoto. 1998. Methodology of fever research: why are polyphasic fevers often thought to be biphasic? Am J Physiol-Reg I 275:R332R338.

Ross, G., J. Roth, B. Störr, K. Voigt, and E. Zeisberger. 2000. Afferent nerves are involved in the febrile response to injection of LPS into artificial subcutaneous chambers in guinea pigs. Physiol Behav 71:305-313.

Roth, J., and G.E. De Souza. 2001. Fever induction pathways: evidence from responses to systemic or local cytokine formation. Braz J Med Biol Res 34:301-314. 
Roth, J., E.M. Harre, C. Rummel, R. Gerstberger, and T. Hubschle. 2004. Signaling the brain in systemic inflammation: Role of sensory circumventricular organs. Front Biosci 9:290-300.

Rothwell, N.J., and S.J. Hopkins. 1995. Cytokines and the nervous-system.2. Actions and mechanisms of action. Trends Neurosci 18:130-136.

Rothwell, N.J., and G.N. Luheshi. 2000. Interleukin 1 in the brain: biology, pathology and therapeutic target. Trends Neurosci 23:618-625.

Rummel, C., S.W. Barth, T. Voss, S. Korte, R. Gerstberger, T. Hubschle, and J. Roth. 2005. Localized vs. systemic inflammation in guinea pigs: a role for prostaglandins at distinct points of the fever induction pathways? Am J Physiol-Reg I 289:R340-R347.

Rummel, C., K. Matsumura, and G.N. Luheshi. 2011. Circulating IL-6 contributes to peripheral LPSinduced mPGES-1 expression in the rat brain. Brain Res Bull 86:319-325.

Ruud, J., A. Nilsson, L.E. Ruud, W.H. Wang, C. Nilsberth, B.M. Iresjo, K. Lundholm, D. Engblom, and A. Blomqvist. 2013a. Cancer-induced anorexia in tumor-bearing mice is dependent on cyclooxygenase-1. Brain Behav Immun 29:124-135.

Ruud, J., D.B. Wilhelms, A. Nilsson, A. Eskilsson, Y.J. Tang, P. Strohle, R. Caesar, M. Schwaninger, T. Wunderlich, F. Backhed, D. Engblom, and A. Blomqvist. 2013b. Inflammation- and tumorinduced anorexia and weight loss require MyD88 in hematopoietic/myeloid cells but not in brain endothelial or neural cells. Faseb J 27:1973-1980.

Ryan, G.B., and G. Majno. 1977. Acute-inflammation- review. Am J Pathol 86:183-276.

Saha, S., L. Engström, L. Mackerlova, P.J. Jakobsson, and A. Blomqvist. 2005. Impaired febrile responses to immune challenge in mice deficient in microsomal prostaglandin E synthase-1. Am J Physiol-Reg I 288:R1100-R1107.

Samad, T.A., K.A. Moore, A. Sapirstein, S. Billet, A. Allchorne, S. Poole, J.V. Bonventre, and C.J. Woolf. 2001. Interleukin-1[beta]-mediated induction of Cox-2 in the CNS contributes to inflammatory pain hypersensitivity. Nature 410:471-475.

Samuelsson, B. 2012. Role of basic science in the development of new medicines: examples from the eicosanoid field. J Biol Chem 287:10070-10080.

Samuelsson, B., E. Granström, K. Green, M. Hamberg, and S. Hammarström. 1975. Prostaglandins. Annu Rev Biochem 44:669-695.

Samuelsson, B., R. Mörgenstern, and P.J. Jakobsson. 2007. Membrane prostaglandin E synthase-1: A novel therapeutic target. Pharmacol Rev 59:207-224.

Saper, C.B., and B.B. Lowell. 2014. The hypothalamus. Curr Biol 24:R1111-1116.

Saper, C.B., A.A. Romanovsky, and T.E. Scammell. 2012. Neural circuitry engaged by prostaglandins during the sickness syndrome. Nat Neurosci 15:1088-1095.

Sapolsky, R., C. Rivier, G. Yamamoto, P. Plotsky, and W. Vale. 1987. Interleukin-1 stimulates the secretion of hypothalamic corticotropin-releasing factor. Science 238:522-524.

Scammell, T.E., J.K. Elmquist, J.D. Griffin, and C.B. Saper. 1996. Ventromedial preoptic prostaglandin E2 activates fever-producing autonomic pathways. J Neurosci 16:6246-6254.

Scammell, T.E., J.D. Griffin, J.K. Elmquist, and C.B. Saper. 1998. Microinjection of a cyclooxygenase inhibitor into the anteroventral preoptic region attenuates LPS fever. Am J Physiol-Reg I 274:R783-R789.

Scheller, J., A. Chalaris, D. Schmidt-Arras, and S. Rose-John. 2011. The pro- and anti-inflammatory properties of the cytokine interleukin-6. Biochim Biophys Acta 1813:878-888.

Schiltz, J.C., and P.E. Sawchenko. 2002. Distinct brain vascular cell types manifest inducible cyclooxygenase expression as a function of the strength and nature of immune insults. J Neurosci 22:5606-5618. 
Schmidt, E.E., and U. Schibler. 1995. Cell size regulation, a mechanism that controls cellular RNA accumulation: consequences on regulation of the ubiquitous transcription factors Oct1 and NFY and the liver-enriched transcription factor DBP. J Cell Biol 128:467-483.

Schroder, K., and J. Tschopp. 2010. The Inflammasomes. Cell 140:821-832.

Schultzberg, M., C. Lindberg, Å.F. Aronsson, E. Hjorth, S.D. Spulber, and M. Oprica. 2007. Inflammation in the nervous system - Physiological and pathophysiological aspects. Physiol Behav 92:121-128.

Schuster, V.L. 1998. Molecular mechanisms of prostaglandin transport. Annu Rev Physiol 60:221-242.

Schuster, V.L. 2002. Prostaglandin transport. Prostag Oth Lipid M 68-69:633-647.

Serrano, G.E., N. Lelutiu, A. Rojas, S. Cochi, R. Shaw, C.D. Makinson, D. Wang, G.A. FitzGerald, and R. Dingledine. 2011. Ablation of Cyclooxygenase-2 in Forebrain Neurons is Neuroprotective and Dampens Brain Inflammation after Status Epilepticus. J Neurosci 31:14850-14860.

Serrats, J., J.C. Schiltz, B. Garcia-Bueno, N. van Rooijen, T.M. Reyes, and P.E. Sawchenko. 2010. Dual Roles for Perivascular Macrophages in Immune-to-Brain Signaling. Neuron 65:94-106.

Shimazu, R., S. Akashi, H. Ogata, Y. Nagai, K. Fukudome, K. Miyake, and M. Kimoto. 1999. MD-2, a Molecule that Confers Lipopolysaccharide Responsiveness on Toll-like Receptor 4. J Exp Med 189:1777-1782.

Shiraya, K., T. Hirata, R. Hatano, S. Nagamori, P. Wiriyasermkul, P. Jutabha, M. Matsubara, S. Muto, H. Tanaka, S. Asano, N. Anzai, H. Endou, A. Yamada, H. Sakurai, and Y. Kanai. 2010. A Novel Transporter of SLC22 Family Specifically Transports Prostaglandins and Co-localizes with 15Hydroxyprostaglandin Dehydrogenase in Renal Proximal Tubules. J Biol Chem 285:2214122151.

Simard, A.R., D. Soulet, G. Gowing, J.P. Julien, and S. Rivest. 2006. Bone marrow-derived microglia play a critical role in restricting senile plaque formation in Alzheimer's disease. Neuron 49:489502.

Sims, J.E., and D.E. Smith. 2010. The IL-1 family: Regulators of immunity. Nat Rev Immunol 10:89102.

Siso, S., M. Jeffrey, and L. Gonzalez. 2010. Sensory circumventricular organs in health and disease. Acta Neuropathol 120:689-705.

Six, D.A., and E.A. Dennis. 2000. The expanding superfamily of phospholipase A2 enzymes: classification and characterization. Biochim Biophys Acta 1488:1-19.

Skibicka, K.P., A.L. Alhadeff, T.M. Leichner, and H.J. Grill. 2011. Neural Controls of Prostaglandin 2 Pyrogenic, Tachycardic, and Anorexic Actions Are Anatomically Distributed. Endocrinology 152:2400-2408.

Smith, W.L., Y. Urade, and P.J. Jakobsson. 2011. Enzymes of the cyclooxygenase pathways of prostanoid biosynthesis. Chem Rev 111:5821-5865.

Steiner, A.A., S. Chakravarty, A.Y. Rudaya, M. Herkenham, and A.A. Romanovsky. 2006a. Bacterial lipopolysaccharide fever is initiated via Toll-like receptor 4 on hematopoietic cells. Blood 107:4000-4002.

Steiner, A.A., J.C. Hunter, S.M. Phipps, T.B. Nucci, D.L. Oliveira, J.L. Roberts, A.C. Scheck, D.L. Simmons, and A.A. Romanovsky. 2009. Cyclooxygenase-1 or-2-which one mediates lipopolysaccharide-induced hypothermia? Am J Physiol-Reg I 297:R485-R494.

Steiner, A.A., A.I. Ivanov, J. Serrats, H. Hosokawa, A.N. Phayre, J.R. Robbins, J.L. Roberts, S. Kobayashi, K. Matsumura, P.E. Sawchenko, and A.A. Romanovsky. 2006b. Cellular and molecular bases of the initiation of fever. PLoS Biol 4:e284. 
Steinmetz, T., M. Schaadt, R. Gahl, V. Schenk, V. Diehl, and M. Pfreundschuh. 1988. Phase-I study of 24-hour continuos intravenous-infusion of recombinant human-tumor necrosis factor. $J$ Biol Resp Modif 7:417-423.

Sternberg, E.M. 2006. Neural regulation of innate immunity: a coordinated nonspecific host response to pathogens. Nat Rev Immunol 6:318-328.

Sugimoto, Y., and S. Narumiya. 2007. Prostaglandin E receptors. J Biol Chem 282:11613-11617.

Sugimoto, Y., M. Negishi, Y. Hayashi, T. Namba, A. Honda, A. Watabe, M. Hirata, S. Narumiya, and A. Ichikawa. 1993. 2 isoforms of the EP3 receptor with different carboxyl-terminal domainsidentical ligand-binding properties and different coupling properties with Gi proteins. $J$ Biol Chem 268:2712-2718.

Sugimoto, Y., R. Shigemoto, T. Namba, M. Negishi, N. Mizuno, S. Narumiya, and A. Ichikawa. 1994. Distribution of the messenger RNA for the prostaglandin E receptor subtype EP3 in the mouse nervous system. Neuroscience 62:919-928.

Sundgren-Andersson, A.K., P. Ostlund, and T. Bartfai. 1998. IL-6 is essential in TNF-alpha-induced fever. Am J Physiol 275:R2028-2034.

Swiergiel, A.H., and A.J. Dunn. 2002. Distinct roles for cyclooxygenases 1 and 2 in interleukin-1induced behavioral changes. J Pharmacol Exp Ther 302:1031-1036.

Tachikawa, M., G. Ozeki, T. Higuchi, S. Akanuma, K. Tsuji, and K. Hosoya. 2012. Role of the bloodcerebrospinal fluid barrier transporter as a cerebral clearance system for prostaglandin E(2) produced in the brain. $J$ Neurochem 123:750-760.

Tai, H.-H., C.M. Ensor, M. Tong, H. Zhou, and F. Yan. 2002. Prostaglandin catabolizing enzymes. Prostag Oth Lipid M 68-69:483-493.

Tai, H.H., H. Cho, M. Tong, and Y. Ding. 2006. NAD(+)-linked 15-hydroxyprostaglandin dehydrogenase: Structure and biological functions. Curr Pharm Design 12:955-962.

Takao, T., D.E. Tracey, W.M. Mitchell, and E.B. Desouza. 1990. Interleukin-1 receptors in mousebrain - characterization and neuronal localization. Endocrinology 127:3070-3078.

Takeuchi, K., T. Abe, N. Takahashi, and K. Abe. 1993. Molecular-cloning and intrarenal localization of rat prostaglandin-E2 receptor EP3 subtype. Biochem Biophys Res Co 194:885-891.

Tanioka, T., Y. Nakatani, N. Semmyo, M. Murakami, and I. Kudo. 2000. Molecular identification of cytosolic prostaglandin E-2 synthase that is functionally coupled with cyclooxygenase- 1 in immediate prostaglandin E-2 biosynthesis. J Biol Chem 275:32775-32782.

Thoren, S., and P.J. Jakobsson. 2000. Coordinate up- and down-regulation of glutathione-dependent prostaglandin E synthase and cyclooxygenase-2 in A549 cells - Inhibition by NS-398 and leukotriene C-4. Eur J Biochem 267:6428-6434.

Tracey, D., L. Klareskog, E.H. Sasso, J.G. Salfeld, and P.P. Tak. 2008. Tumor necrosis factor antagonist mechanisms of action: A comprehensive review. Phamacol Therapeut 117:244-279.

Tracey, K.J., B. Beutler, S.F. Lowry, J. Merryweather, S. Wolpe, I.W. Milsark, R.J. Hariri, T.J. Fahey, A. Zentella, J.D. Albert, G.T. Shires, and A. Cerami. 1986. Shock and tissue-injury induced by recombinant human cachectin. Science 234:470-474.

Trebino, C.E., J.L. Stock, C.P. Gibbons, B.M. Naiman, T.S. Wachtmann, J.P. Umland, K. Pandher, J.M. Lapointe, S. Saha, M.L. Roach, D. Carter, N.A. Thomas, B.A. Durtschi, J.D. McNeish, J.E. Hambor, P.J. Jakobsson, T.J. Carty, J.R. Perez, and L.P. Audoly. 2003. Impaired inflammatory and pain responses in mice lacking an inducible prostaglandin E synthase. P Natl Acad Sci USA 100:9044-9049.

Tsuchiya, H., T. Oka, K. Nakamura, A. Ichikawa, C.B. Saper, and Y. Sugimoto. 2008. Prostaglandin E2 attenuates preoptic expression of GABAA receptors via EP3 receptors. $J$ Biol Chem 283:11064-11071. 
Turner, M.D., B. Nedjai, T. Hurst, and D.J. Pennington. 2014. Cytokines and chemokines: At the crossroads of cell signalling and inflammatory disease. Biochim Biophys Acta

Turrin, N.P., M.M. Plante, M. Lessard, and S. Rivest. 2007. Irradiation does not compromise or exacerbate the innate immune response in the brains of mice that were transplanted with bone marrow stem cells. Stem Cells 25:3165-3172.

Turrin, N.P., and S. Rivest. 2004. Unraveling the molecular details involved in the intimate link between the immune and neuroendocrine systems. Exp Biol Med 229:996-1006.

Ueno, A., H. Matsumoto, H. Naraba, Y. Ikeda, F. Ushikubi, T. Matsuoka, S. Narumiya, Y. Sugimoto, A. Ichikawa, and S. Oh-ishi. 2001. Major roles of prostanoid receptors IP and EP3 in endotoxininduced enhancement of pain perception. Biochem Pharmacol 62:157-160.

Ulrich-Lai, Y.M., and J.P. Herman. 2009. Neural regulation of endocrine and autonomic stress responses. Nat Rev Neurosci 10:397-409.

Urade, Y., K. Kitahama, H. Ohishi, T. Kaneko, N. Mizuno, and O. Hayaishi. 1993. Dominant expression of mRNA for prostaglandin D synthase in leptomeninges, choroid plexus, and oligodendrocytes of the adult rat brain. P Natl Acad Sci USA 90:9070-9074.

Ushikubi, F., E. Segi, Y. Sugimoto, T. Murata, T. Matsuoka, T. Kobayashi, H. Hizaki, K. Tuboi, M. Katsuyama, A. Ichikawa, T. Tanaka, N. Yoshida, and S. Narumiya. 1998. Impaired febrile response in mice lacking the prostaglandin E receptor subtype EP3. Nature 395:281-284.

Vallieres, L., and S. Rivest. 1997. Regulation of the genes encoding interleukin-6, its receptor, and gp130 in the rat brain in response to the immune activator lipopolysaccharide and the proinflammatory cytokine interleukin-1 beta. J Neurochem 69:1668-1683.

Van Dam, A.M., M. Brouns, A.H.W. Man, and F. Berkenbosch. 1993. Immunocytochemical detection of prostaglandin E2 in microvasculature and in neurons of rat brain after administration of bacterial endotoxin. Brain Res 613:331-336.

Van Dam, A.M., H.E. De Vries, J. Kuiper, F.J. Zijlstra, A.G. De Boer, F.J. Tilders, and F. Berkenbosch. 1996. Interleukin-1 receptors on rat brain endothelial cells: a role in neuroimmune interaction? Faseb J 10:351-356.

Wan, W., L. Wetmore, C.M. Sorensen, A.H. Greenberg, and D.M. Nance. 1994. Neural and biochemical mediators of endotoxin and stress-induced c-fos expression in the rat brain. Brain Res Bull 34:7-14.

Wan, W.H., L. Janz, C.Y. Vriend, C.M. Sorensen, A.H. Greenberg, and D.M. Nance. 1993. Differential induction of c-FOS immunoreactivity in the hypothalamus and brain-stem nuclei following central and peripheral administration of endotoxin. Brain Res Bull 32:581-587.

Vane, J.R. 1971. Inhibition of prostaglandin synthesis as a mechanism of action for aspirin-like drugs. Nat New Biol 231:232-235.

Vardeh, D., D.R. Wang, M. Costigan, M. Lazarus, C.B. Saper, C.J. Woolf, G.A. FitzGerald, and T.A. Samad. 2009. COX-2 in CNS neural cells mediates mechanical inflammatory pain hypersensitivity in mice. $J$ Clin Invest 119:287-294.

Watabe, A., Y. Sugimoto, A. Honda, A. Irie, T. Namba, M. Negishi, S. Ito, S. Narumiya, and A. Ichikawa. 1993. Cloning and expression of cDNA for a mouse EP(1) subtype of prostaglandinE receptor. J Biol Chem 268:20175-20178.

Watkins, L.R., L.E. Goehler, J.K. Relton, N. Tartaglia, L. Silbert, D. Martin, and S.F. Maier. 1995a. Blockage of interleukin-1 induced hyperthermia by subdiaphragmatic vagotomy- evidence for vagal mediation of immune brain communication. Neurosci Lett 183:27-31.

Watkins, L.R., S.F. Maier, and L.E. Goehler. 1995b. Cytokine-to-brain communication: A review \&amp; analysis of alternative mechanisms. Life Sci 57:1011-1026. 
Watkins, L.R., E.P. Wiertelak, L.E. Goehler, K. Mooneyheiberger, J. Martinez, L. Furness, K.P. Smith, and S.F. Maier. 1994. Neurocircuitry of illness-induced hyperalgesia. Brain Res 639:283-299.

Verma, S., R. Nakaoke, S. Dohgu, and W.A. Banks. 2006. Release of cytokines by brain endothelial cells: A polarized response to lipopolysaccharide. Brain Behav Immun 20:449-455.

Wilhelms, D.B., M. Kirilov, E. Mirrasekhian, A. Eskilsson, U.O. Kugelberg, C. Klar, D.A. Ridder, H.R. Herschman, M. Schwaninger, A. Blomqvist, and D. Engblom. 2014. Deletion of Prostaglandin E-2 Synthesizing Enzymes in Brain Endothelial Cells Attenuates Inflammatory Fever. J Neurosci 34:11684-11690.

Williams, J.W., T.A. Rudy, T.L. Yaksh, and C.T. Viswanathan. 1977. An extensive exploration of the rat brain for sites mediating prostaglandin-induced hyperthermia. Brain Res 120:251-262.

Williams, K.W., and J.K. Elmquist. 2012. From neuroanatomy to behavior: central integration of peripheral signals regulating feeding behavior. Nat Neurosci 15:1350-1355.

Wohleb, E.S., J.M. Patterson, V. Sharma, N. Quan, J.P. Godbout, and J.F. Sheridan. 2014. Knockdown of Interleukin-1 Receptor Type-1 on Endothelial Cells Attenuated Stress-Induced Neuroinflammation and Prevented Anxiety-Like Behavior. J Neurosci 34:2583-2591.

Wohleb, E.S., N.D. Powell, J.P. Godbout, and J.F. Sheridan. 2013. Stress-Induced Recruitment of Bone Marrow-Derived Monocytes to the Brain Promotes Anxiety-Like Behavior. J Neurosci 33:13820-13833.

Wong, M.-L., and J. Licinio. 1994. Localization of interleukin 1 type I receptor mRNA in rat brain. Neuroimmunmod 1:110-115.

Wood, W.B., Jr. 1962. Pathogenesis of fever. Triangulo 5:101-106.

Woodward, D.F., R.L. Jones, and S. Narumiya. 2011. International Union of Basic and Clinical Pharmacology. LXXXIII: Classification of Prostanoid Receptors, Updating 15 Years of Progress. Pharmacol Rev 63:471-538.

Xie, W.L., J.G. Chipman, D.L. Robertson, R.L. Erikson, and D.L. Simmons. 1991. Expression of a mitogen-responsive gene encoding prostaglandin synthase is regulated by mRNA splicing. $P$ Natl Acad Sci USA 88:2692-2696.

Yamagata, K., K.I. Andreasson, W.E. Kaufmann, C.A. Barnes, and P.F. Worley. 1993. Expression of a mitogen-inducible cyclooxygenase in brain neurons-regulation by synaptic activity and glucocorticoids. Neuron 11:371-386.

Yamagata, K., K. Matsumura, W. Inoue, T. Shiraki, K. Suzuki, S. Yasuda, H. Sugiura, C.Y. Cao, Y. Watanabe, and S. Kobayashi. 2001. Coexpression of microsomal-type prostaglandin E synthase with cyclooxygenase-2 in brain endothelial cells of rats during endotoxin-induced fever. $J$ Neurosci 21:2669-2677.

Yamazaki, K., J. Gohda, A. Kanayama, Y. Miyamoto, H. Sakurai, M. Yamamoto, S. Akira, H. Hayashi, B. Su, and J. Inoue. 2009. Two Mechanistically and Temporally Distinct NF-kappa B Activation Pathways in IL-1 Signaling. Sci Signal 2:ra66.

Yokoyama, U., K. Iwatsubo, M. Umemura, T. Fujita, and Y. Ishikawa. 2013. The Prostanoid EP4 Receptor and Its Signaling Pathway. Pharmacol Rev 65:1010-1052.

Zetterstrom, M., A.K. Sundgren-Andersson, P. Ostlund, and T. Bartfai. 1998. Delineation of the proinflammatory cytokine cascade in fever induction. Ann N Y Acad Sci 856:48-52.

Zhang, F.X., C.J. Kirschning, R. Mancinelli, X.P. Xu, Y.P. Jin, E. Faure, A. Mantovani, M. Rothe, M. Muzio, and M. Arditi. 1999. Bacterial lipopolysaccharide activates nuclear factor-kappa B through interleukin-1 signaling mediators in cultured human dermal endothelial cells and mononuclear phagocytes. J Biol Chem 274:7611-7614. 
Zhang, H., S. Ching, Q. Chen, Q. Li, Y. An, and N. Quan. 2008. Localized inflammation in peripheral tissue signals the CNS for sickness response in the absence of interleukin-1 and cyclooxygenase2 in the blood and brain. Neuroscience 157:895-907.

Zhang, J., and S. Rivest. 1999. Distribution, regulation and colocalization of the genes encoding the EP2- and EP4-PGE2 receptors in the rat brain and neuronal responses to systemic inflammation. Eur J Neurosci 11:2651-2668.

Zhang, J., and S. Rivest. 2000. A functional analysis of EP4 receptor-expressing neurons in mediating the action of prostaglandin E2 within specific nuclei of the brain in response to circulating interleukin-1beta. J Neurochem 74:2134-2145.

Zhang, Y.H., J. Lu, J.K. Elmquist, and C.B. Saper. 2003. Specific roles of cyclooxygenase-1 and cyclooxygenase-2 in lipopolysaccharide-induced fever and Fos expression in rat brain. $J$ Comp Neurol 463:3-12. 


\section{Publications}

The articles associated with this thesis have been removed for copyright reasons. For more details about these see:

http://urn.kb.se/resolve?urn=urn:nbn:se:liu:diva-114274 